Portland State University

PDXScholar

Spring 7-23-2013

\title{
Grounding Zone Processes: Ice Mechanics and Margin Lakes, Kamb Ice Stream and Whillans Ice Stream, West Antarctica
}

Mason Joseph Fried

Portland State University

Follow this and additional works at: https://pdxscholar.library.pdx.edu/open_access_etds

Part of the Geology Commons, and the Glaciology Commons Let us know how access to this document benefits you.

Recommended Citation

Fried, Mason Joseph, "Grounding Zone Processes: Ice Mechanics and Margin Lakes, Kamb Ice Stream and Whillans Ice Stream, West Antarctica" (2013). Dissertations and Theses. Paper 1112.

https://doi.org/10.15760/etd.1112

This Thesis is brought to you for free and open access. It has been accepted for inclusion in Dissertations and Theses by an authorized administrator of PDXScholar. Please contact us if we can make this document more accessible: pdxscholar@pdx.edu. 
Grounding Zone Process: Ice Mechanics and Margin Lakes, Kamb Ice Stream and Whillans Ice Stream, West Antarctica

by

Mason Fried

A thesis submitted in partial fulfillment of the requirements for the degree of

Master of Science

in

Geology

Thesis Committee:

Christina Hulbe, Chair

Kenneth Cruikshank

Sasha Carter

Portland State University

2013 
ABSTRACT

The lateral "corners" where Kamb and Whillans Ice Streams (KIS and WIS) discharge into the Ross Ice Shelf share common geometries and ice mechanical settings. At both corners of the now-stagnant KIS outlet, shear margins of apparently different ages confine regions with a relatively flat, smooth surface expression. These features are called the "Duckfoot" on the northern, right-lateral side and the "Goosefoot" on the other. It has been suggested, on evidence found in ice internal layers, that the flat ice terrains on KIS were afloat in the recent past, at a time when the ice stream grounding line was upstream of its present location. The overdeepening in the bed just upstream of the KIS grounding line supports this view of the past geometry.

The right-lateral margin at the outlet of the currently active WIS, the location of Subglacial Lake Englehardt (SLE), appears to have many similarities with the right lateral margin of KIS, though with a less developed looking inboard margin. This paper presents a mechanical analysis using surface and bed topography and velocity datasets comparing the Duckfoot flat ice terrain with the terrain around Subglacial Lake Englehardt. At both locations mechanical thinning along shear margins and lows in the bed topography redirects basal water routing towards the features. Here, I consider the history of these features and their role in ice stream variability by comparison of the relict and modern features and via numerical modeling of ice shelf grounding and ungrounding in response to variations in ice flow.

We propose two scenarios for the development of flat ice terrains/subglacial lakes at the outlets of ice streams. In the first, development of a lake in the hydraulic 
potential low along a shear margin forces a margin jump as shearing develops along the inboard shore of the margin lake. This thesis presents evidence for an inboard (relative to the main outboard shear margin) zone of shear along the inboard shoreline of SLE, suggesting that subglacial lakes along shear margins are capable of facilitating shear margin jumps. In the second, grounding line advance around a relative low in the bed, creating adjacent margins along the lakeshores, forms a remnant lake. Discerning which of these scenarios is appropriate at the KIS outlet has implications for understanding the history of the ice stream grounding line.

An ice flow model is used to place these local conditions in a regional context by studying the effect of internal perturbations, such as ice rise stagnation or inward margin jumps, on grounding line position. Bathymetry is important in determining ice stream flow in the ways that might not be otherwise realized in 1-D flow model studies. In the numerical modeling experiments, grounding line advance across the KIS outlet is mediated by the overdeepening in the bed and proceeds not in the direction of ice flow but transverse to flow. This finding adds complexity to both a flowline view of grounding line migration and the theory that grounding lines are unstable in the presence of inward sloping bed topography. 


\section{ACKNOWLEDGEMENTS}

This project was completed with the help and encouragement of many. I would like to thank Christina Hulbe for supporting me and for her inspiration, curiosity and patience. Always generous with her time, Christina helped foster new avenues of thinking that propelled this project. She also got me to Portland. Sasha Carter introduced me to new subglacial processes and also proved to be a wonderful drag racing companion. I would also like to thank Kenneth Cruikshank for his insight into project design and for his ability to challenge others to make their own discoveries. Mark Fahnestock provided much of the data for this project and also gave special insight. My family, Hope, Jane and Steve Fried have always been the most supportive and loving group and have pushed me to follow what I love to do. A special thanks to Justin Hiester, Scott Waibel and Chris LeDoux for their help and friendship. I'd like to thank Christian Kunhardt for always thinking of better things. Eugene Domack deserves a great deal of thanks for fostering my love of glaciology and geology and for giving me many opportunities. This research is supported by National Science Foundation through an Office of Polar Programs Grant: 0838810 to Dr. Christina Hulbe. 


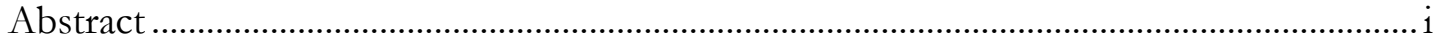

Acknowledgements ......................................................................................................... iii

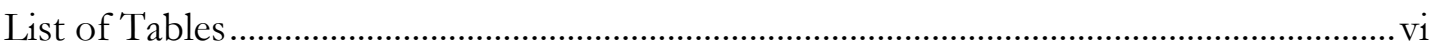

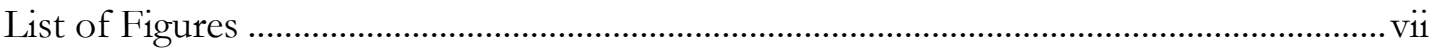

Chapters:

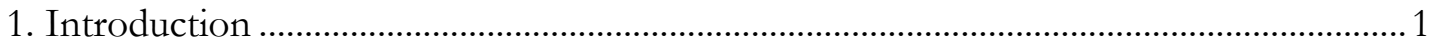

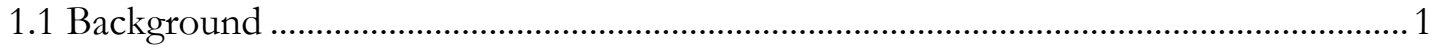

1.2 Thesis Goals and Contributions ...................................................................................... 5

2. Ice Mechanics and Flow Dynamics of Siple Coast Ice Streams, West Antarctica ......... 7

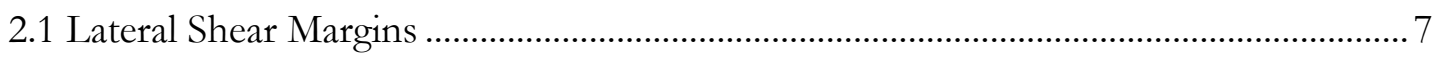

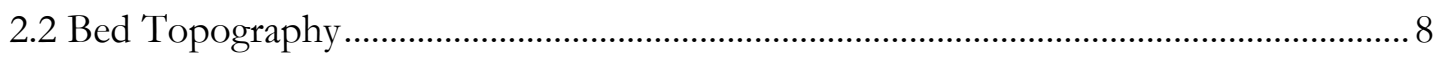

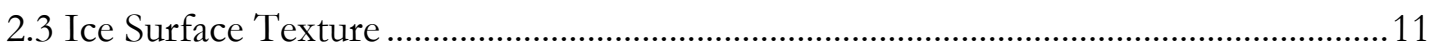

2.4 Mechanical Analysis Across the KIS and WIS Ice Plain .............................................13

3. Ice Mechanics and Subglacial Lakes at Ice Stream Outlet Margins.................................24

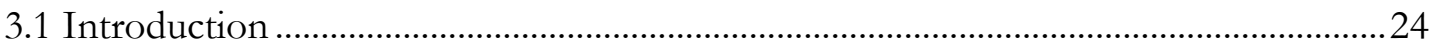

3.2 SLE as a Modern Analogue for the Duckfoot Flat-Ice Terrain ....................................25

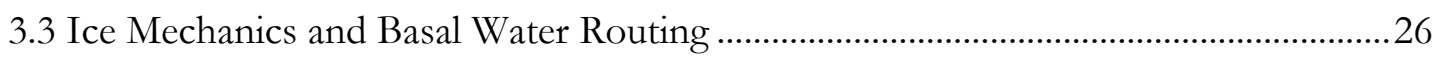

3.4 Surface Morphology and Mechanical Signature of SLE and DF Terrains.................28

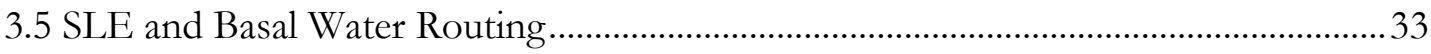

3.6 Summary of Comparison of SLE and DF and Consequences for Flow.....................35

4. Model Simulations of the Effect of Perturbations on Grounding Zone Dynamics at the Downstream End of Kamb and Whillans Ice Streams, West Antarctica .....................38

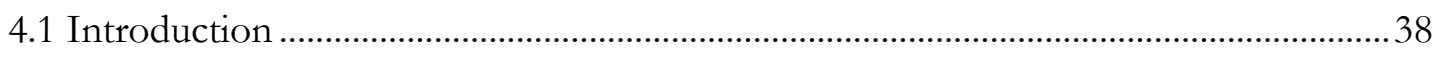

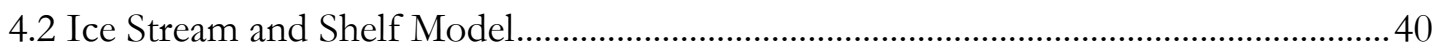

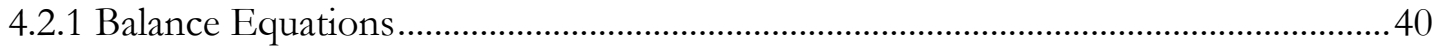

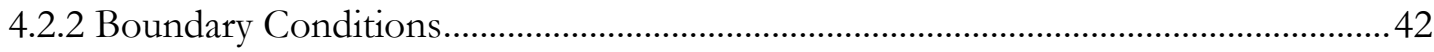




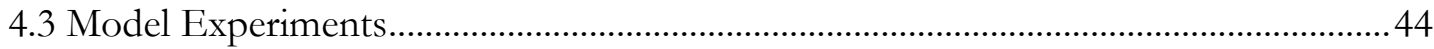

4.3.1 Perturbation Effects ................................................................................................... 48

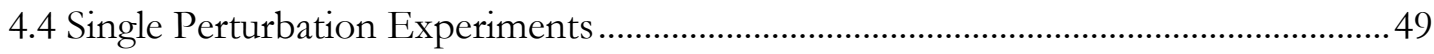

4.4.1 WIS Stagnation and Reactivation ..................................................................................4

4.4.2 CIR Stagnation ………………………………………………………………... 54

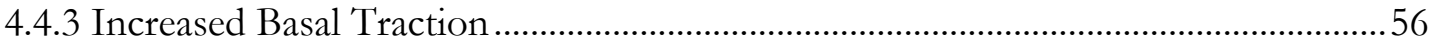

4.4.4 CIR and SH Stagnation with Beta Increase ………………………………………...60

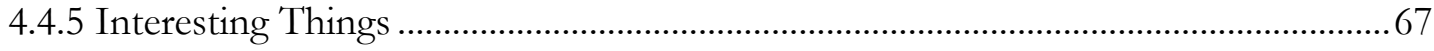

4.5 The Role of the GF in KIS Grounding Zone Dynamics .............................................67

4.5.1 CIR, SH and GF stagnation and Beta Increase ...........................................................68

4.5.2 CIR and GF stagnation and Beta Increase...............................................................72

4.5.3 CIR, SH, GF and DF stagnation and Beta Increase.................................................76

4.5.4 CIR, GF stagnation and inner DF and Beta Increase ...............................................79

4.5.5 CIR, GF and SH and Beta Increase …………………………………………..... 82

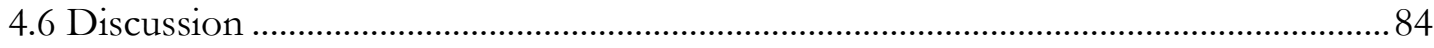

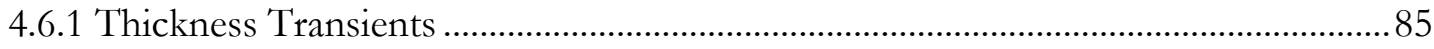

4.6.1.1 Transients Associated with Changes in Ice Stream Flux ..........................................86

4.6.1.2 Transients Associated with Increases in Basal Traction ...........................................87

4.6.1.3 Transients Associated with Ice Rises and Obstructions to Flow .............................8 88

4.6.2 Bed Topography and Grounding Zone Dynamics....................................................... 89

4.6.3 The Role of GF in Grounding Zone Dynamics ......................................................92

4.6.4 The Duckfoot as a Remnant Lake.................................................................................... 94

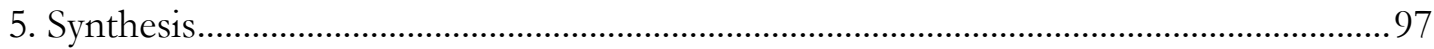

5.1 Ice Mechanics and Shear Margin Characterization .........................................................97

5.2 Characterization of Flat-ice Terrains and Subglacial Lakes at the Outlets of KIS

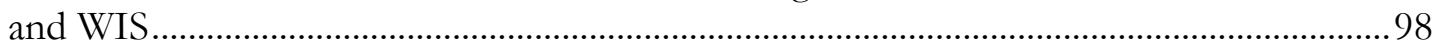

5.3 Grounding Zone Dynamics...................................................................................99

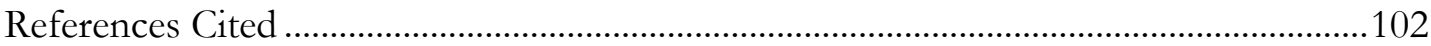




\section{LIST OF TABLES}

TABLE

PAGE

3.1 Comparison between Duckfoot and Subglacial Lake Englehardt features ..........36

4.1 Changing boundary conditions in numerical model experiments..........................47 
1.1 Schematic showing ice stream and ice shelf system .............................................. 2

1.2 Composite MODIS image of RIS and location map with geographic place

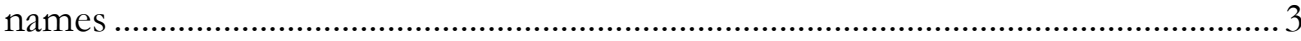

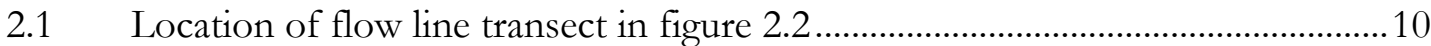

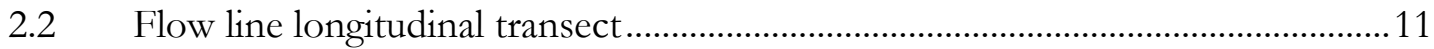

2.3 Composite MODIS image of Siple and Gould coasts overlain by surface

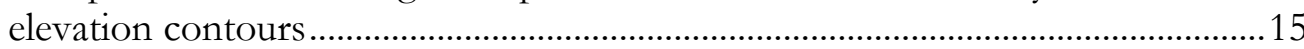

2.4 Across-flow transects showing effective strain rates $\left(\mathrm{a}^{-1}\right)$, velocity $\left(\mathrm{m} \mathrm{a}^{-1}\right)$ and ice surface elevation and thickness (m)

3.1 MOA image showing effective strain rates, hydropotential and locations of subglacial lakes across the WIS ice plain.....

3.2 MOA image showing SLE and flat-ice terrain with annotations for ice surface expression, shear margin pattern and subglacial lake location................................2 29

3.3 High-resolution image of outboard shear zone surface morphology .....................30

3.4 High-resolution image of SLE inboard shoreline surface morphology ................31

3.5 MOA image showing Duckfoot flat-ice terrain and relic margin configuration.32

3.6 MOA image showing effective strain rates, hydropotential and location of SLE across the right-lateral downstream flat-ice terrain.....................................................34

4.1 Map showing locations of flux gates (pink) for the FEM domain.........................43

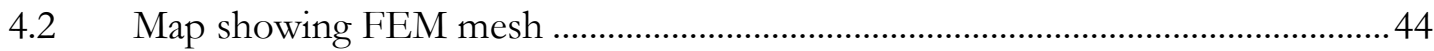

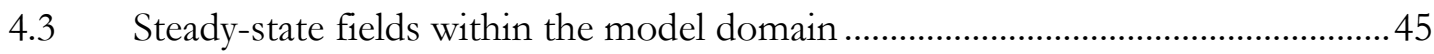

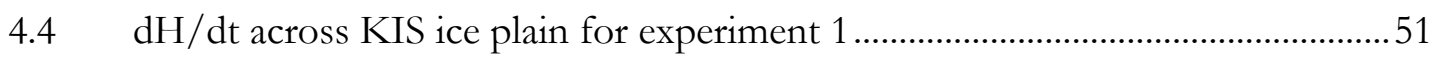

4.5 Grounded nodes, $\mathrm{dH} / \mathrm{dt}$ and $\mathrm{dU} / \mathrm{dt}$ for experiment 1 at $300 \mathrm{a}$ and 400 a..........51

4.6 Grounded nodes, $\mathrm{dH} / \mathrm{dt}$ and $\mathrm{dU} / \mathrm{dt}$ for experiment 1 at $650 \mathrm{a}$ and $1000 \mathrm{a}$.......52

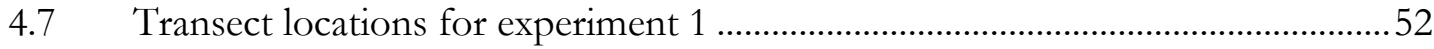

4.8 Along flow surface elevation transect for experiment 1 ..........................................53

4.9 Across flow surface elevation transect for experiment 1 .........................................53

4.10 Principal strain rate components for experiment 2 at 90 a ....................................54

4.11 Principal strain rate components for experiment 2 at 150 a ...................................55

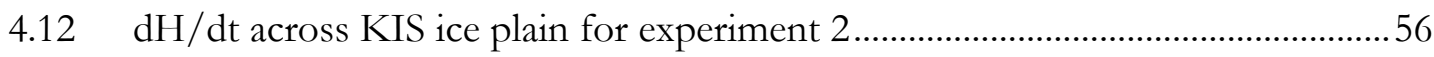


4.13 Grounded nodes, $\mathrm{dH} / \mathrm{dt}$ and $\mathrm{dU} / \mathrm{dt}$ for experiment 2 at $100 \mathrm{a}$ and 125 a...........56

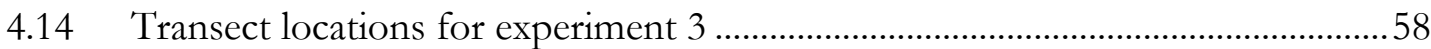

4.15 Along flow surface elevation transect for experiment 3 ........................................59

4.16 Change in volume flux map for experiment 3 at 400 a.........................................59

4.17 Grounded nodes, $\mathrm{dH} / \mathrm{dt}$ and $\mathrm{dU} / \mathrm{dt}$ for experiment 3 at 350 and 550 a..........60

4.18 Principal strain rate components for experiment 4 at 195 a ...................................61

4.19 Change in volume flux map for experiment 4 at 195 a............................................62

4.20 Grounded nodes in FEM domain for experiment 4 at 290 a .................................63

4.21 Principal strain rate components for experiment 4 at 290 a ...................................63

4.22 Change in volume flux map for experiment 4 at 290 a..........................................64

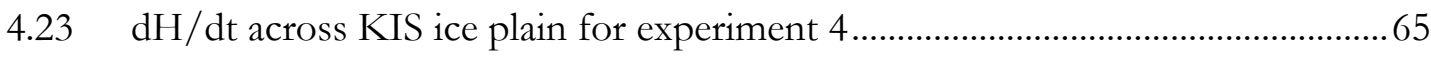

4.24 Grounded nodes, $\mathrm{dH} / \mathrm{dt}$ and $\mathrm{dU} / \mathrm{dt}$ for experiment 4 at $150 \mathrm{a}$ and $250 \mathrm{a}$...........65

4.25 Grounded nodes, $\mathrm{dH} / \mathrm{dt}$ and $\mathrm{dU} / \mathrm{dt}$ for experiment 4 at $350 \mathrm{a}$ and 600 a...........66

4.26 Height above buoyancy for experiment at 350 a .........................................................6

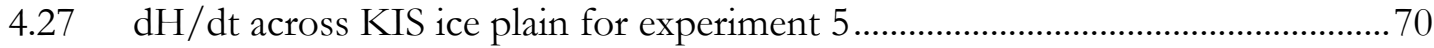

4.28 Grounded nodes, $\mathrm{dH} / \mathrm{dt}$ and $\mathrm{dU} / \mathrm{dt}$ for experiment 5 at $250 \mathrm{a}$ and 300 a...........70

4.29 Grounded nodes, $\mathrm{dH} / \mathrm{dt}$ and $\mathrm{dU} / \mathrm{dt}$ for experiment 5 at $350 \mathrm{a}$ and 400 a...........71

4.30 Height above buoyancy for experiment 5 at $350 \mathrm{a}$................................................. 71

4.31 Principal strain rate components for experiment 6 at 105 a .................................73

4.32 Principal strain rate components for experiment 6 at 330 a ..................................74

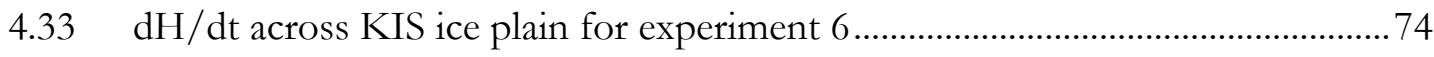

4.34 Grounded nodes, $\mathrm{dH} / \mathrm{dt}$ and $\mathrm{dU} / \mathrm{dt}$ for experiment 6 at $150 \mathrm{a}$ and $300 \mathrm{a}$...........75

4.35 Grounded nodes, $\mathrm{dH} / \mathrm{dt}$ and $\mathrm{dU} / \mathrm{dt}$ for experiment 6 at 350 a and 400 a...........76

4.36 Height above buoyancy for experiment 7 at 380 a ................................................... 77

4.37 Height above buoyancy for experiment 7 at 420 a ...................................................77

4.38 Grounded nodes, $\mathrm{dH} / \mathrm{dt}$ and $\mathrm{dU} / \mathrm{dt}$ for experiment 7 at $300 \mathrm{a}$ and 400 a...........78

4.39 Grounded nodes, $\mathrm{dH} / \mathrm{dt}$ and $\mathrm{dU} / \mathrm{dt}$ for experiment 7 at $500 \mathrm{a}$ and 700 a...........79

4.40 Grounded nodes, $\mathrm{dH} / \mathrm{dt}$ and $\mathrm{dU} / \mathrm{dt}$ for experiment 8 at $150 \mathrm{a}$ and $250 \mathrm{a} . \ldots \ldots . . . .81$

4.41 Grounded nodes, $\mathrm{dH} / \mathrm{dt}$ and $\mathrm{dU} / \mathrm{dt}$ for experiment 8 at 350 a and 450 a...........82

4.42 Grounded nodes, $\mathrm{dH} / \mathrm{dt}$ and $\mathrm{dU} / \mathrm{dt}$ for experiment 9 at $225 \mathrm{a}$ and 375 a...........83

4.43 Schematic showing the evolution of grounded ice across the KIS ice plain .......91 
4.44 Bed topography across the KIS ice plain and northern WIS ice plain..................91

4.45 Calculated effective strain rates $\left(\mathrm{a}^{-1}\right)$ for northern Siple Dome embayment .......94

4.46 Schematic for formation of remnant lake and paleo grounding line at DF.........96 
Chapter 1

\section{INTRODUCTION}

\subsection{Background}

Understanding the physical processes underlying systems considered vulnerable to rapid change is critical to preparing for the effects of global warming. Ice sheets comprise one of those systems. Today, the polar ice contribution to sea level rise is positive and growing (Cazenave and Llovel, 2010). This trend has two components: changes in melting and changes in the rate at which ice flows from the ice sheets to the ocean. Here I focus on the second.

Ice streams are channels of fast moving ice that can be tens of kilometers in width and hundreds of kilometers long. Gravity drives internal deformation of the ice and conditions at the base of the ice stream regulate melting, which in turn generates water that lubricates the ice/bed interface enhancing flow. In general, an ice stream transports ice mass from an interior catchment down to a grounding zone where the stream goes afloat and becomes an ice shelf (Fig. 1.1). Ice shelves flow through coastal embayments toward the open ocean where the ice eventually calves and form icebergs. Basal melting below the ice shelf is highest near the grounding line (Carter and Fricker, 2012) and is partly controlled by the discharge of fresh water across the grounding line and under the ice shelf cavity (Motyka et al., 2011). 


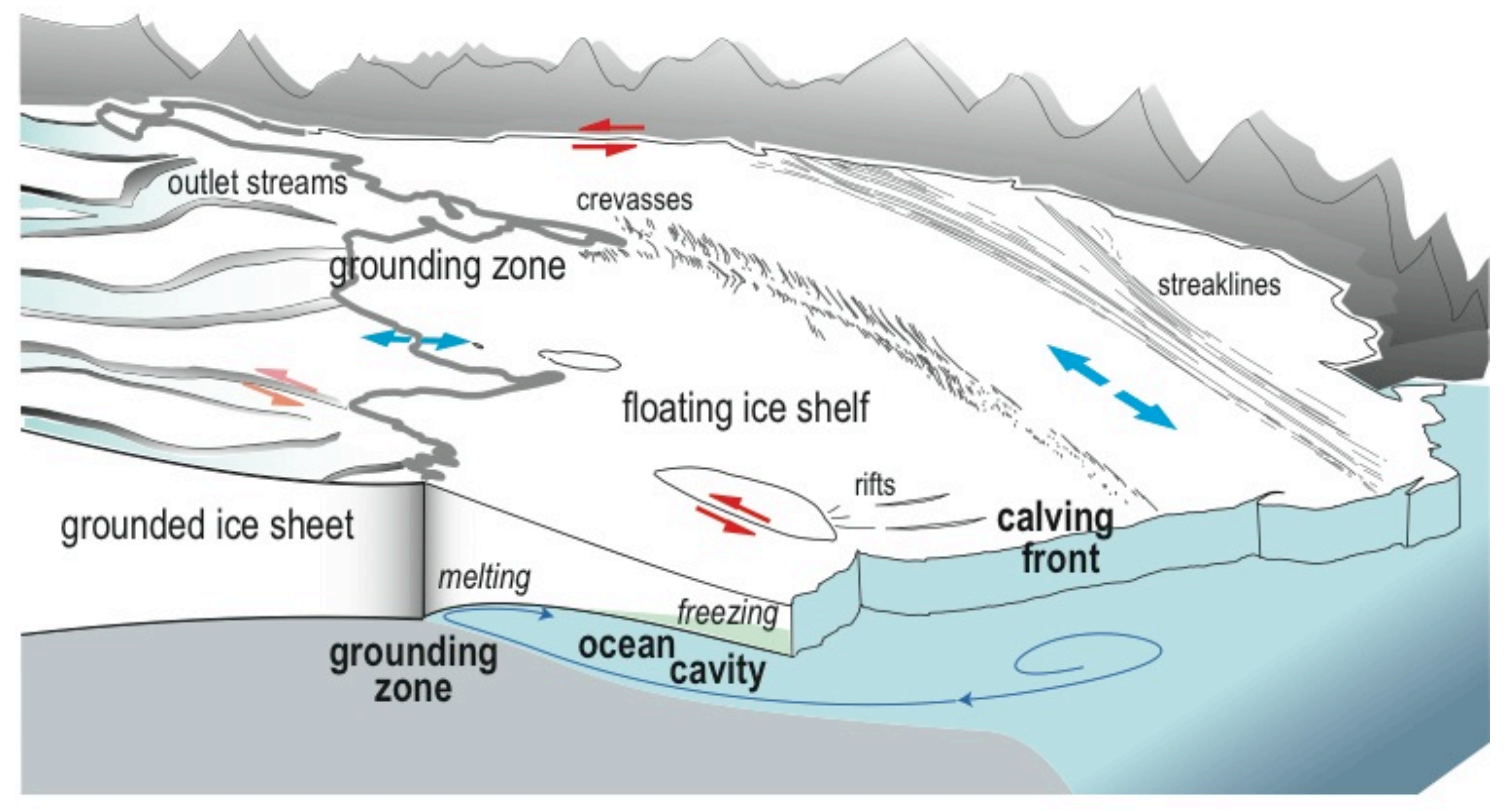

Figure 1.1. Schematic showing ice stream and ice shelf system. The grounding zone represents the transition from grounded to floating ice. Blue arrows designate regions dominated by longitudinal stresses, while red arrows designate regions dominated by shear stresses.

The interior of the West Antarctic Ice Sheet (WAIS) feeds four large ice streams that transport ice to the Ross Ice Shelf along the Siple and Gould coast. At present, the mass balance for this catchment of WAIS is slightly positive because Kamb Ice Stream (KIS) is stagnant and Whillans Ice Stream (WIS) is slowing down (Joughin et al., 2005) (Fig. 1.2). However, WAIS has the potential for rapid and significant grounding line change due to the marine character and fast-flowing ice streams (Alley and Whillans, 1991). Projecting future behavior of the system requires adequate knowledge of all the processes underlying its behavior, as well as the time and spatial scales on which they change.

The ice streams have persisted since at least the Last Glacial Maximum (LGM) when the grounding line retreated from the continental shelf edge (Shipp et al., 1999). Seismically imaged grounding zone sedimentary wedges on the Ross Sea bed are evidence that retreat of 
the grounding line to its present-day location preceded in an episodic series of regressions.

In addition, deformed ice-internal stratigraphy suggests that the KIS grounding line was well upstream of its present day location within the last few hundred years (Catania et al., 2006).

The conclusion drawn from these observations is that the general retreat of the WAIS

grounding line in the Ross Sea sector since the LGM is transient in nature with local

regressions and readvances punctuating stable stands (Hulbe and Fahnestock, 2007).

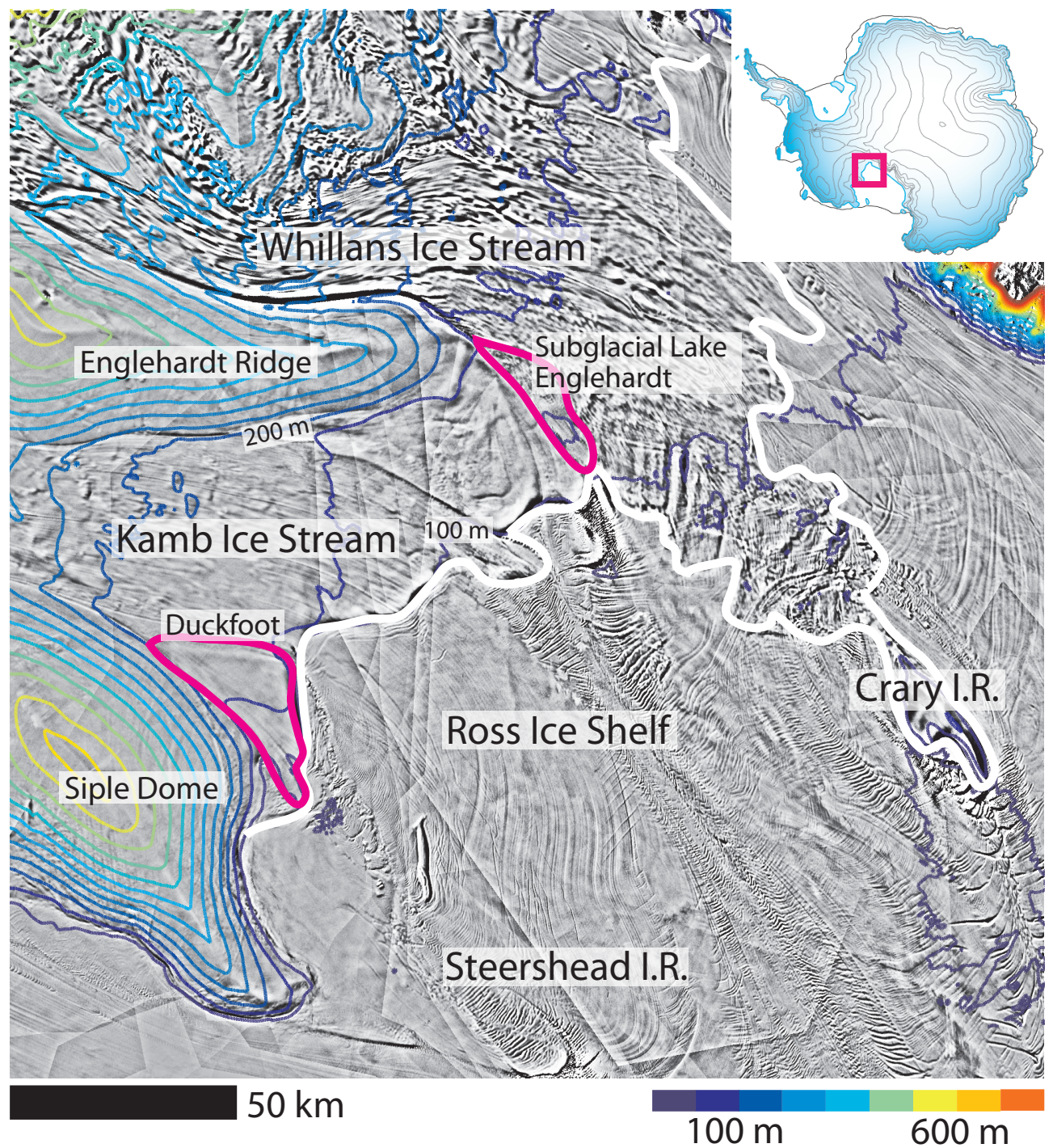

Figure 1.2. Composite MODIS image of study area and with geographic place names. Contours represent ice surface elevation (contour interval $=50 \mathrm{~m}$ ). Linear artifacts are edges of individual images in the stacked composite. 
Sreaklines emanating from KIS and WIS into the Ross Ice Shelf reveal each ice stream's unique flow history. WIS stagnated approximately 850 years ago (Hulbe and Fahnestock, 2007) and then reactivated 400 years later. KIS stagnated about 150 years ago and is currently quiescent along most of its length. Two flat ice terrains (areas of moderately smooth surface relief) at the downstream end of KIS, the Goosefoot along the left lateral margin and the Duckfoot along the right, lie between the most recently active part of the stream and inter-stream ridges. Ice-penetrating radar measurements of internal layering at the downstream margin of KIS suggests a grounding line position $\sim 100 \mathrm{~km}$ inland of its present position after the time of WIS stagnation (Catania et al., 2006). Ice downstream of the old grounding line must have been afloat at this time although some areas may have been lightly grounded as part of a broad ice plain. The KIS grounding line must have advanced to its present location after WIS reactivation and before KIS stagnation. The Duckfoot margin is interpreted to have migrated rapidly inward (toward the center of the ice stream) tens of kilometers during the advance of the KIS grounding line. The ages of the margins together with relatively undistorted internal layers have been used together to suggest a margin migration rate on the order of $500 \mathrm{~m} \mathrm{a}^{-1}$ (Catania, 2004). Today, the Duckfoot is bounded by two relic shear margins and its relatively smooth surface slopes away from the trunk of the ice stream and toward the older, outboard margin. Following grounding line advance and creation of the Duckfoot, the ice stream ceased its rapid flow.

Grounding line advance and retreat are tied to variability in the volume of ice discharged through ice streams feeding the Ross Ice Shelf. In general terms, a greater volume of ice discharge results in grounding line advance. However, ice discharge and grounding line position are further modified by cross-ice stream communication across the 
large downstream ice plain (where basal traction is slightly above zero) in the form of thickness transients propagating between ice streams and the resulting transients in local hydraulic gradient.

\subsection{Thesis Goals and Contributions}

This thesis addresses two specific goals. The first is to examine the role of ice mechanics and basal water routing in the stagnation of KIS at least 150 years ago. The current quiescence of KIS is an expression of century scale variability in discharge rates of ice streams in the Ross Sea sector of West Antarctica (Hulbe and Fahnestock, 2007, Catania et al., 2006, Retzlaff and Bentley, 1993). Because rapid ice flow depends on water at the ice/bed interface, the stagnation of KIS is most likely related to changes in basal water distribution (Anandakrishnan and Alley, 1997). Parizek et al., 2003, discuss the effects of local variability within the hydrologic system on promoting either basal freeze-on or lubrication at the ice/bed interface. While overall energy balance and ice/till interactions related to ice stream stagnation have been explored in idealized settings (Tulaczyk et al., 2000, Bougamont et al., 2003 and Christoffersen and Tulaczyk, 2003), the sequence of events associated with stagnation have not often been examined in a specific geographic and glaciological context.

A mechanical analysis of the modern WIS outlet allows for characterization of the interaction between spatial patterns in ice thickness, surface slope and water distribution. Conclusions from the modern system may be used to analyze the configuration of the KIS outlet in terms of its past mechanics. In particular, a mechanical and hydrological comparison may be made between the inactive Duckfoot region and, at the northern edge of 
the WIS ice plain, Subglacial Lake Englehardt, suggesting that the Duckfoot may have been a subglacial lake in the past and contributed to ice stream stagnation.

The second goal is to investigate multi-decadal scale changes in grounding line position and ice stream discharge. Some combination of internally-driven perturbations, such as ice stream discharge variability and thickness gradients linked to grounding events at the downstream end of KIS and WIS (for example, grounding at Crary Ice Rise and Steershead), led to the grounding line advance at the mouth of KIS 100 years ago (Catania et al., 2006). Previous work on grounding line migration (Conway et al., 1999) has focused on longer time scales than those considered here. An ice shelf and stream model adapted from Hulbe and Fahnestock (2007) is used, not to recreate past events, but to investigate the effects of various perturbations in their actual geographic context. In particular, thickness transients communicating laterally across the broad ice plain between KIS and WIS lead to large variability in ice stream discharge and grounding line position. 
Chapter 2

\section{ICE MECHANICS AND FLOW DYNAMICS OF SIPLE COAST ICE STREAMS, WEST ANTARCTICA}

\subsection{Lateral Shear Margins}

Ice streams flow by basal slip over a well-lubricated bed of unconsolidated sediments (Kamb, 2001). Studinger et al., 2001, found that the onsets and lateral margins of WAIS ice streams coincide with the limit of marine subglacial sediments. Low yield strengths at the bed shift much of the resistance to the gravitational driving stress to the lateral boundaries of the ice stream. The lateral boundaries, or shear margins, are thus characterized by high strain rates. Ice speeds are largest near the center of an ice stream and go to nearly zero at the margin.

High strain rates at the margins produce mechanical thinning of the ice. Relatively thinner ice generates a hydraulic gradient that tends to drive water toward the margin, leading to the formation of subglacial lakes along the margins and perhaps also altering ice stream flow along the margins. The position of a lateral margin may shift as thermodynamic conditions at the margin dictate (Harrison et al., 1998).

Unlike the rigidly constrained lateral boundaries in fjords and outlet glaciers, the shear margins of ice streams may migrate over time. In the past, the effects of strain softening and heating have been considered (Raymond, 1996), as well as jumps in conjunction with grounding line position (Catania et al., 2006). Here, two additional possibilities are considered. First, the formation of subglacial lakes can facilitate migration. Subglacial lakes reduce basal traction locally above the lake and focus shear along the lateral shorelines. When a subglacial lake develops along an ice stream shear margin, the opening 
of two shoreline shear margins may facilitate a margin "jump" to one of the shorelines depending on whether local dynamics promote widening or thickening of the ice stream. Ice thickness transients caused by ice volume discharge variability may also lead to shear margin migration via grounding and ungrounding events at the downstream end of ice streams and particularly in areas that are part of the broad ice plain.

\subsection{Bed Topography}

The bed topography across the Gould, Siple and Shiraze Coasts' ice streams, particularly near the grounding zone, comprises the physical backdrop for the ice system. Thus, regional and local topographic features affect the interplay of dynamic processes within the system.

The Siple coast ice streams flow along shallow troughs in the bedrock that act to focus subglacial meltwater and marine sediment, both of which facilitiate fast ice flow (Shipp et al., 1999). Bordering the troughs are inter-stream ridges represented by local highs in the bed topography. These ridges confine the ice streams and follow the trend of the TransAntarctic Mountains to the south toward their terminus at the continental shelf (Shipp et al., 1999) and are part of the larger basin and range structural fabric within the West Antarctic Rift System (Behrendt, 1999).

Smaller-scale (in terms of height and spatial extent) bed topography along the coast plays a significant role in determining where ice is likely to ground and, in turn, where thickness transients are likely to occur and propagate. Transients in the thickness field may be generated by variations in the mass flux from upstream, changes in basal melt rate or basal traction or changes in the geometry of the ice shelf among other factors. Persistent 
basal freeze-on occurs due to conductive cooling where water pools against sufficiently steep topography (Bell et al., 2011). Thickness transients propagating away from such a feature will likely lead to further grounding and further affect ice stream flow.

An ice plain is a transitional area between an ice stream and the floating ice shelf (Bindschadler, 2005). A broad ice plain is situated at the downstream end of KIS and WIS where the basal traction is only slightly above zero and the ice surface elevation is relatively flat (Hulbe and Fahnestock, 2007). The ice plain facilitates communication of thickness gradients from one side of an ice stream to the other and also between ice streams, for example between KIS and WIS across the Goosefoot. The relatively flat bed topography within the ice plain allows for small variations in ice thickness and surface slope to have a large effect in determining basal water routing. Both these factors play a large role in determining ice stream dynamics on moderately short time scales.

Crary Ice Rise (CIR) and the Steershead (SH) (Fig. 1.2) are topographic highs downstream of the present day grounding line overlying relatively shallow features on the ocean floor. The ice rises are contiguous with the inter-stream ridges, Siple Dome (SD) and Englehardt Ridge (ER), which define the lateral margins of KIS and WIS farther upstream (Fig. 1.2). At these high points, floating ice in the ice shelf is more likely to ground and remain stuck due, in part, to the temperature gradient of newly grounded ice. When ice grounds, the temperature gradient changes quickly between the thermally equilibrated floating ice - ice that is fixed at the freezing point of the ocean water - and grounded ice atop the topographic high. The basal temperature for grounded ice is determined by the rate of heat conduction from the underlying rock to the surface (Bindschadler et al., 1990). CIR and $\mathrm{SH}$ are significant obstacles to ice flow, which makes them important geographic focal 
points for the generation of ice thickness gradients that propagate upstream and further affect flow dynamics and grounding zone position.

Upstream of the ice plain, the downstream end of KIS is characterized by a large overdeepening $(\sim 50 \mathrm{~m})$ roughly oriented with its long axis in the direction of ice flow $(\sim 150$ $\mathrm{km}$ along flow and $\sim 75 \mathrm{~km}$ across flow). The overdeepening favors a grounding line position well upstream of its present day location. The present day grounding line position requires ice advance across the overdeepening. Today, the KIS grounding line lies stagnant along the reverse slope that forms the downstream boundary of the overdeepening (Fig. 2.2).

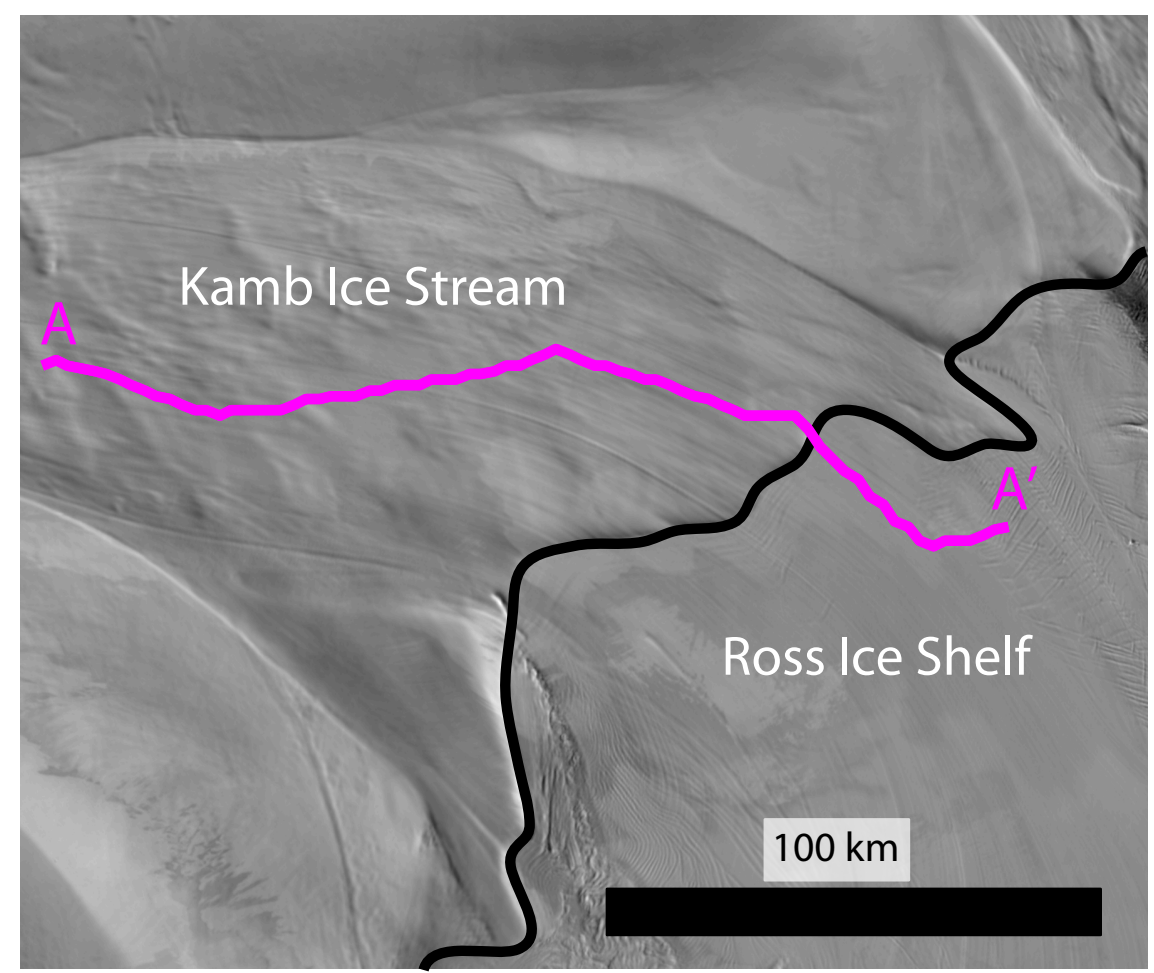

Figure 2.1. Location (A-A') of flow line transect in figure 2.2. Modern grounding line is outlined in black. 


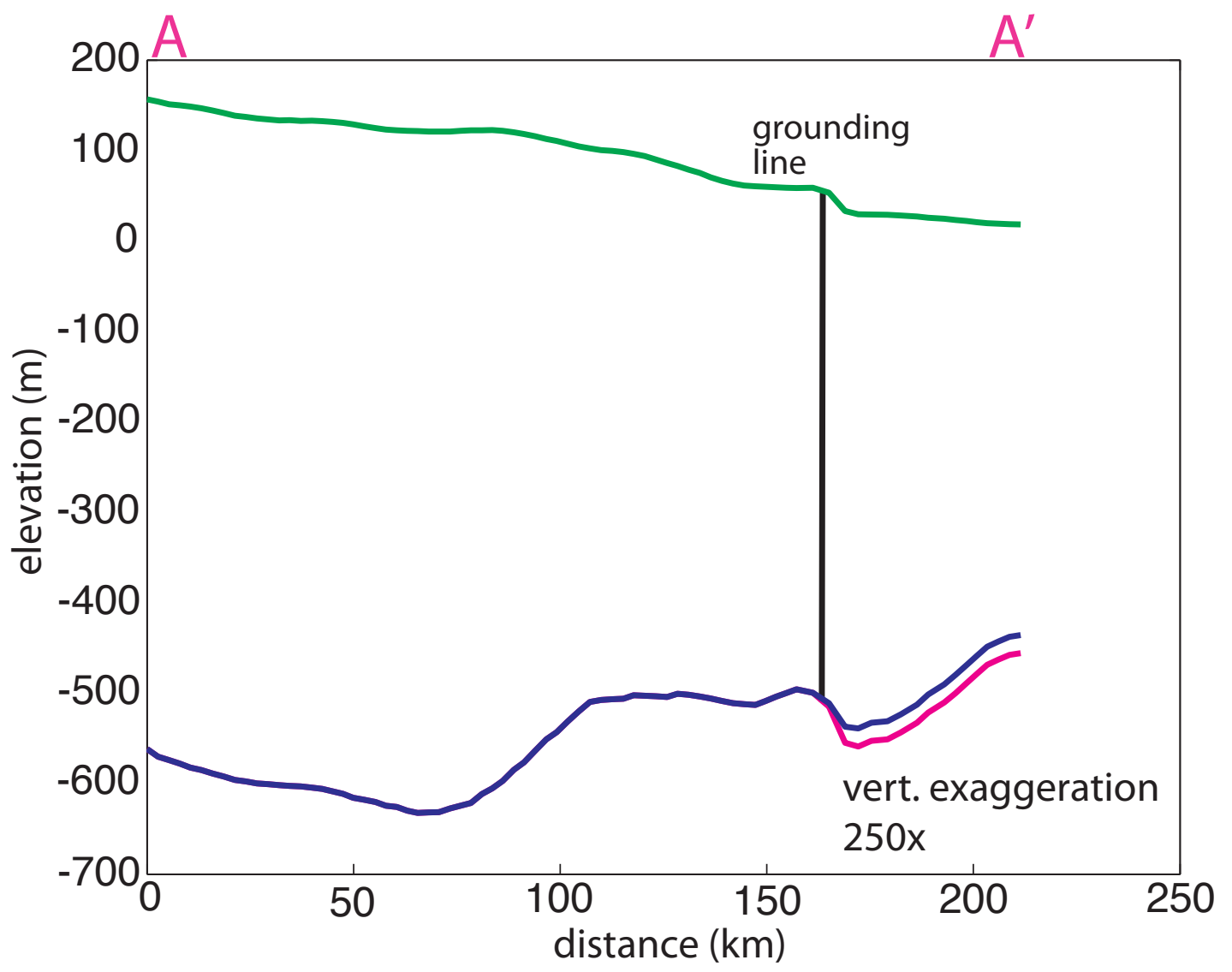

Figure 2.2. Flow line longitudinal transect (refer to figure 2.1 for location). Green line represents ice surface, blue line is ice bed and pink line is bed topography.

\subsection{Ice Surface Texture}

The surface texture of the ice can be interpreted in terms of ice mechanics, that is different morphologies reflect different subglacial material or thermal state and different rates of ice flow. Where grounded ice is moving rapidly, variations in bed shape or traction at the ice/bed interface propagate upward, producing a surface that is relatively rough at length scales similar to the ice thickness (Gudmundsson and Raymond, 2008). In contrast, where ice is stagnant or moving only very slowly, surface relaxation due to gravity dominates and relatively smooth features result. At length scales many times the ice thickness, rigid beds can support steeper slopes than can softer beds (for example, frozen or thawed 
interfaces) (Cuffey and Peterson, 2011). Smooth and low slope surfaces indicate a very weak substrate, that is, a contiguous water body such as a subglacial lake or the ocean.

Moderate relief due to reduced basal traction characterizes the surface expression of subglacial lakes. Fricker and Scambos (2009) documented an active subglacial hydrologic system below the downstream end of WIS and Mercer Ice Stream (MIS). In their analysis they identified nine subglacial lakes and showed that some were linked. The surface expression of subglacial Lake Englehardt (SLE), one of the largest in the study, is typical of others across the WIS ice plain. The ice above the SLE is in hydrostatic equilibrium and the surface is profile across the lake is remarkably flat. Ice above SLE is relatively thin $(\sim 800 \mathrm{~m})$ (Shabtaie and Bentley, 1988) which minimizes the effects of ice-plate flexure at the edges of the flat ice terrain (Fricker and Scambos, 2009).

The surface elevation profiles of subglacial lakes identified by Fricker and Scambos (2009) share similar characteristics to the two flat ice terrains at the downstream end of KIS, the Goosefoot along the left lateral margin and the Duckfoot along the right. The flat ice terrains separate the ice stream from the inter-stream ridges. Surface slopes $\left(10^{-4}\right)$ and velocities $\left(<0.3 \mathrm{~m} \mathrm{a}^{-1}\right)$ are small on the flat ice terrains (Jacobel et al., 2000) and surface relief is intermediate between the relatively rough ice stream and the very smooth inter-stream ridge morphology. The surface shape of these terrains tells us that the ice was floating and internal ice stratigraphy suggests that they stagnated at some time before the main trunk of KIS stagnated (Catania et al., 2006).

Differences in ice surface textures help to define ice mechanical boundaries. Several ice mechanical settings exist at the downstream ends of the Siple and Gould Coast ice streams, particularly at the grounding zone of KIS and WIS where very smooth surface 
textures in the nearly stagnant interstream ridges coarsen towards the main trunk of the ice streams where ice is moving quicker and differences in basal traction propagate to the ice surface.

\subsection{Mechanical Analysis Across the KIS and WIS Ice Plain}

While surface texture analysis provides an overview of ice mechanics across regions, the present work requires more detailed analysis at specific locations. That objective is addressed using high-resolution surface elevation, bed elevation, and velocity data sets. Project collaborator Mark Fahnestock produced the high-resolution digital elevation model used here. The DEM features an optimized elevation field from MODIS slope field and ICESat laser tracks. Fahnestock generated the optimal surface using a combination of a detailed local topography derived using a machine vision technique: shapelet (related to wavlelet) characterization of a surface by fitting shapelet derivatives to the slope field, with a longer-wavelength regional topography generated from fitting ICESat elevation points. The result of the dataset is a detailed view of the grounding zones (125 m postings, independent at a horizontal distance of about $250 \mathrm{~m}$, with a few-meter vertical accuracy) for ice streams flowing into the Ross ice shelf. The benefits of using this high-resolution dataset are twofold. The dataset allows for detection of small variations in surface elevation across the grounding zone where transitions are gradual and also for a physical analysis of topographic features related to past flow events. I also used bed topography from BEDMAP1_plus dataset (Pritchard, British Antarctic Survey) and velocity datasets for the grounding zone region from Joughin et al., 2005 and Rignot et al., 2011.

A series of transects runs across KIS and WIS, including the ice plain at their 
downstream end (Fig. 2.3). The ice mechanical settings in different locations are compared using surface elevation, bed elevation, surface speed, and effective strain rate. Strain rates are calculated as velocity gradients (Cuffey and Peterson, 2011). The effective strain rate, a measure of the total deformation experienced by the ice, is given by,

$$
\dot{\varepsilon}=\frac{1}{2}\left[\frac{\partial u_{i}}{\partial x_{j}}+\frac{\partial u_{j}}{\partial x_{i}}\right]
$$

where $u_{i}$ is the velocity field in the material.

High strain rates are found along the strike-oriented transects highlight shear margins where ice velocities change rapidly between flowing and non-moving ice (Fig. 2.4). Thinning at lateral margins is associated with higher effective strain rates accompanying shear margins are a result of either strain heating and local melting (Jacobson and Raymond, 1998) or recrystallization and crevasse formation (Thorsteinsson et al., 2003). After a shear margin is well established, ice within the shear zone undergoes intense shearing and its speed is greatly reduced. 


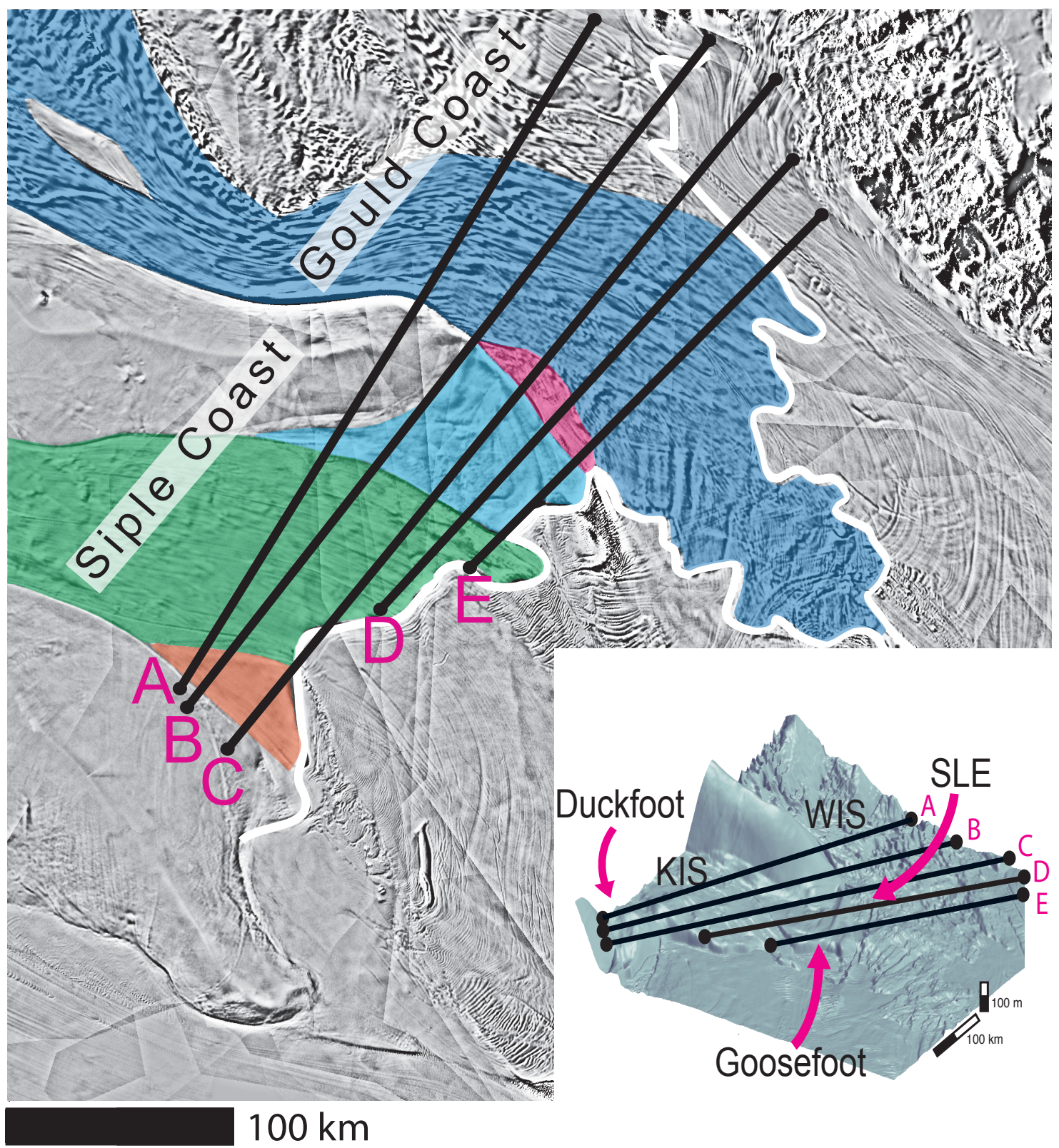

Figure 2.3. Composite MODIS image of Siple and Gould coasts overlain by surface elevation contours. Strike-oriented transect locations are noted. Shaded areas represent different ice regions shown in transects (Fig. 2.4). Inset shows IceSAT + MODIS composite surface elevation. 

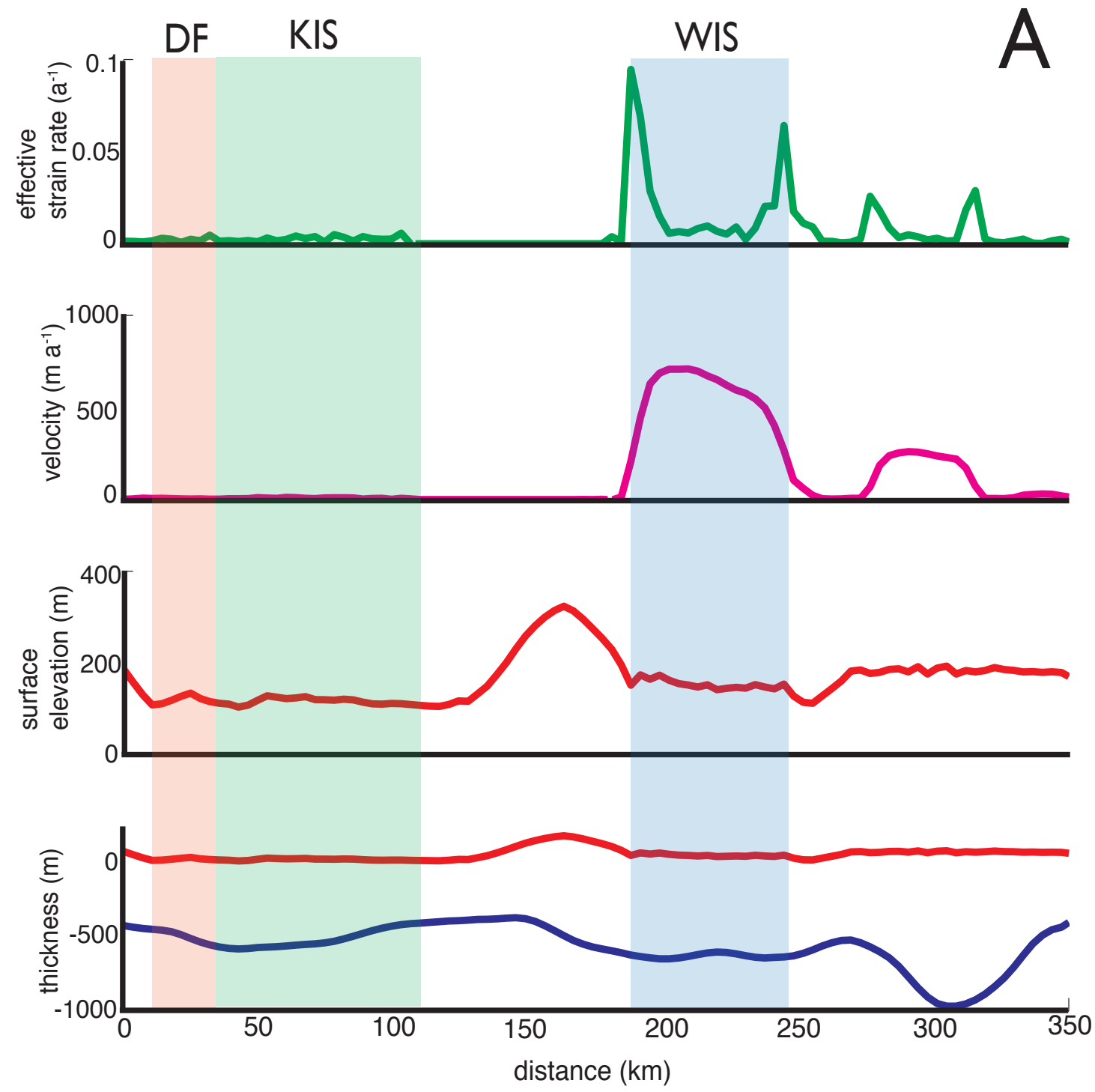

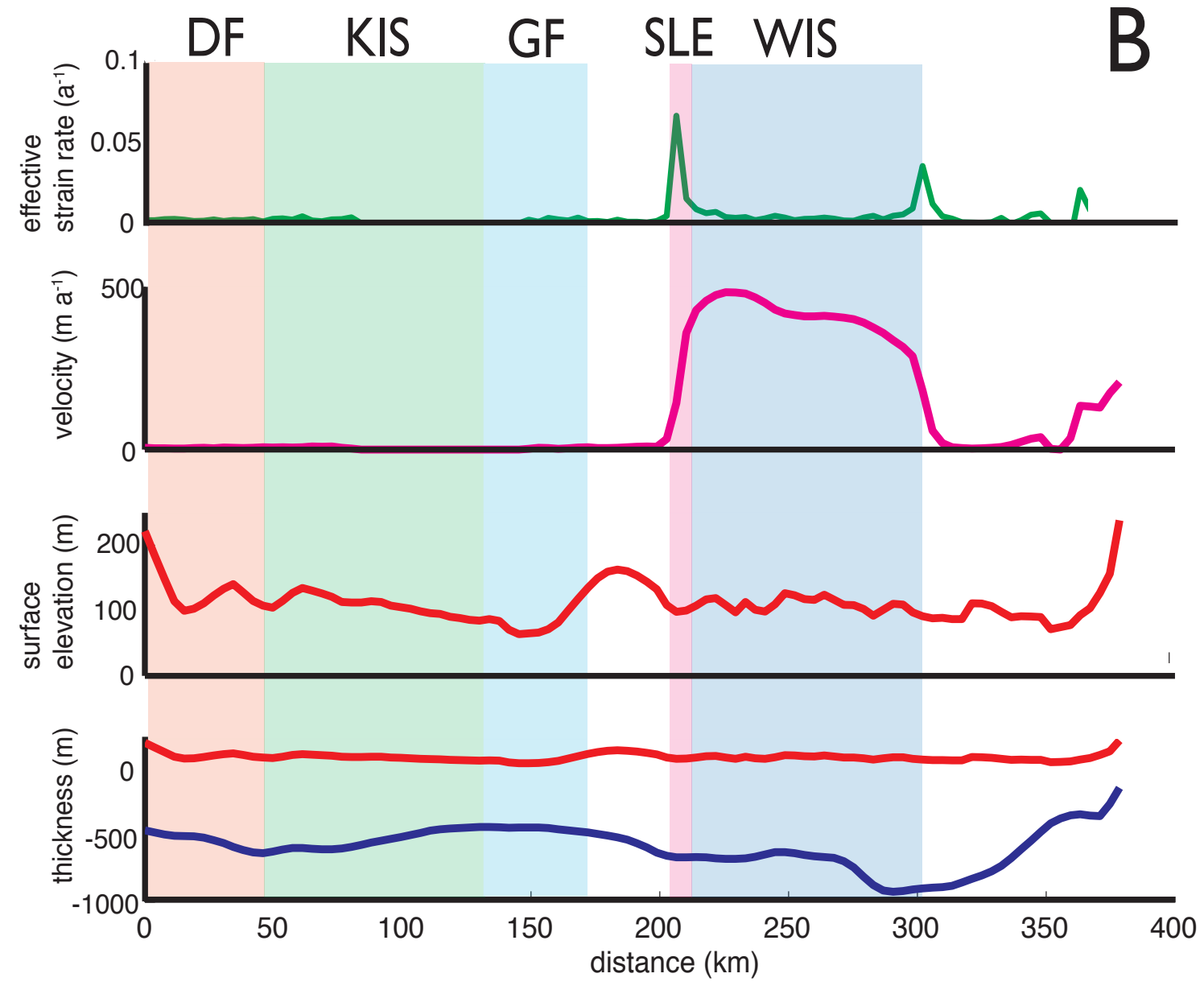


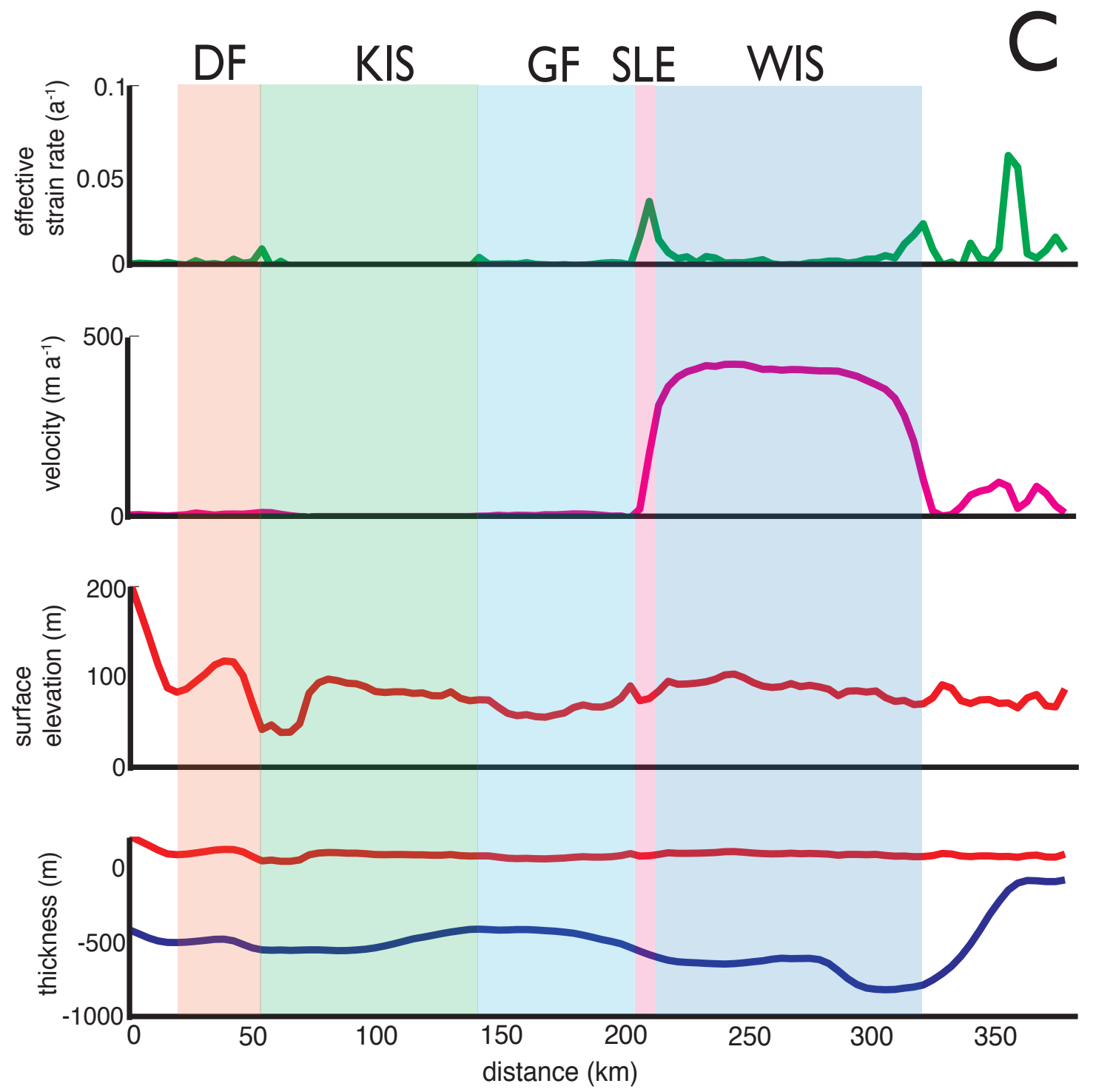



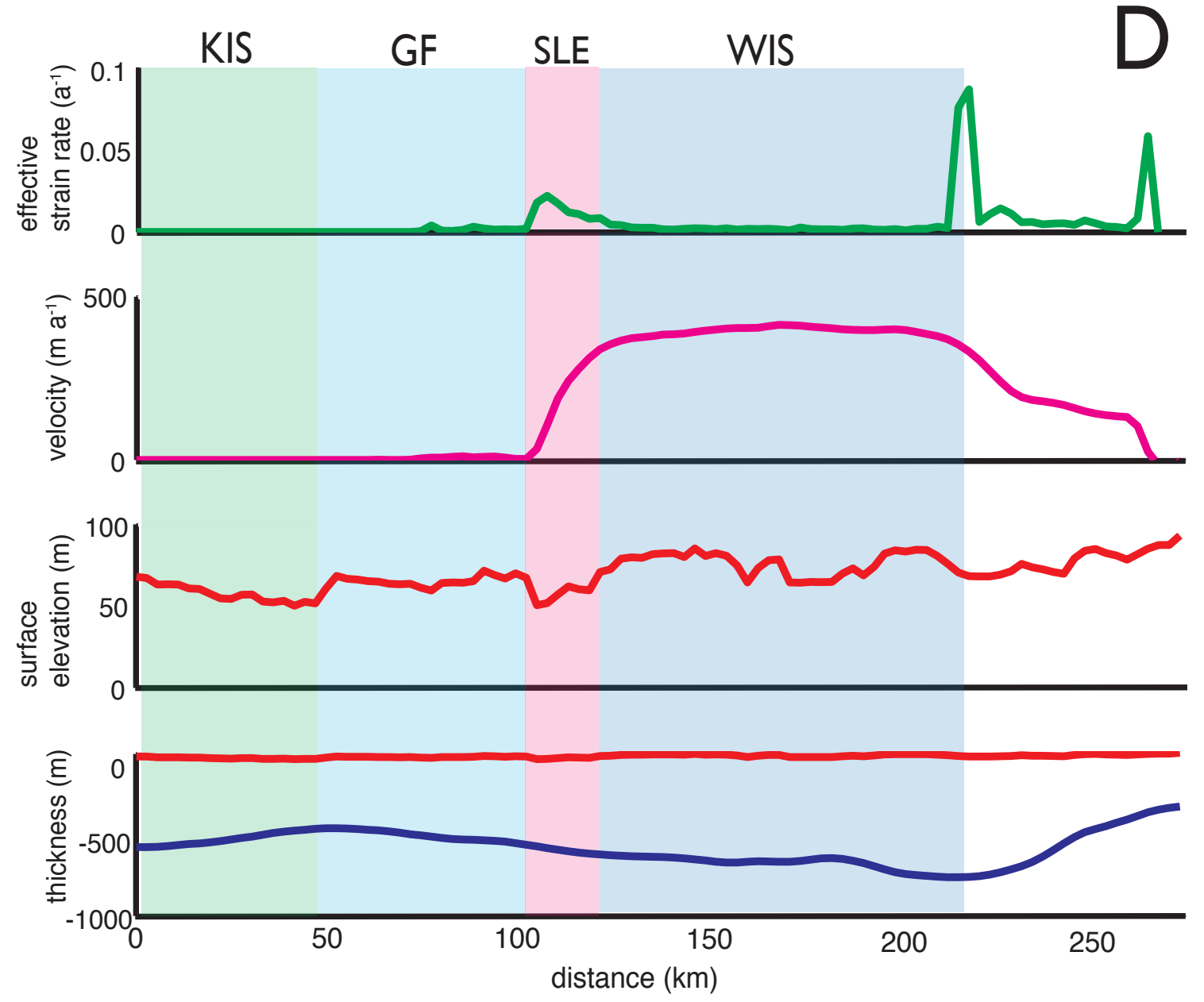

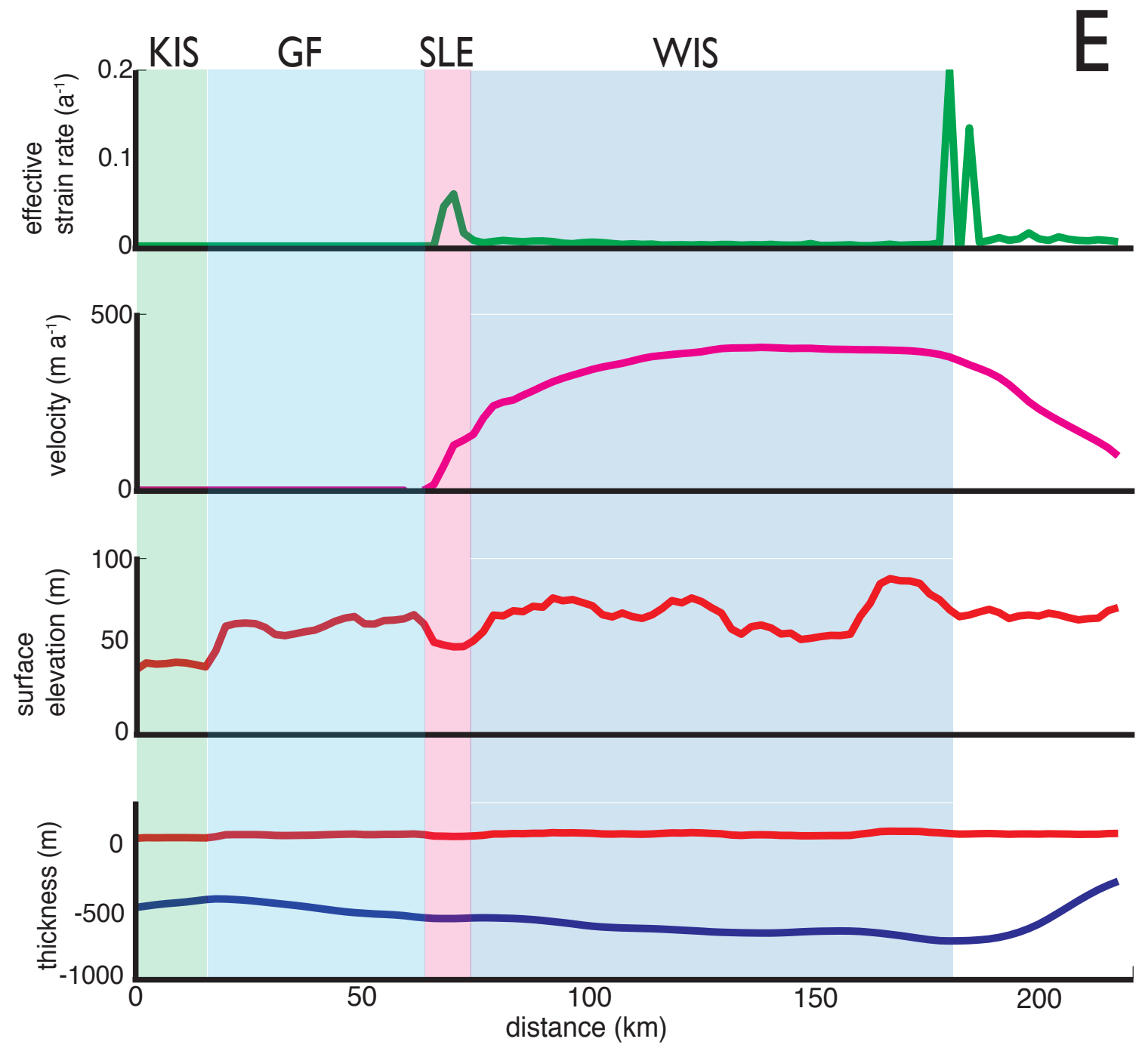

Figure 2.4. Across-flow transects with the direction of ice flow toward the viewer showing effective strain rates $\left(\mathrm{a}^{-1}\right)$, velocity $\left(\mathrm{m} \mathrm{a}^{-1}\right)$ and ice surface elevation and thickness $(\mathrm{m})$. Color shading represents geographic regions. Orange represents the Duckfoot, green represents KIS, light blue represents the Goosefoot, pink represents SLE and dark blue represents WIS. Velocity data from Joughin, 2005, and enhanced surface elevation created using a combination of ICEsat altimetry and shapelet analysis using MODIS.

The transects cross the relatively wide downstream reach of KIS and the WIS ice plain. The WIS ice plain is typified by thicker ice than the main trunk of KIS and a deeper bed (transect A). The surface topography across the ice plain shows moderate variability, most likely reflecting changes in bed topography. The WIS margins, both along the northern shear margin and the southern margin suture zone between WIS and MIS are 
characterized by zones of surface thinning.

With increasing distance downstream on WIS, the cross-stream speed profile changes from the strongly U-shaped profile (transects A, B, C) typical of ice streams to a more gradually changing profile. The change reflects the broadening of the stream (transects $\mathrm{D}$ and $\mathrm{E}$ ) and the loss of strong lateral margins and their associated shearing. Speed also varies with ice thickness, and this is seen at the confluence of WIS and MIS, where the bed is relatively deep and the ice is relatively thick. Ice speeds are generally lower along the northern margin near SLE and leeward of ER (transect E). Patterns of effective strain rates parallel the distribution of velocity gradients across the ice plain, also, notably, become more diffuse downstream, especially along the northern margin near SLE. A sharp change in ice speed is observed further upstream along the ice margin suture zone between WIS and MIS (transects A, B and C) but less so downstream (transects D and E). However, effective strain rates remain consistently high along the margin suture zone where mechanical thinning is also active.

Transects A and B cross the elevated topography of ER, while transects C, D and E traverse the Goosefoot flat ice terrain between KIS and WIS. The Goosefoot is stagnant and is characterized relatively shallow bed $(\sim 30 \mathrm{~m})$ along the relic southern KIS shear margin and a sunken surface topography, perhaps indicating, along with internal syncline stratigaphy (Catania et al., 2006), that the region experienced a quick transition from floating to grounded ice.

While the morphologies of the Duckfoot and Goosefoot are generally similar, some differences emerge upon careful inspection. At the Duckfoot, the thinnest ice is at the boundary of the flat ice terrain, along the relict shear margins. At the Goosefoot, the 
thinnest ice is in the middle of the feature. This may indicate differences in mechanical histories of the two features.

The overdeepening ( $\sim 150$ meters deeper than the up and downstream highs) in the bed upstream of the present KIS grounding line presents a challenge with respect to grounding line position. Its upstream extent aligns well with the past KIS grounding line position proposed by (Catania et al., 2006). This makes sense on theoretical grounds, as grounding lines tend to be unstable on reverse slopes and over relatively deep reaches of the bed (Schoof, 2007 and Weertman, 1974). The modern grounding line, however, rests part way along a reverse slope, rather than on either of the adjacent relative highs in the bed. This may represent the effects of processes other than those captured by flowline models of the relationship among bed elevation, ice flow, and grounding line position. Assuming the Catania et al., 2006 chronology is correct, then the KIS grounding line appears to have been advancing downstream at the time of its arrest.

Today KIS is stagnant, but the surface topography captures the imprint of past ice mechanics. The main trunk of KIS is bounded by relict shear margins that appear as reverse slopes toward the adjacent interstream ridges, either SD or ER. Overall, the surface elevation across the main trunk of KIS dips to the south $\left(\sim 0.5 \mathrm{~m} \mathrm{~km}^{-1}\right.$, refer to Fig. 2.4$)$. The slope may reflect processes associated with KIS stagnation, for example, if the southern portion of the ice stream remained active longer than the northern side. A small tongue of grounded ice extends into the Ross Sea at the downstream end of KIS adjacent to the Goosefoot where the surface elevation continues to decrease (transect D and E).

Surface elevation profiles across the Duckfoot are distinguished by the two relict shear margins that define the boundaries of the flat ice terrain (Catania et al., 2006). These 
are zones where, in the past, effective strain rates were relatively large, as is the case today along the shear margins at the downstream end of WIS.

Changes in ice thickness and surface slope related to the formation of shear margins near the marine margin may cause changes in basal water routing that may in turn yield variations in ice flow. The hydraulic potential, $\Phi$, is

$$
\Phi=\rho_{i} g\left(Z_{\text {surface }}-Z_{b e d}\right)+\rho_{w} g Z_{b e d},
$$

where $\rho_{I}$ and $\rho_{w}$ are ice and water density, $Z_{\text {sufface }}$ and $Z_{b e d}$ is the ice surface and bed elevation and $g$ is the acceleration due to gravity. Meltwater production has both kinetic (melt water from basal friction) and potential (basal water routing) components and is quantified according to energy balance at the interface between ice and the underlying materials and perhaps processes within the underlying materials. Along shear margins, a combination of the surface shape and the bed elevation produce a low in the hydraulic gradient that directs water away from the main trunk of the ice stream and toward the margin. Higher effective strain rates focus mechanical thinning along the ice margin, resulting in a surface gradient toward the margin. Local variability in meltwater flow pattern has implications in determining areas of basal freeze-on (Parizek et al., 2003). In this scenario, meltwater flow toward and along the shear margin would promote basal freezing toward the main trunk of the WIS.

Subglacial Lake Englehardt (SLE) is a right lateral margin feature at the downstream end of WIS and adjacent to ER and the Goosefoot. The subglacial lake extent as defined by Fricker and Scambos (2009) shares its northern shoreline with the northern WIS shear margin and resides within a flat ice terrain. 
Chapter 3

\section{ICE MECHANICS AND SUBGLACIAL LAKES AT ICE STREAM OUTLET MARGINS: COMPARISON OF DUCKFOOT AND ENGLEHARDT LAKE FEATURES, WEST ANTARCTICA}

\subsection{Introduction}

Grounding line position is variable on a range of time scales. At the shorter end of the spectrum, both vertical and horizontal motion of grounded ice has been observed to vary with ocean tide height (Bindschadler et al., 2003). Where the bed has a relatively uniform elevation over a large region, as at the WIS ice plain, ephemeral grounding and ungrounding can be a pervasive feature. Over time scales of years and longer, grounding line position must be related to the mass balance of the system as a whole, but mediated by local and regional-scale (a few $\mathrm{km}$ to a few $100 \mathrm{~km}$ ) processes. Conway et al., 1999, discuss characteristics of grounding line retreat across the Ross Sea Embayment since the early to mid Holocene glacial maximum. Transience in the grounding zone associated with bed shape and basal water are of particular interest here.

The corners of the KIS outlet are defined by conspicuously smooth and low-slope "flat ice terrains" (Catania et al., 2006). These features are often identified by informal names, the Duckfoot (DF), at the northern, right-lateral corner, and the Goosefoot (GF), coined by Ted Scambos (Jacobel et al., 2000). Two relict shear margins bounding the DF flat ice terrain were identified by the presence of near-surface diffractors and distorted, discontinuous deep layers in the ice stratigraphy (Catania et al., 2006). Additionally, the relict shear margins are coincident with broad topographic troughs (Catania et al., 2005 and 2006). Catania et al, 2006, used snow accumulation rates of $0.049 \mathrm{~m} \mathrm{a}^{-1}$ and $0.058 \mathrm{~m} \mathrm{a}^{-1}$ to estimate stagnation ages of $\sim 340$ years and $\sim 150$ years, for the outboard and inboard margins, 
respectively (Fig. 3.6). Stratigraphic continuity across the DF led Catania to conclude that the switch from active shearing along the outboard margin to the inboard margin must have happened quickly, perhaps synchronously with the stagnation of the outboard margin.

One explanation for the formation flat ice terrains and the related ice internal stratigraphy is that the terrains were floating in the past (Catania and Hulbe, 2012). This would surely have been the case if the KIS grounding line was $\sim 100 \mathrm{~km}$ upstream of its present location with the last few hundred years. Details of grounding line advance from that postulated upstream position are not recorded in an obvious way in the ice. The advance may have been uniform across the width of the stream or, more likely, may have followed the contour of the sea floor in some way. For example, the grounding line may have become a "shoreline" along a subglacial lake underneath the DF, where the bed is locally relatively deep. Mechanical thinning along the then-active margins could have focused water to the lake, in turn creating a mechanism by which a margin position switch could occur. The formation of the lake may also have played a role in ice stream stagnation.

\subsection{SLE as a Modern Analogue for Duckfoot Flat Ice Terrain}

A modern mechanical analogue for the now stagnant DF margin may exist at the downstream end of WIS. The northern margin of WIS, adjacent to Englehardt Ridge (ER), is characterized by a $50 \mathrm{~km}$ long region of relatively thin ice $(\sim 600-800 \mathrm{~m})$ bounded by surface crevasses. The ice surface between these boundaries is relatively smooth, intermediate between the rougher ice stream surface and smoother interstream ridge, and thus similar in appearance to the DF. Fricker and Scambos (2009), described this area as 
Subglacial Lake Englehardt (SLE), a location where water is stored and periodically discharges below the Ross Ice Shelf (RIS).

Both the northern and southern boundaries of SLE are characterized by crevasses and differences in crevasse patterns at the two lakeshores can be used to investigate the origin and evolution of the lake. SLE is bounded to the north by the WIS shear margin. Effective strain rates are large along the relatively narrow northern margin, which is thus characterized by mechanical thinning (Fig. 3.1) and pervasive crevassing (Fig. 3.2). The southern boundary of SLE is identifiable in the change from relatively smooth surface over the lake to relatively rougher in the ice stream. A faint-but detectable—set of arcuate crevasses are observed along this shoreline of the lake (Fig. 3.4). The faintness and relatively uncomplicated geometries of the fractures (mature shear margins are "chaotic" with many cross-cutting relationships) along the southern lakeshore suggest that this feature is young. Nevertheless, the arrangement is otherwise identical to the situation at the DF. It may thus be hypothesized that SLE and the DF have similar origins and relationships to ice stream flow.

\subsection{Ice Mechanics and Basal Water Routing}

Both water availability and water routing at the ice/bed interface are important to ice stream flow. Because changes in surface slope affect the hydraulic gradients that direct basal water flow, such changes may play a role in discharge cycles and stagnation events. Thus, it might be expected that decadal to century scale grounding and ungrounding associated with ice stream stagnation and reactivation lead to variations in basal water routing. Ice 
dynamics-driven changes in basal water could in turn lead to further variations in ice stream flow.

Due to the relative uniformity of ice thickness across an ice stream, especially along the ice plain at the outlet of a large ice stream, small changes in ice surface morphology may lead to relatively large rerouting of underlying basal water. High effective strain rates at the margins produce mechanical thinning of the ice that in turn affects local thickness and surface elevation gradients and, in turn, local basal water routing (Fig. 3.1). The four spatially largest subglacial lakes documented by Fricker and Scambos (2009) and Carter and Fricker (2012) are located along shear margins or, in the case of Lake 7, a shear margin suture zone now advecting from the confluence of WIS and Mercer ice streams (Fig. 3.1). The shear margins bounding WIS are heavily crevassed with widths of a few kilometers and effective strain rates of $\sim 0.01-0.14 \mathrm{a}^{-1}$ (Fig. 3.1). 


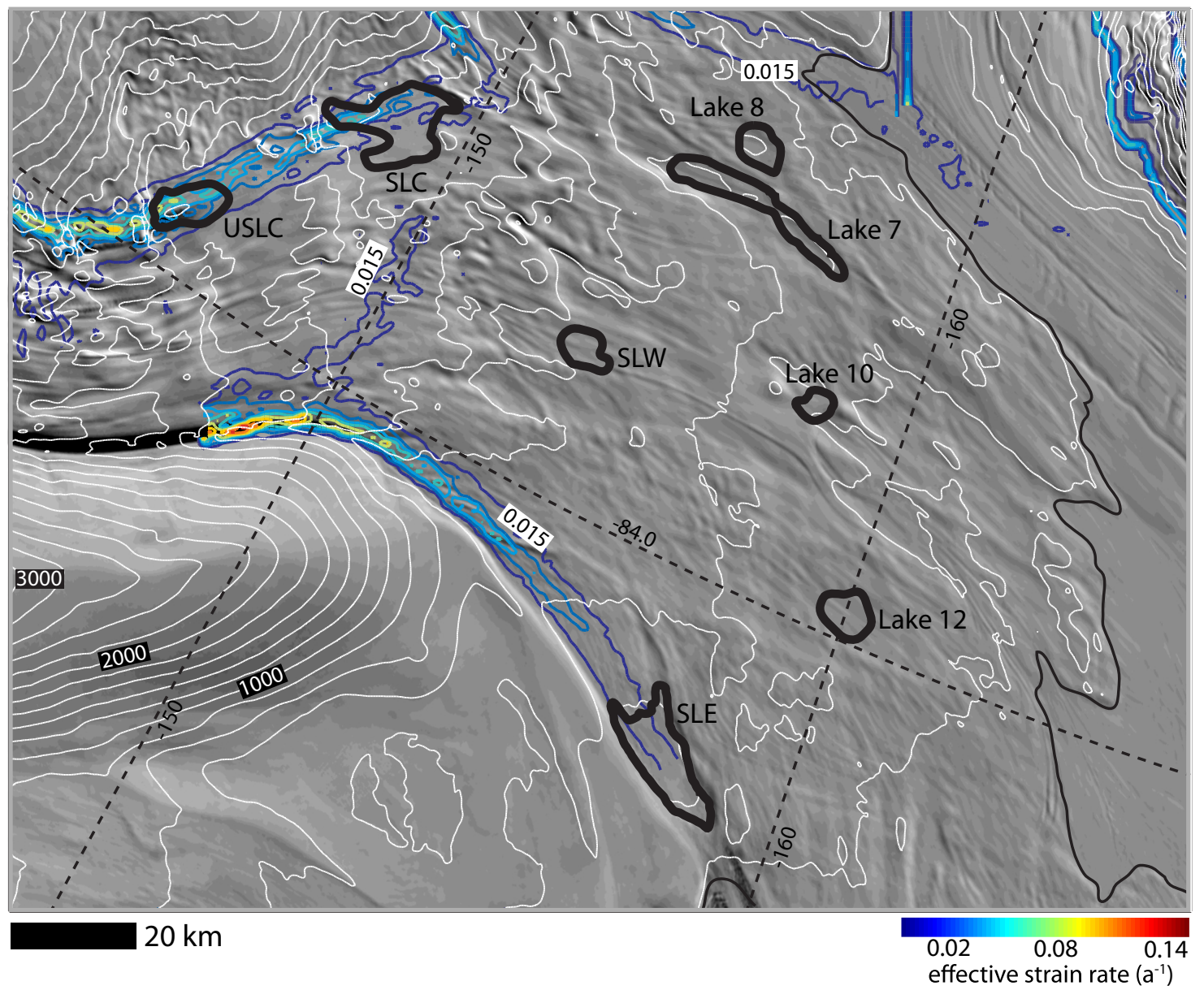

Figure 3.1. MOA image showing Whillans Ice Plain and the locations of subglacial lakes (Ficker and Scambos, 2009). Colored contours are calculated effective strain rates (contour interval $=0.015 \mathrm{a}^{-1}$ ). Shear margins are characterized as narrow bands of high effective strain rates separating the active ice stream with adjacent ice ridges. White contours indicate hydropotential (contour interval $=200 \mathrm{kPa}$ ). Grounding line is shown as a black line.

\subsection{Surface Morphology and Mechanical Signature of Subglacial Lake Englehardt and Duckfoot Flat Ice Terrains}

A map of hydraulic potential for WIS shows that basal water routing (down the potential gradient) is, in part, guided by local thinning along the shear margins where it may then collect in subglacial lakes (Fig. 3.1 and 3.2). Effective strain rates are the highest, $>0.05$ $\mathrm{a}^{-1}$, and most focussed at the onset of the flat ice terrain upstream of SLE. Downstream, 
effective strain rates become more diffuse as the ice stream widens across the ice plain.

Here effective strain rates are on the order of $0.01-0.02 \mathrm{a}^{-1}$ (Fig. 3.7).

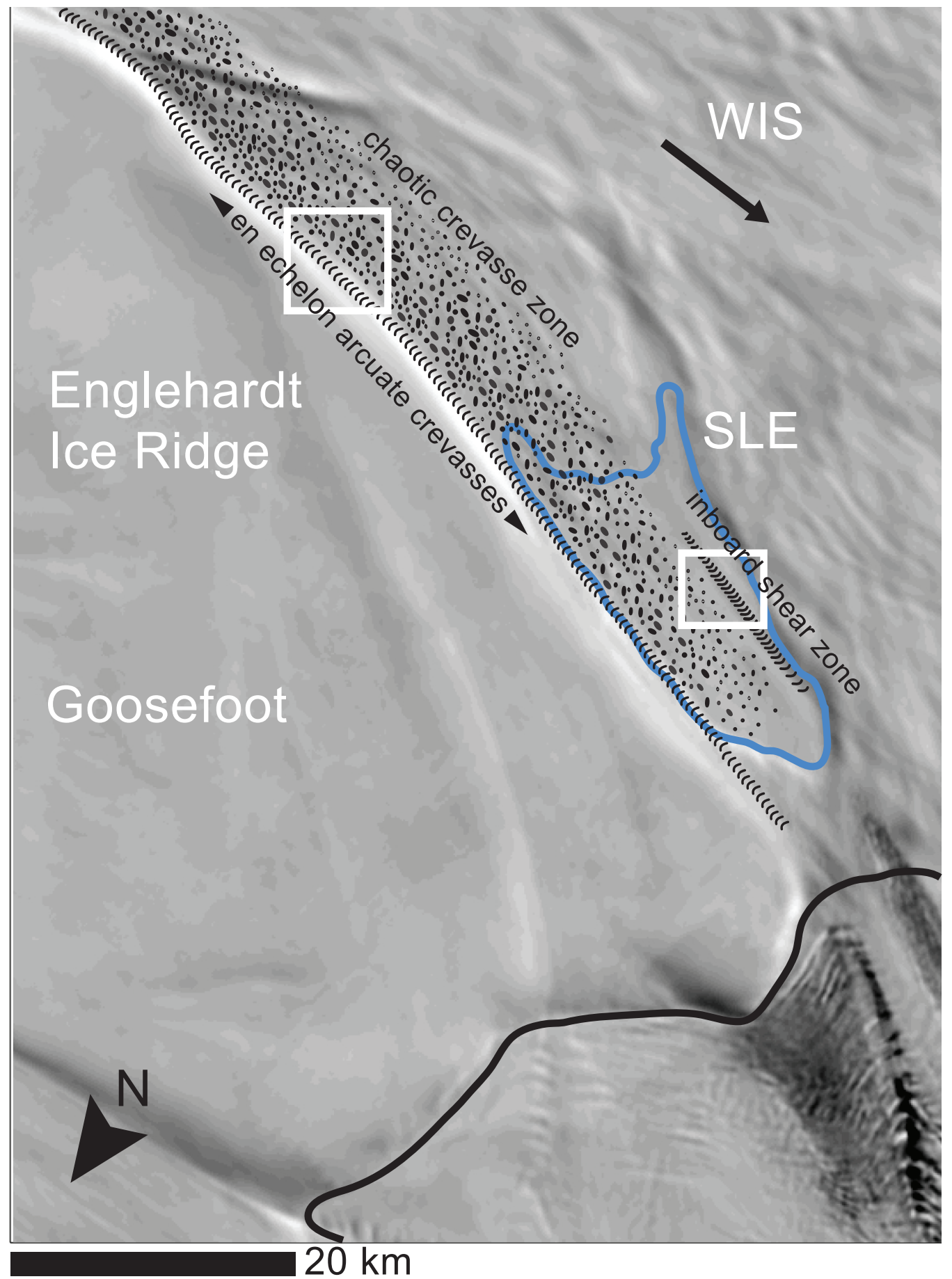

Figure 3.2. MOA image (Scambos et al, 2007) showing the right lateral flat ice terrain at the downstream end of WIS. Curved blue line is the SLE boundary as defined by Fricker and Scambos, 2009. Surface expression and shear margin pattern is annotated. Ice flow direction is shown in the 
upper right hand corner. (5 m) (Polar Geospatial Data Center). White boxes represent areal extent of high-resolution imagery ( $5 \mathrm{~m}$ from Polar Geospatial Data Center) used in figures 3.3 and 3.4 .

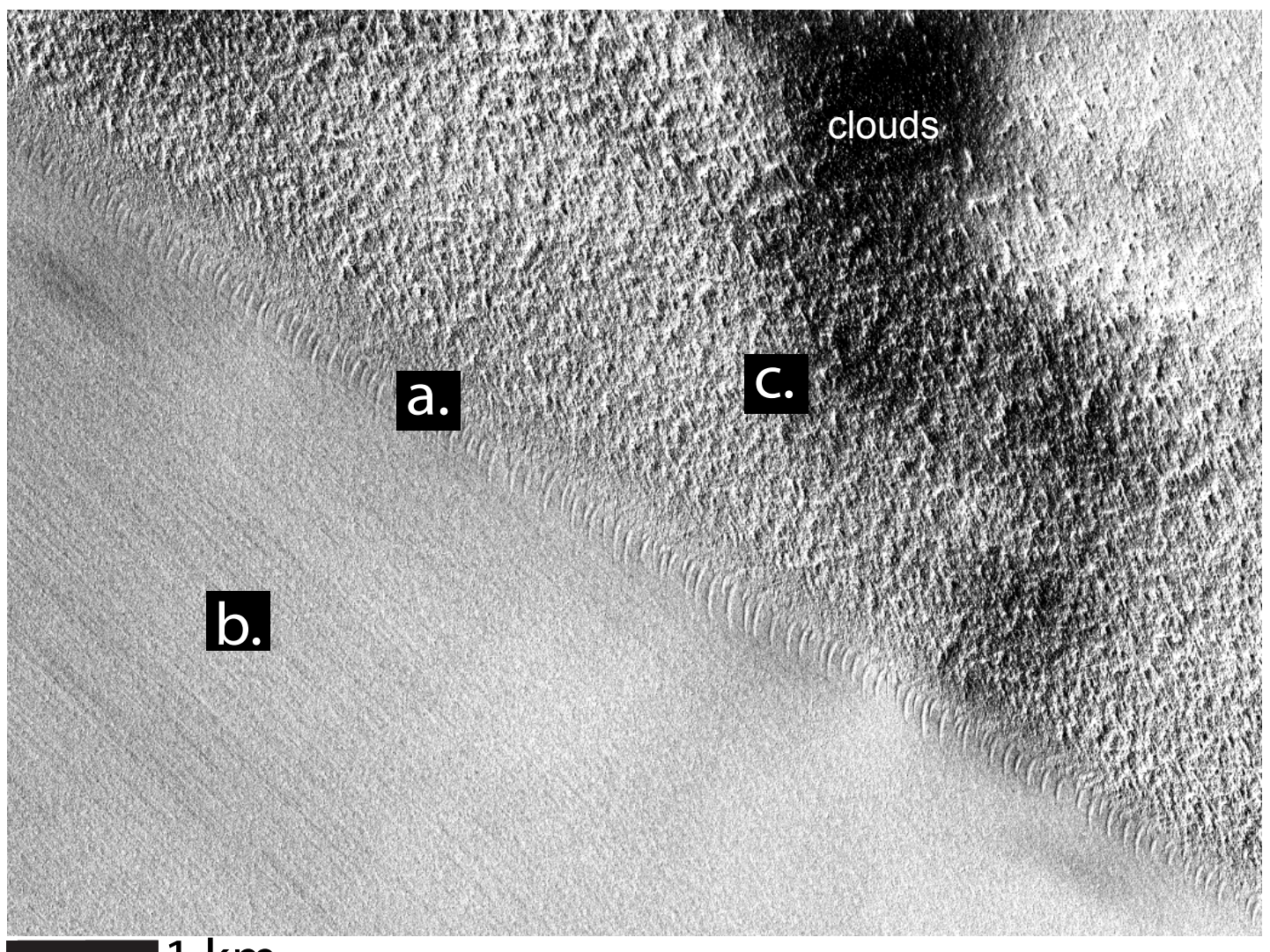

Figure 3.3. High-resolution image showing outboard shear zone surface morphology (Polar Geospatial Data Center). a) en echelon arcuate crevasses, b) Englehardt Ridge terrain and c) chaotic crevasse zone. 


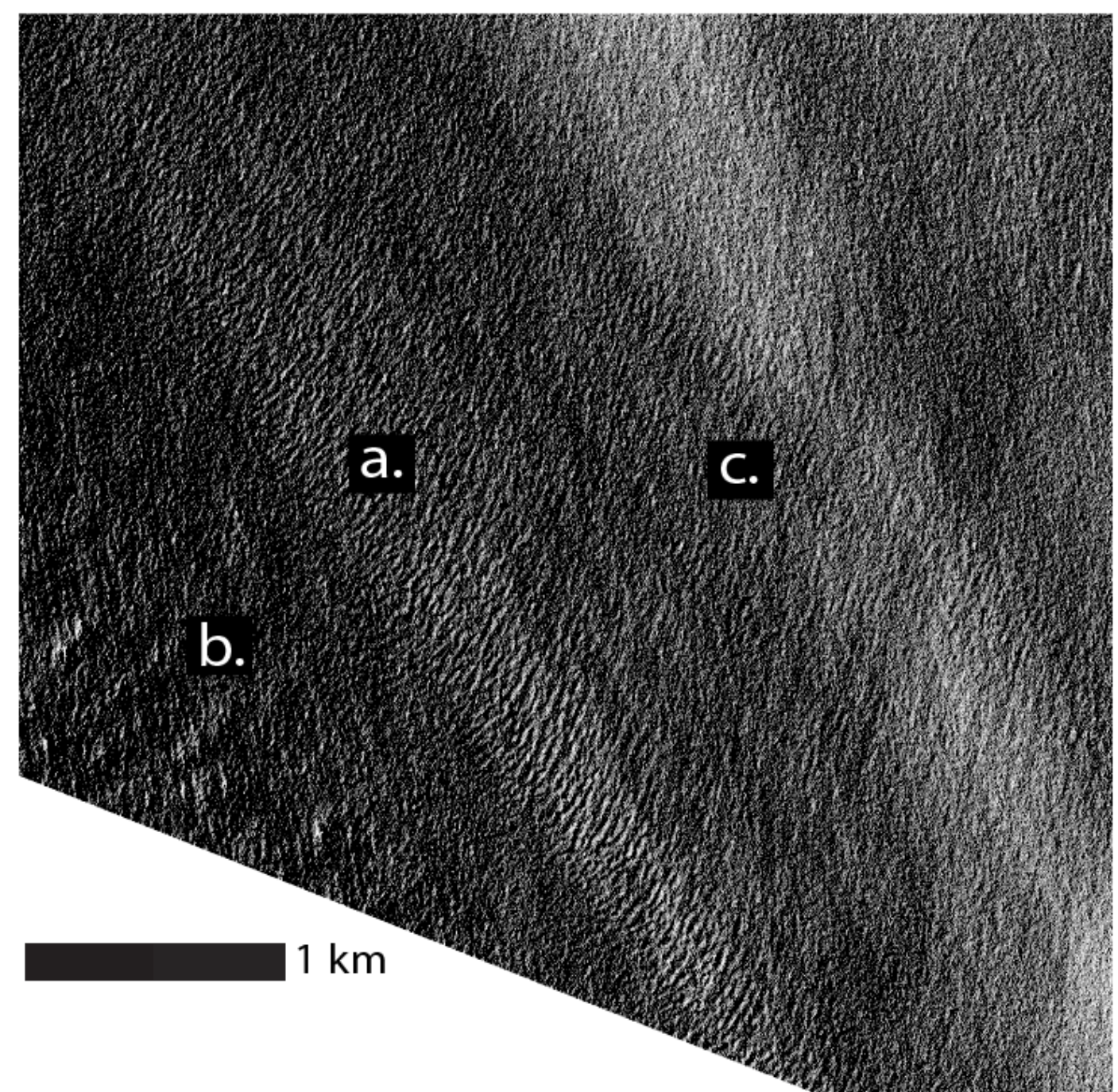

Figure 3.4. High-resolution image showing SLE inboard shoreline surface morphology (Polar Geospatial Data Center). a) en echelon arcuate crevasses, b) chaotic crevasse zone and c) main trunk of WIS.

High-resolution imagery of SLE and the surrounding flat ice region distinguishes several zones of distinctive surface morphology (following the example of Merry and Whillans, 1993) (Fig. 3.3 and 3.4). The highest effective strain rates along the outboard shear margin are coincident with a narrow band of en echelon hook-shaped surface crevasses marking the transition between flowing ice in the flat ice terrain and slow moving ice on ER (Fig. 3.3). As ice in the stream moves past ER, simple shear rotates the inboard ends of the crevasses into hooks that are concave down the ice stream. Inboard of the en echelon 
crevasses is a wide chaotic crevassed zone. Here, further shearing and opening of new crevasses creates a large zone of complex crevassing (Merry and Whillans, 1993). Upstream of SLE, the main trunk of WIS borders the chaotic crevassed zone on its inboard side. However, inboard of SLE, a second narrow zone of en echelon hook-shaped crevasses emerges over the lakeshore, forming a second fractured (that is, shearing) margin in the stream (Fig. 3.4).

Buried crevasses in the DF region display a similar arrangement (Fig. 3.5). At the DF, a band of outboard near-surface crevasses tracks the boundary between the SD and fast flowing ice, most likely reflecting a zone of high paleo effective strain rates along the relic shear margin. Inboard, a second zone of near surface crevasses marks the boundary between the shear margin and the main trunk of KIS. The arrangement may be read as a map of past effective strain rates and ice flow. The similarity to the present-day SLE is clear.

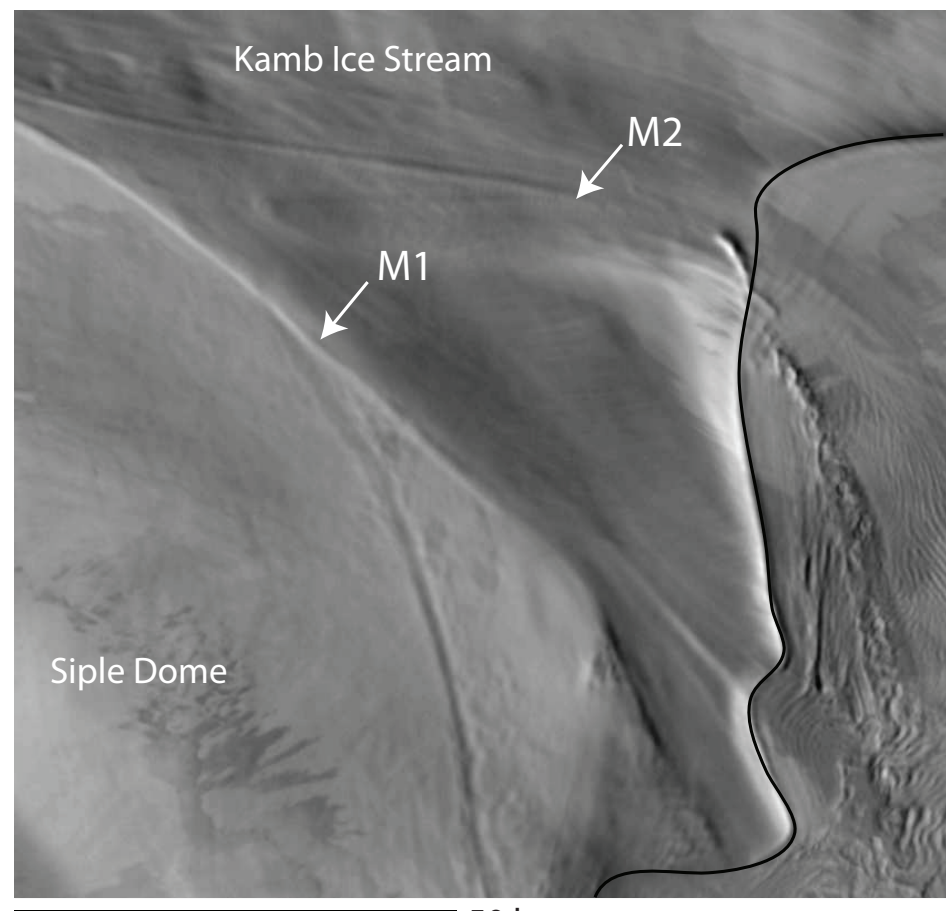

$50 \mathrm{~km}$

Figure 3.5. MOA image showing Duckfoot flat ice terrain. M1 represent oldest outboard relic shear margin (350 a) and M2 is younger inboard relic shear margin (150 a). 


\subsection{Subglacial Lake Englehardt and Basal Water Routing}

SLE is an outlet through which subglacial meltwater leaves the ice stream system. Fricker and Scambos (2009) concluded that the elevation anomalies reported from repeattrack laser altimetry were the result of water discharge events. This lake is thus clearly the involved in water routing. Carter et al., 2012, calculated estimated volume fluxes for the area and reported input values of $\sim 110 \mathrm{~m}^{3} \mathrm{~s}^{-1}$ and outputs of $\sim 60 \mathrm{~m}^{3} \mathrm{~s}^{-1}$ during drainage events. This may be a persistent feature, however the relatively recent development of fractures on the inboard lakeshore suggests instead that it is a relatively new feature. If so, it may be involved in the recent slowdown of the downstream end of WIS (Joughin et al, 2002 and 2005). 


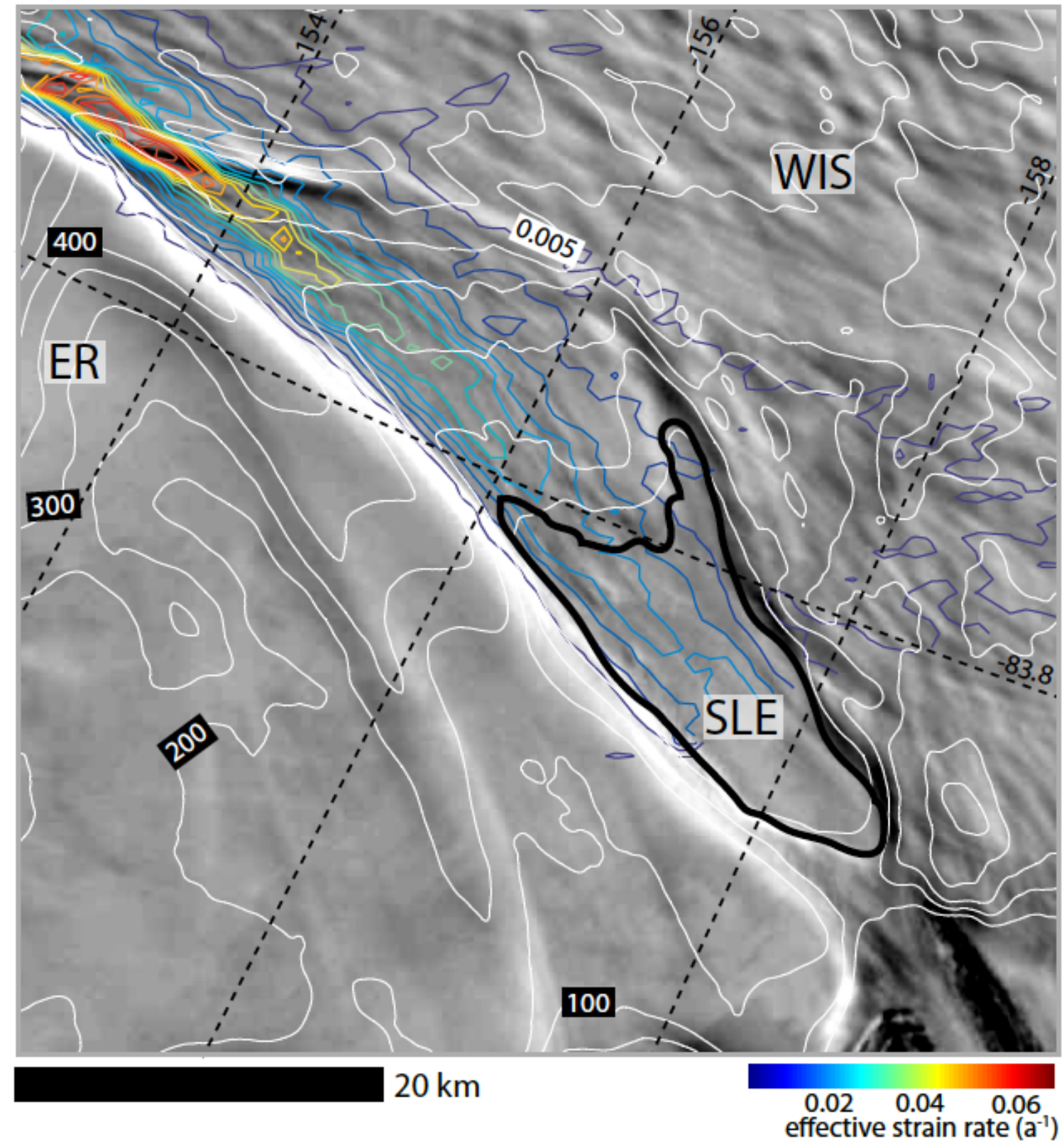

Figure 3.6. MOA image showing flat ice region around SLE. Colored contours are calculated effective strain rates (contour interval $=0.004 \mathrm{a}^{-1}$ ). White contours indicate hydropotential (contour interval $=50 \mathrm{kPa}$ ). Outline of SLE is shown as a blue line.

Today the downstream reach of WIS is decelerating at an average of $5.7 \mathrm{~m} \mathrm{a}^{-2}$ with the largest rates farthest downstream on the ice plain (Joughin et al., 2002 and 2005). The slowing started in at least 1974, the time of the earliest surface measurements (Bindschadler et al., 2005 and Joughin et al., 2005). Because SLE diverts water away from the center of the 
ice stream and, in turn, increases basal traction, the subglacial lake may contribute to the deceleration.

\subsection{Summary of Comparison of Subglacial Lake Englehardt and Duckfoot Features and Consequences for Ice Stream Flow}

SLE may be an analogue for the DF margin prior to KIS stagnation 150 years ago.

In general, changes in surface slope associated with ungrounding and regrounding across the ice plain downstream of the ice stream outlet or associated jumps in lateral margin location could redirect basal water flow and lead to the formation of margin lakes where basal water is stored and episodically released at the grounding line. It may be that for the DF, like present day SLE, the combination of a topographic low in the bed and mechanical thinning at the ice stream margin produced a low in the hydraulic potential that diverted water producing such a lake.

The setting of the DF at the right lateral outlet of KIS is remarkably similar to the setting of the SLE region at the outlet of WIS (table 3.1). As on SLE, the DF is characterized by a slope break that must be the result of high effective strain rates and localized thinning along the former shear margin. The slope is oriented toward the lateral margin and, in turn, directs basal water toward that margin. 
TABLE 3.1 COMPARISON BETWEEN DUCKFOOT AND SLE FEATURES

\begin{tabular}{|c|c|c|}
\hline Parameter & Duckfoot & Subglacial Lake Englhardt \\
\hline $\begin{array}{l}\text { Geometery in } \\
\text { context of ice } \\
\text { stream }\end{array}$ & $\begin{array}{l}\text { Right lateral downstream feature } \\
\text { with outboard shear margin } \\
\text { bordering Siple Dome. }\end{array}$ & $\begin{array}{l}\text { Right lateral downstream feature } \\
\text { with outboard margin bordering } \\
\text { Englehardt Ridge }\end{array}$ \\
\hline $\begin{array}{l}\text { Surface } \\
\text { expression }\end{array}$ & $\begin{array}{l}\text { Flat ice terrain: low relief curved } \\
\text { lineation features oriented sub- } \\
\text { parallel to the ice flow direction. } \\
\text { Slope break towards relic lateral } \\
\text { margin. }\end{array}$ & $\begin{array}{l}\text { Flat ice terrain: low relief curved } \\
\text { lineation features oriented sub- } \\
\text { parallel to the ice flow direction. } \\
\text { Slope break towards relic lateral } \\
\text { margin. }\end{array}$ \\
\hline $\begin{array}{l}\text { Inboard and } \\
\text { outboard shear }\end{array}$ & $\begin{array}{l}\text { Bounded by two relic margins } \\
\text { determined by analysis of } \\
\text { internal layering and near surface } \\
(\leq 100 \mathrm{~m}) \text { crevasses (Catania et } \\
\text { al., 2006). }\end{array}$ & $\begin{array}{l}\text { High-resolution imagery reveals } \\
\text { outboard shear zone featuring en } \\
\text { echelon, hook shaped crevasses } \\
\text { bordering a more disaggregated } \\
\text { and chaotic crevassed zone. A } \\
\text { second inboard shear zone is } \\
\text { congruent with the southern } \\
\text { (inboard) shoreline of SLE and } \\
\text { features a second set of en } \\
\text { echelon surface crevasses. }\end{array}$ \\
\hline
\end{tabular}

The similarities between the DF and SLE derived from their shared mechanical and geomorphological context suggests that the two areas are similar features within the greater ice stream system. It follows that the DF was a likely setting for a subglacial lake prior to KIS stagnation. If the DF was a subglacial lake in the past, the development of the lake may have played a role in the sudden margin jump there, facilitating the jump as lake development caused formation of the inboard shear margin. After the margin jumped inward, mechanical thinning, apparent in the modern surface slope and hydraulic gradient, began along its new inbound trace. We speculate that a similar sequence of events may be unfolding at the outlet of WIS. 
If in the past the DF was a subglacial lake, it is likely that the DF would have played a role in controlling the basal water regime at the downstream end of KIS. Today, SLE diverts water away from the main trunk of WIS and thus may be contributing to the deceleration of the ice stream. Similarly, the DF would have diverted water to its location along the lateral margin and, in turn, also contributed to the stagnation of KIS. Thus, one interpretation of the relict features is that, based on similarities in inboard and outboard shear and surface expression between the DF and SLE, the DF is a likely location for a past subglacial lake that served to divert water away from the main trunk of KIS and help lead to its ultimate stagnation. 
Chapter 4

\section{MODEL SIMULATIONS OF THE EFFECT OF PERTURBATIONS ON GROUNDING ZONE DYNAMICS AT THE DOWNSTREAM END OF KAMB AND WHILLANS ICE STREAMS, WEST ANTARCTICA}

\subsection{Introduction}

Fahnestock et al (2000) used stacked AVHRR images to create a more detailed view of flow features in the Ross Ice Shelf (RIS) than had been previously recongnized. These features indicated that the flow of the shelf had not been steady over time and those authors concluded that such variability must be related to discharge from the West Antarctic Ice Sheet (WAIS). Hulbe and Fahnestock (2004 and 2007) used higher resolution composite Moderate Resolution Imaging Spectroradiometer (MODIS) images of the RIS and numerical models to infer the timing and magnitude of the past events. Together, these works extended the record of flow variability in West Antarctica back about 1000 years and demonstrated that WAIS ice streams experienced stagnation and reactivation events on century time scales. These findings suggest that the grounding zone may experience far more frequent regression and transgression events than previously understood. These findings are supported by the marine record (Anderson et al., 2002) and also borehole observations (Vogel et al., 2005).

The boundary conditions for an ice stream are the most important factors in determining discharge variability and, in turn, grounding line migration. Grounding zones differ from grounding lines in that they feature a broad ice plain of lightly grounded ice. As noted in previous chapters, bed topography below ice streams is an important factor in determining ice thickness. Ice thickness and surface slope control basal water routing and, in 
turn, ice stream speed. Resistance forces at the base of the ice stream that combine to make basal drag (Cuffey and Peterson, 2011) may be modified by basal freeze and subsequent strengthening of subglacial till (Bougamont et al., 2003) and the presence of sticky spots, or subglacial areas of high basal traction (Sergienko and Hulbe, 2011). Ice stream outlet geometry is important in determining discharge and grounding zone variability. For instance, lateral margin position switches, and subsequent narrowing of the ice stream trunk, at the downstream end of an ice stream may lead to changes in ice stream discharge (Catania et al., 2006). Furthermore, at high points in the bed, such as at Crary Ice Rise (CIR) and Steershead (SH), can lead to thickness gradients that further modify outlet width upstream at ice stream outlets.

This chapter presents output from a numerical model of the RIS and the downstream reaches of its tributary ice streams, configured to represent possible past states of the system. The goal is to investigate the timescales and grounding and ungrounding events associated with various perturbations, such as changes in basal traction, rather than to recreate past discharge history as informed by the ice shelf record. Ice mechanics controlling grounding events across the ice plain at the Kamb Ice Stream (KIS) and Whillans Ice Stream (WIS) outlets are diagnostic to understanding century scale grounding zone dynamics and variability. In particular, Hulbe and Fahnestock (2007) noted that communication between ice streams across the ice plain via thickness gradients may be instrumental in controlling grounding events and, in turn, grounding line position and discharge cycle variability. Accompanying changes in surface slope, and basal water routing, may also alter ice stream dynamics. 


\subsection{Ice Stream and Shelf Model}

The finite element model used here is described in detail in Hulbe and Fahnestock (2007) and Hulbe and MacAyeal (1999). The model solves vertically integrated conservation equations for mass and momentum in a horizontal $(\mathrm{x}, \mathrm{y})$ plane. The simplification in the vertical ( $z$, positive upward) reflects the very small basal traction at the ice base in both the ice shelf and the ice streams.

\subsubsection{Balance Equations}

Change in ice sheet thickness over time described by a mass continuity equation,

$$
\frac{\partial h}{\partial t}=\dot{a}+\dot{b}-\nabla \cdot(u h)
$$

where $b$ represents thickness, $t$ represents time, $\dot{a}$ is ice accumulation at the upper surface specified as a boundary condition, $\dot{b}$ is ice accumulation at the lower surface and $u$ is the horizontal velocity and a vector quantity. The product, $u h$ is a vector-valued mass flux integrated over the ice thickness, in which $u$ is derived from the solution to the stress balance equations.

Stress balance in the floating ice shelf, where basal shear stress is nearly zero, is between gravitational driving stress due to surface slope and ice thickness and horizontal normal stresses and shear due to bay walls and ice rises (such as Crary Ice Rise). This is expressed,

$$
\frac{\partial}{\partial x}\left[2 v_{e} h\left(2 \frac{\partial u}{\partial x}+\frac{\partial v}{\partial y}\right)\right]+\frac{\partial}{\partial y}\left[v_{e} h\left(\frac{\partial u}{\partial y}+\frac{\partial v}{\partial x}\right)\right]-\rho g h \frac{\partial z_{s}}{\partial x}=0
$$




$$
\frac{\partial}{\partial y}\left[2 v_{e} h\left(2 \frac{\partial u}{\partial y}+\frac{\partial v}{\partial x}\right)\right]+\frac{\partial}{\partial x}\left[v_{e} h\left(\frac{\partial u}{\partial y}+\frac{\partial v}{\partial x}\right)\right]-\rho g h \frac{\partial z_{s}}{\partial y}=0,
$$

where $\rho$ is ice density and $g$ is the acceleration due to gravity. The ice shelf surface elevation, $z_{s}$, is determined by flotation,

$$
z_{s}=\left(1-\frac{\rho}{\rho_{w}}\right)
$$

where $w$ represents water. Finally, $v_{e}$ is the effective viscosity of the ice,

$$
v_{e}=\frac{\bar{B}}{2\left[\left(\frac{\partial u}{\partial x}\right)^{2}+\left(\frac{\partial v}{\partial y}\right)^{2}+\frac{1}{4}\left(\frac{\partial u}{\partial y}+\frac{\partial v}{\partial x}\right)^{2}+\frac{\partial u}{\partial x} \frac{\partial v}{\partial y}\right]^{\frac{n-1}{n}}},
$$

where $\bar{B}$ is a temperature dependent rate constant which varies in a simple way with the surface temperature (see Hulbe and Fahnestock, 2007). The first term in equations (2) represents longitudinal strain rates. The second term describes horizontal shear-strain rates and the third term is the pressure gradient due to gravity.

For the ice streams, where basal shear stresses are small but not zero, a traction term $u \beta$, is used to represent the effect of subglacial till on the flow of the overlying ice,

$$
\frac{\partial}{\partial x}\left[2 v_{e} h\left(2 \frac{\partial u}{\partial x}+\frac{\partial v}{\partial y}\right)\right]+\frac{\partial}{\partial y}\left[v_{e} h\left(\frac{\partial u}{\partial y}+\frac{\partial v}{\partial x}\right)\right]-\rho g h \frac{\partial z_{s}}{\partial x}-u \beta=0 .
$$

This formulation follows MacAyeal (1989). MacAyeal assumed linear viscous deformation in the till, a situation likely not the case, but because $u \beta$ is a tunable parameter only known by inversion of surface measurements (Sergienko et al., 2008 ) it is not necessary to think of the till in this way. The requirement that basal traction be in some way related to the speed associated with ice deformation is reasonable. 
The position of the "grounding line" is determined according to floatation. When the bedrock surface elevation, $z_{r}$, is equal to or greater than the ice bed elevation, the ice is grounded,

$$
z_{r} \geq z_{s l}-\frac{\rho}{\rho_{w}} h
$$

where $z_{s l}$ is the sea surface elevation. At all other locations ice is floating. Where ice thickness is great enough to overcome floatation, the ice is classifed as grounded and equation (5) is solved. Where this is not the case, ice is classified as floating and equation (2) is solved. As will be seen later, the floatation condition yields, in some locations, complicated grounding line geometries. Flux and surface slope continuity are imposed across grounded/floating boundaries.

\subsubsection{Boundary Conditions}

Boundary conditions are needed to solve the balance equations described above. Kinematic boundary conditions describe interactions at the edges of the model domain. Ice inflow boundaries define ice volume flux entering the ice stream system and are taken from MacAyeal and Thomas (1986) and Shabtaie and Bentley (1987) (Fig. 4.1). An outflow condition is defined at the seaward edge of the ice shelf, which simply transmits across the calving boundary. Additionally, flux conditions are required at the upper and lower surfaces to represent surface and basal accumulation. The surface accumulation rate is from Vaughan et al. (1999) and the basal accumulation rate is zero.

Some flow resistance must be applied under the ice stream to account for interaction between the ice and underlying sediment. In the model domain, the basal friction parameter, $\beta$, is used to simulate basal resistance. MacAyeal (1995) and Sergienko et al. (2007) 
calculated a mean value of $1.8 \times 10^{9} \mathrm{~Pa} \mathrm{~s} \mathrm{~m}^{-1}$ for basal friction along MacAyeal Ice Stream, however, it is known that basal friction varies throughout the length of an ice stream and is highest near the onset and lowest near the grounding zone (Alley and Whillans, 1991). The experiments here use an initial background basal friction parameter, $\beta_{0}$, of $0.01 \times 10^{9} \mathrm{~Pa} \mathrm{~s} \mathrm{~m}$ 1.

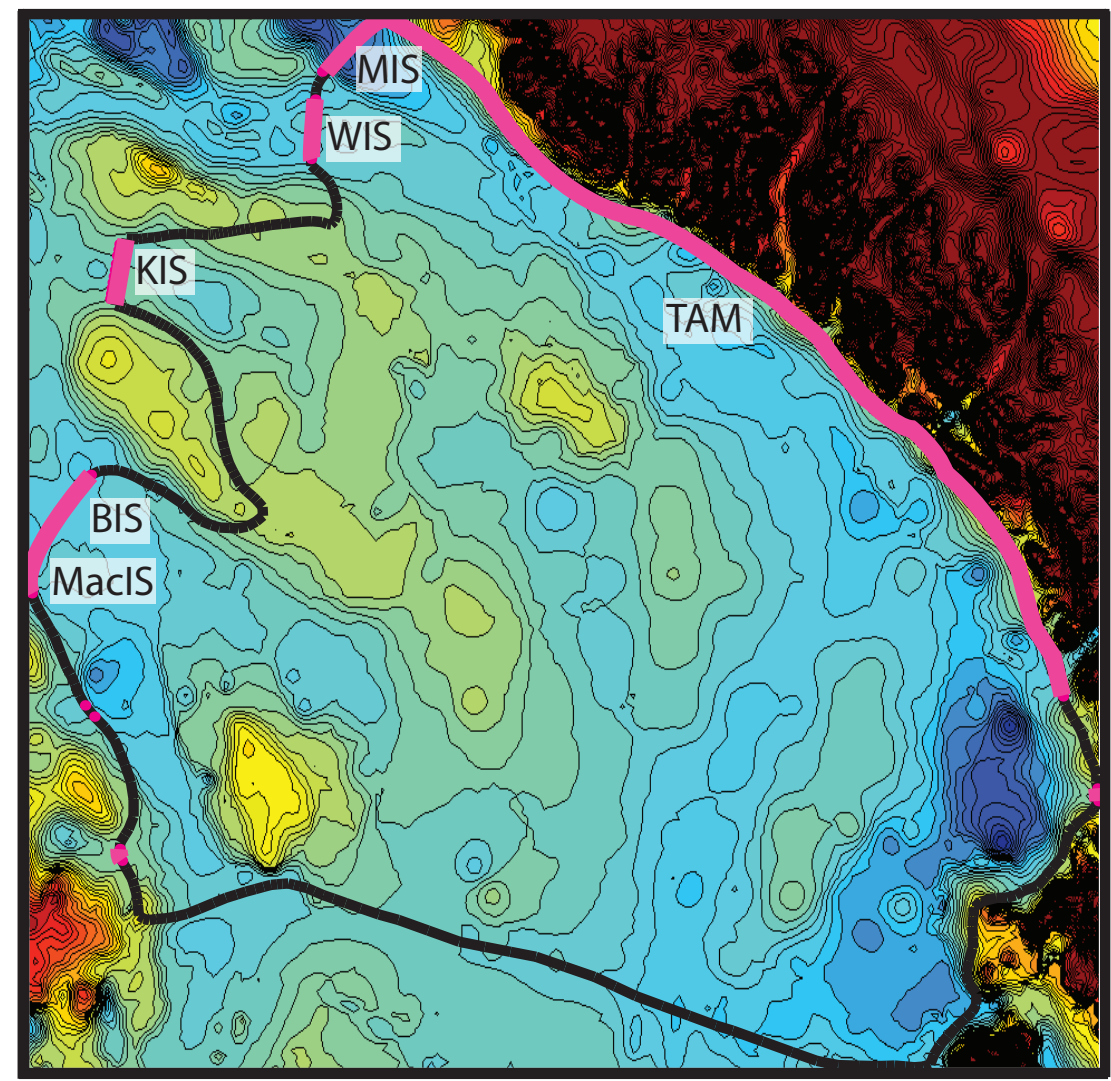

Figure 4.1. Map showing locations of flux gates (pink) for the FEM domain. Kamb (KIS), Whillans (WIS), Mercer (MIS), Bindschadler (BIS) and MacAyeal Ice Stream (MacIS) flux gates are annotated. Additional flux comes from the Trans Antarctic Mountains (TAM). 


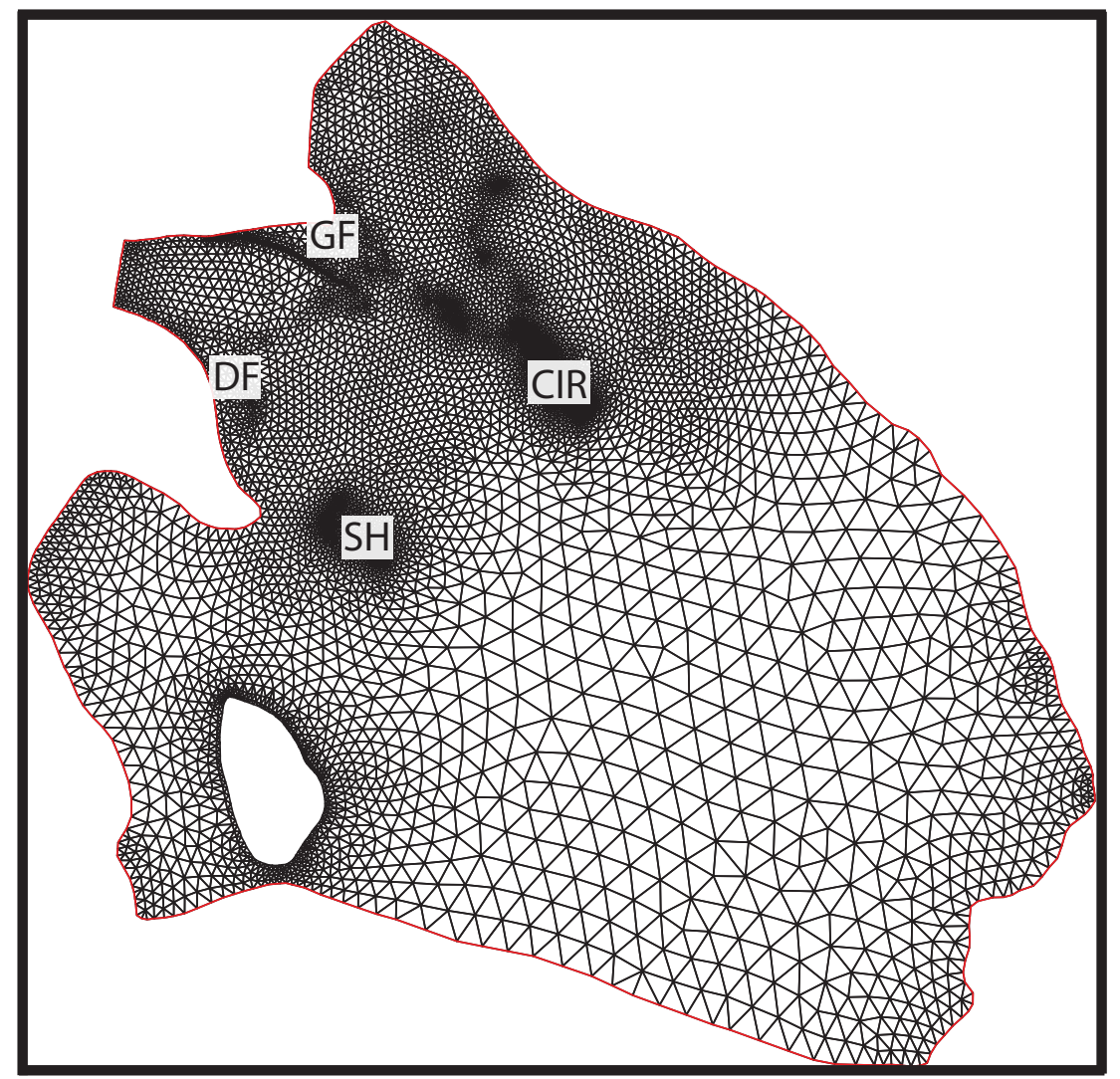

Figure 4.2. Map showing FEM mesh. Locations of Steershead (SH), Crary Ice Rise (CIR), Goosefoot (GF) and Duckfoot (DF) are noted.

\subsection{Model Experiments}

Each model experiment reported here begins from steady state ice thickness and speed for fixed boundary fluxes, flow law rate factor, and basal traction parameter $\beta$. Steady state is defined as a change in $h$ of $\leq 1 \times 10^{-4} \% \mathrm{a}^{-1}$ at nodes within the model domain. From that state (Fig. 4.3), the model continues to step forward in time as a set of perturbations are applied via ice stream fluxes and basal traction. Timing is reported here as "years after the start of perturbation experiments" which means that year 0 initiates when the numerical model has reached steady state (1400 years into the model run). 

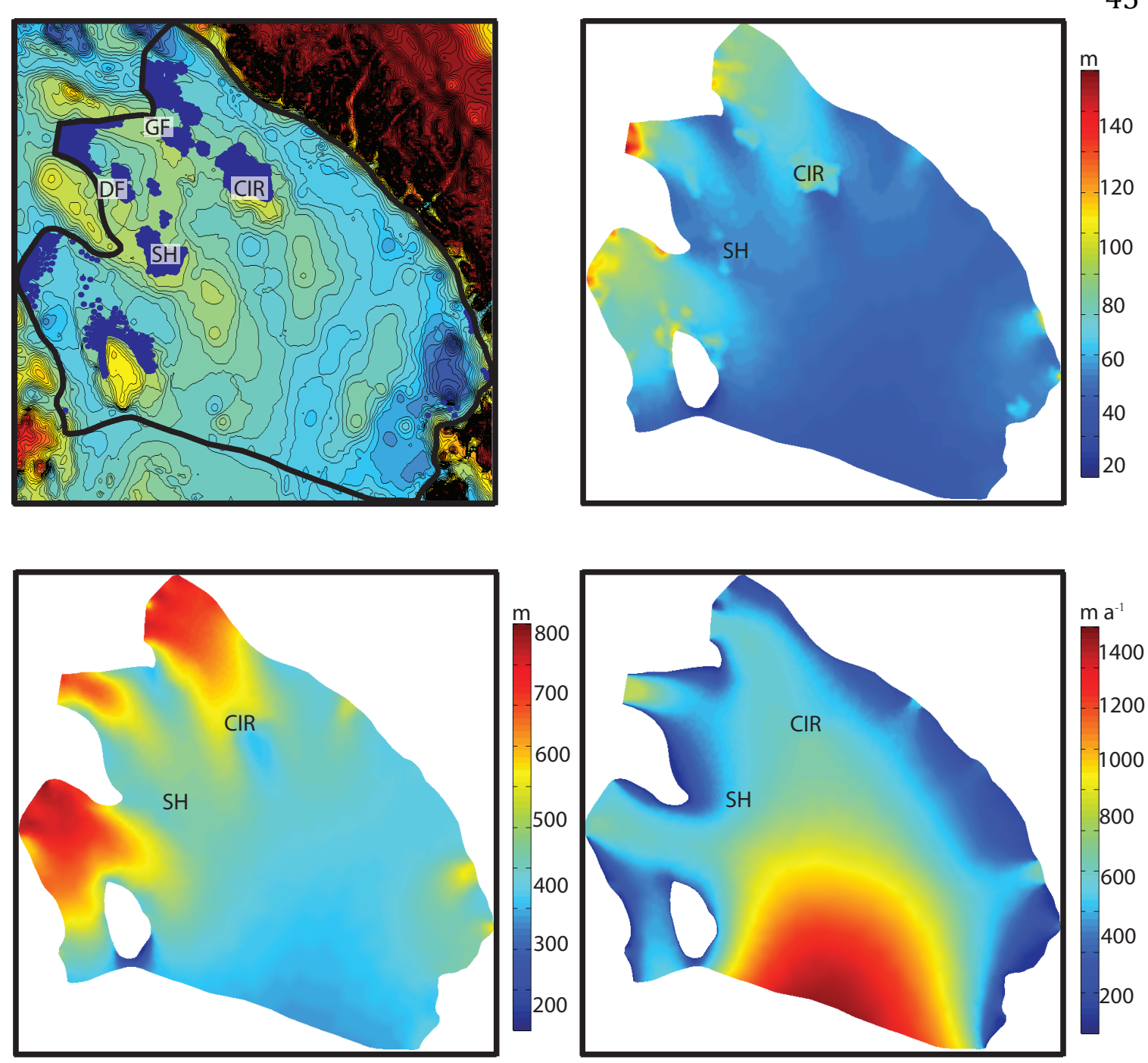

Figure 4.3. Steady-state fields within the model domain. Clockwise from top left: Shaded regions represent grounded nodes in FEM domain and filled contours represent bed elevation where contour interval is $25 \mathrm{~m}$; ice surface elevation (m); ice speed $\left(\mathrm{m} \mathrm{a}^{-1}\right)$; and ice thickness $(\mathrm{m})$. Locations of present day CIR and SH are noted for spatial context.

The experiments are not focused on recreating past events (see Hulbe and

Fahnestock, 2007), but instead are intended to study how individual boundary condition changes and combinations of changes propagate through the ice stream outlet and ice plain region. Perturbations propagate via changes in ice velocity, velocity gradients, and thickness.

Thickness changes may in turn drive grounding, ungrounding, and grounding line migration. 
By proceeding in this way, we hope to better understand the processes and feedbacks that result in a particular grounding line configuration at a particular time, including the spatial and temporal scales involved. It is important to clarify that the interest here is internal variability, not external forcing, of the system. The experiments are evaluated in the context of the present-day KIS and WIS grounding zone, for which the most information is available.

Grounded ice in the model domain exists over the two ice rises in the Ross Ice Shelf, CIR and $\mathrm{SH}$, at the time of steady-state initialization in all of the experiments. Hulbe and Fahnestock (2004) note that this is due to the high bed elevation at these sites. At this time, the KIS grounding line is upstream of the large overdeepening at the downstream end of the ice stream. The WIS grounding line is also upstream of its present location.

Perturbations during a model experiment involve changing boundary conditions. These include changes in ice stream discharge and also basal traction below nodes in the model domain with grounded ice, as summarized in Table 4.1.

TABLE 4.1 TIMING AND TYPE OF CHANGING BOUNDARY CONDITIONS IN NUMERICAL MODELING EXPERIMENTS

\begin{tabular}{lcc}
\hline \hline & $\begin{array}{c}\text { Years after start of } \\
\text { perturbation } \\
\text { experiment }\end{array}$ & Magnitude \\
\hline
\end{tabular}

1: WIS start and stop

WIS stops

WIS reactivates

2: CIR stagnates

CIR stagnates
250

650

100

$$
\begin{gathered}
\boldsymbol{u}=0 \\
\boldsymbol{u}=550
\end{gathered}
$$

3: Increased basal traction $(\beta)$

$$
\text { Background } \beta
$$

100 to 200

$\beta_{\text {o to }} 0.1 \times 10^{8}$ 
4: $\mathrm{CIR}$ and $\mathrm{SH}$ stagnate $+\beta$ increase

CIR stagnates

SH stagnates

100

200

$\boldsymbol{u}=0$

Background $\beta$

100 to 200

$\boldsymbol{u}=0$

5: $\mathrm{CIR}, \mathrm{SH}$ and $\mathrm{GF}$ stagnate $+\beta$ increase

CIR stagnates

SH stagnates

Background $\beta$

GF stagnates
100

200

100 to 200

300

$\beta_{\text {o }}$ to $0.1 \times 10^{8}$

6: CIR and GF stagnate $+\beta$ increase

CIR stagnates

Background $\beta$

GF stagnates
100

100 to 200

300

7: CIR, SH, GF and DF stagnate $+\beta$ increase

CIR stagnates

SH stagnates

Background $\beta$

GF stagnates

DF stagnates
100

200

100 to 200

300

500

$$
\begin{gathered}
\boldsymbol{u}=0 \\
\boldsymbol{u}=0 \\
\beta_{\text {o }} \text { to } 0.1 \times 10^{8} \\
\boldsymbol{u}=0
\end{gathered}
$$

8: CIR, GF stagnate + inner DF $\beta$ increase $+\beta$ increase

CIR stagnates

GF stagnates

Background $\beta$

inner DF $\beta$ increase
100

300

100 to 200

500 to 550

$$
\begin{gathered}
\boldsymbol{u}=0 \\
\beta_{o} \text { to } 0.1 \times 10^{8} \\
\boldsymbol{u}=0
\end{gathered}
$$

9: $\mathrm{CIR}, \mathrm{GF}$ stagnate $+\mathrm{SH} \beta$ increase at stuck nodes $+\beta$ increase

\begin{tabular}{lcc} 
CIR stagnates & 100 & $\boldsymbol{u}=0$ \\
GF stuck & 200 & $\boldsymbol{u}=0$ \\
Background $\beta$ & 100 to 200 & $\boldsymbol{\beta}_{o}$ to $0.1 \times 10^{8}$ \\
$\mathrm{SH} \boldsymbol{\beta}$ increase & 100 to 200 & $\boldsymbol{\beta}_{o}$ to $1.0 \times 10^{8}$ \\
\hline $\boldsymbol{\beta}_{o}=0.01 \times 10^{8}$ & \\
$\beta$ is $\mathrm{Pa} \mathrm{m} \mathrm{s} \mathrm{m}^{-1}$ Boundary speeds are in $\mathrm{m} \mathrm{YR}^{-1}$ &
\end{tabular}




\subsubsection{Perturbation Effects}

The various internally-driven perturbations outlined in Table 4.1 are forced by changing ice stream flux, increasing basal traction across the ice plain either as a fractional change on grounded ice or stagnation of grounded ice. Each type of perturbation initiates in a different sequence of events involving ice mechanics that, in turn, affects flow across other areas of the ice stream.

Perturbations involving changes in ice stream flux result in changes to longitudinal stresses near the downstream outlet that. The relationship between ice thickness and horizontal strain rates is expressed,

$$
\frac{\partial H}{\partial t}=\dot{b}_{i}-H\left[\frac{\partial \bar{u}}{\partial x}+\frac{\partial \bar{v}}{\partial y}\right]-\bar{u} \frac{\partial H}{\partial x}-\bar{v} \frac{\partial H}{\partial y},
$$

For example, when the volume flux through a particular boundary decreases, thinning

ensues and ice that has been grounded may go afloat. Continued thinning in the downstream direction flattens the longitudinal profile, and in turn reduces the surface slope, gravitational driving stress, and velocity of the ice. Changing ice velocity in turn modifies regional strain rates and may in some places lead to relative thickening, even while flux into the ice shelf is declining.

Fractional changes to basal traction in some experiments are forced at grounded nodes in the FEM domain. Increased basal traction decreases ice velocity that, in turn, thickens ice. As ice thickens, ice speed increases until, at some point in time, a new steadystate is found within the system.

Stagnation of a grounded ice area creates a new obstacle for ice flow. In our experiments this takes the form of a creation of an ice rise either at CIR or SH. Introduction 
of an obstacle at a particular location changes the velocity gradient along flow to a more negative value upstream and a more positive value downstream. That is, compression is introduced upstream and extension downstream of the obstacle. Compression upstream generates thickening and locally steepens transverse slopes. These mechanical effects in turn direct flow around the obstacle. Over time, the thickness signal may propagate upstream as ice continues to impinge on the upstream side of the obstacle. This transient may, in turn, affect grounding and thus basal traction, further modifying ice flow in the region.

All of the simple feedback scenarios described here take place in a three dimensional context. Both the shape of the sea floor and the geometries of interstream ridges will modulate how a particular boundary condition change propagates through a region.

\subsection{Experiments}

The first experiments outlined here test how simple perturbations interact with the ice stream - ice shelf system. As each experiment is completed, patterns of grounded ice and changes in ice thickness and velocity are noted in order to interpret how the grounding zone across the KIS and WIS ice plain evolves.

\subsubsection{WIS Stagnation and Reactivation}

Streaklines in the RIS show that WIS stagnated and then reactivated several hundred years later (Hulbe and Fahnestock, 2007). The effect of outlet stagnation is examined in this experiment. Starting from a steady state in which the model WIS ice plain looks much like the present-day ice plain, ice rapidly thins and goes afloat across the ice plain after WIS shuts off (250 a). Fifty years after WIS stagnation (300 a), most of the ice plain has gone afloat 
(Fig. 4.5) and ice shelf speed downstream of the WIS outlet decreases due to thinning. WIS stagnation results in a reorganization of grounded ice at the downstream end of KIS (Fig. 4.6). Ice thins directly upstream of CIR and along the northern shear margin near the DF, but ice thickens and grounds immediately south of the DF towards the middle of the KIS ice plain.

The spatial pattern of thickening and thinning shows one way in which altered flux on one ice stream can affect flow mechanics on an adjacent ice stream. Along flow and across flow transects (Fig. 4.7) show that surface slopes change from dominantly toward the ice front (Fig. 4.8) to incorporate important transverse surface gradients (Fig. 4.9). Through time, the flattening of the along flow surface profile facilitates lateral spreading (Fig. 4.9).

Where ice goes afloat across the WIS ice plain on decadal or shorter time-scales after ice stream stagnation, ice regrounds on multi-decadal time-scales when WIS reactivates. WIS reactivation is characterized by grounding line advance across the WIS ice plain but not past pre-stagnation location. WIS reactivation is not accompanied by grounding line advance at the KIS outlet. That is, the system is tending back toward the initial, preperturbation steady state. This result offers some reassurance that the model correctly reproduces grounding line geometry for different specific mass balance states. 


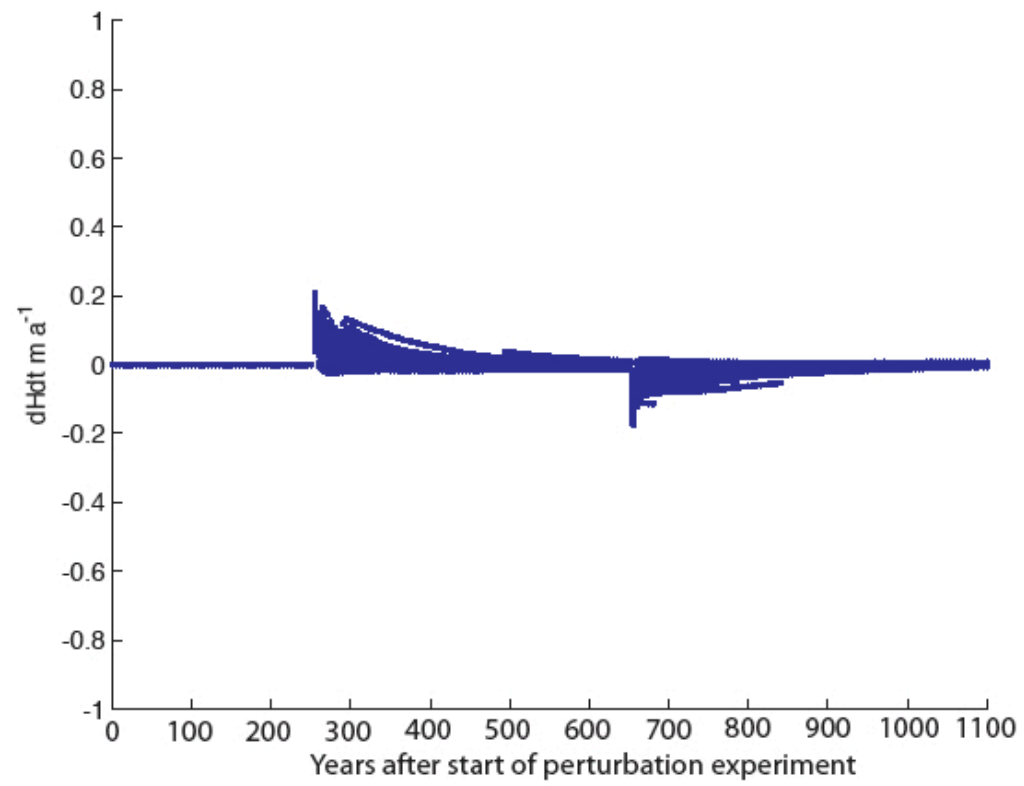

Figure 4.4. $\mathrm{dH} / \mathrm{dt}$ across the KIS ice plain for experiment 1 (table 4.1).

300 a WIS off

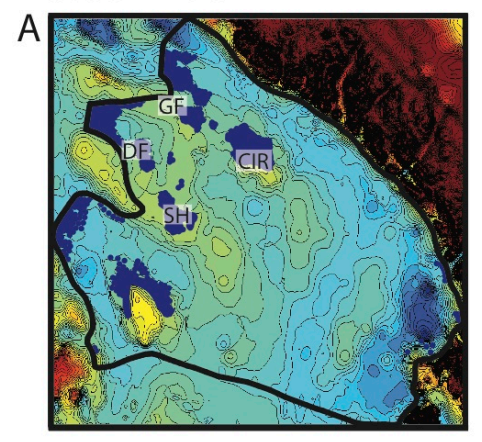

400 a WIS off

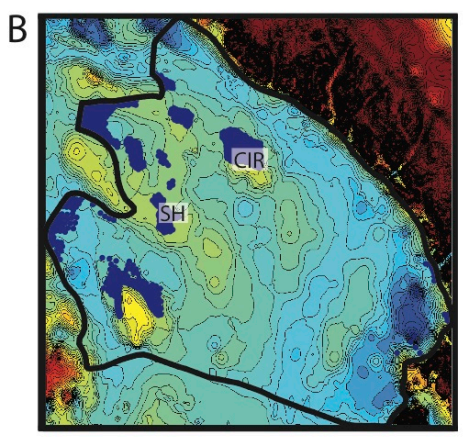

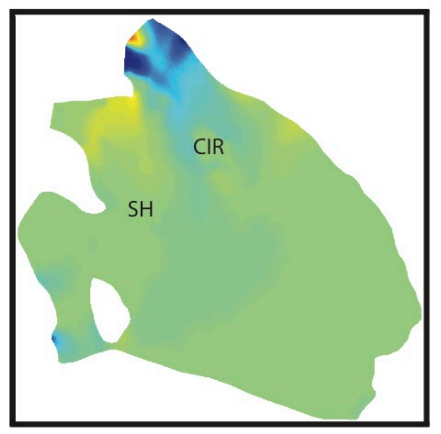
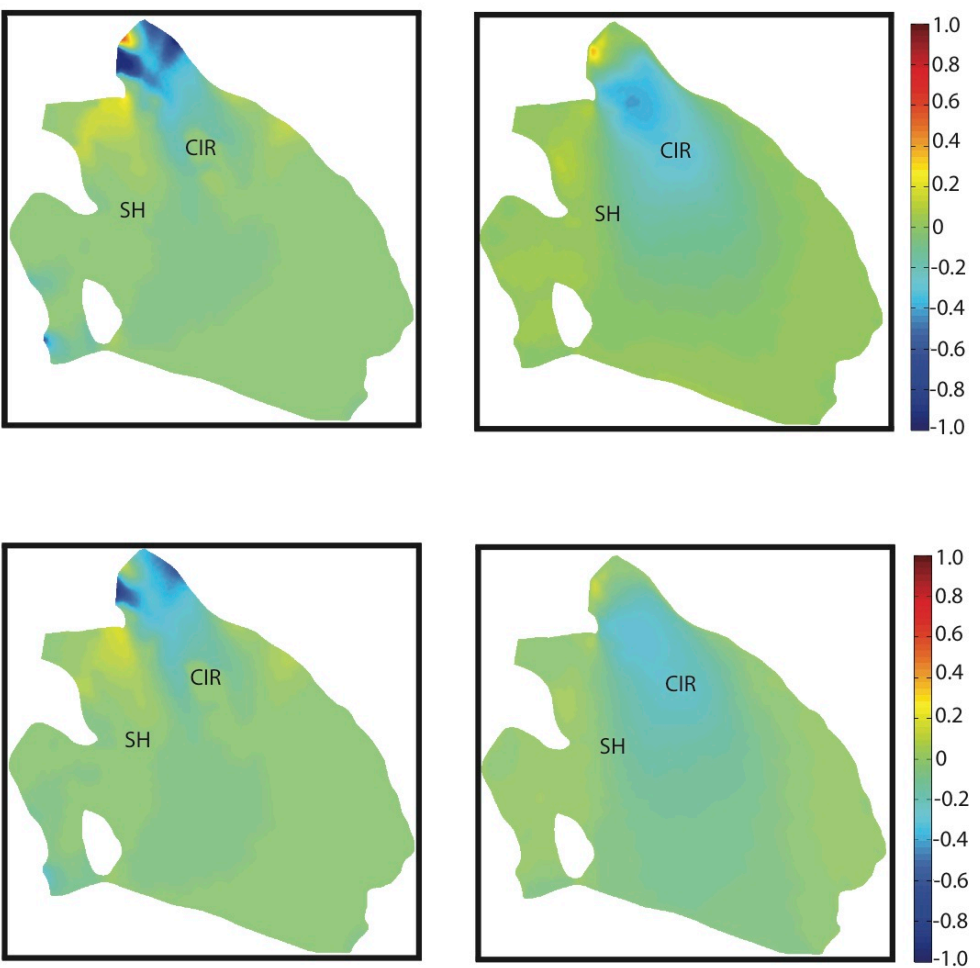

Figure 4.5. Experiment 1: WIS stop and start (table 4.1). Rows of panels represent model output from individual time steps. First column panels show shaded regions representing grounded nodes in the FEM domain. Contours are elevation with an interval of $25 \mathrm{~m}$. Second column panels are rate of thickness change, $\mathrm{dH} / \mathrm{dt}\left(\mathrm{m} \mathrm{a}^{-1}\right)$. Third column panels are rate of ice speed change, $\mathrm{dU} / \mathrm{dt}\left(\mathrm{m} \mathrm{a}^{-1}\right)$. Panels showing rates of change share same the scale to the far right. 
650 a WIS on
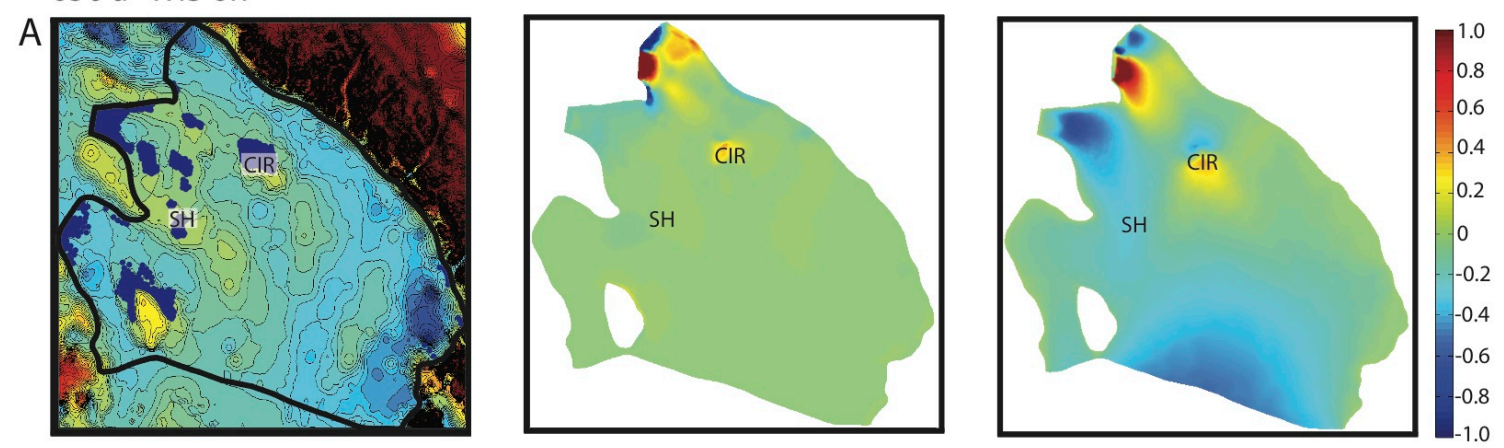

1000 a WIS on
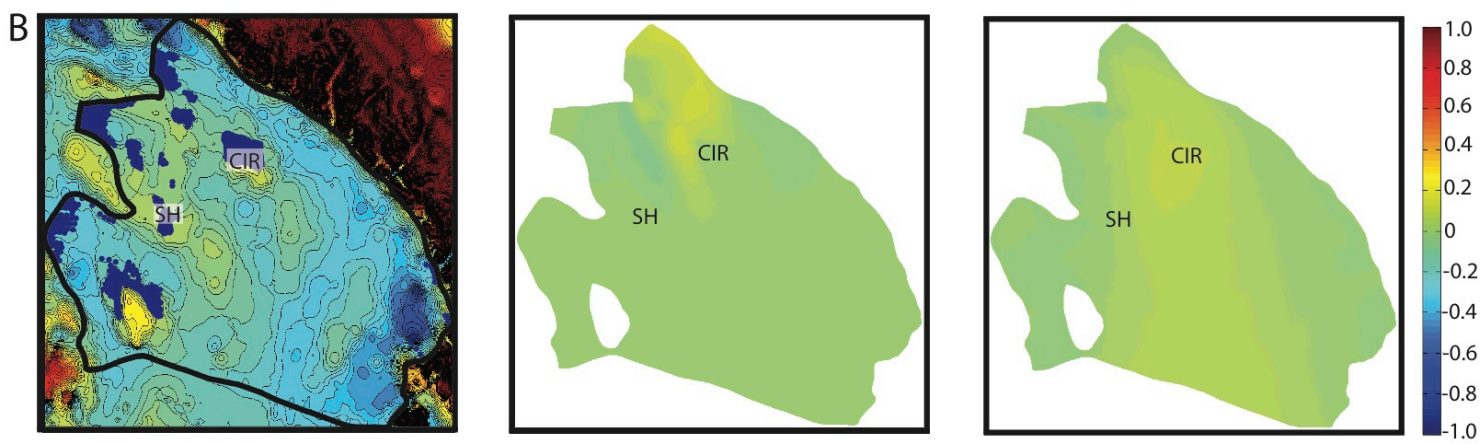

Figure 4.6. Experiment 1: WIS stop and start (table 4.1). Rows of panels represent model output from individual time steps. First column panels show shaded regions representing grounded nodes in the FEM domain. Contours are elevation with an interval of $25 \mathrm{~m}$. Second column panels are rate of thickness change, $\mathrm{dH} / \mathrm{dt}\left(\mathrm{m} \mathrm{a}^{-1}\right)$. Third column panels are rate of ice speed change, $\mathrm{dU} / \mathrm{dt}\left(\mathrm{m} \mathrm{a}^{-1}\right)$. Panels showing rates of change share the same scale to the far right.

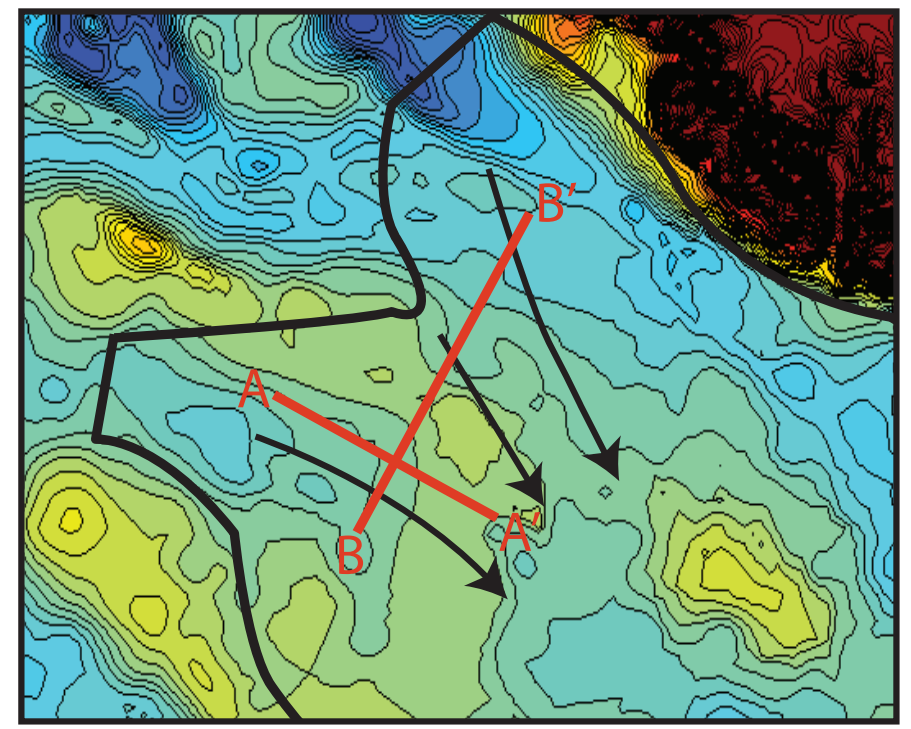

Figure 4.7. Transect locations along flow (A-A') and across flow (B-B') and bed topography for experiment 1 (table 4.1). Black arrows approximate ice flow azimuth when WIS is off and do not represent magnitude. 


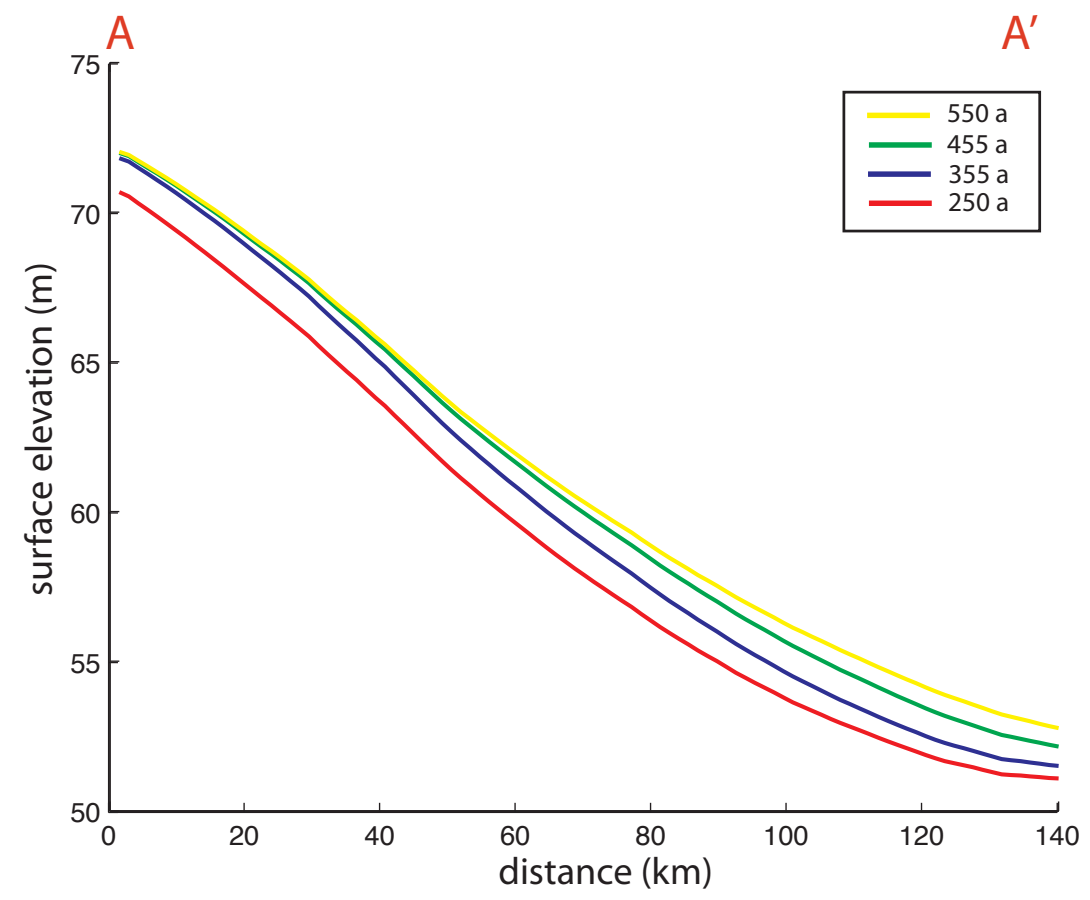

Figure 4.8. Along flow surface elevation profile. Red: surface elevation at 250 a; Blue: 355 a; Green 455 a; Yellow: 555 a.

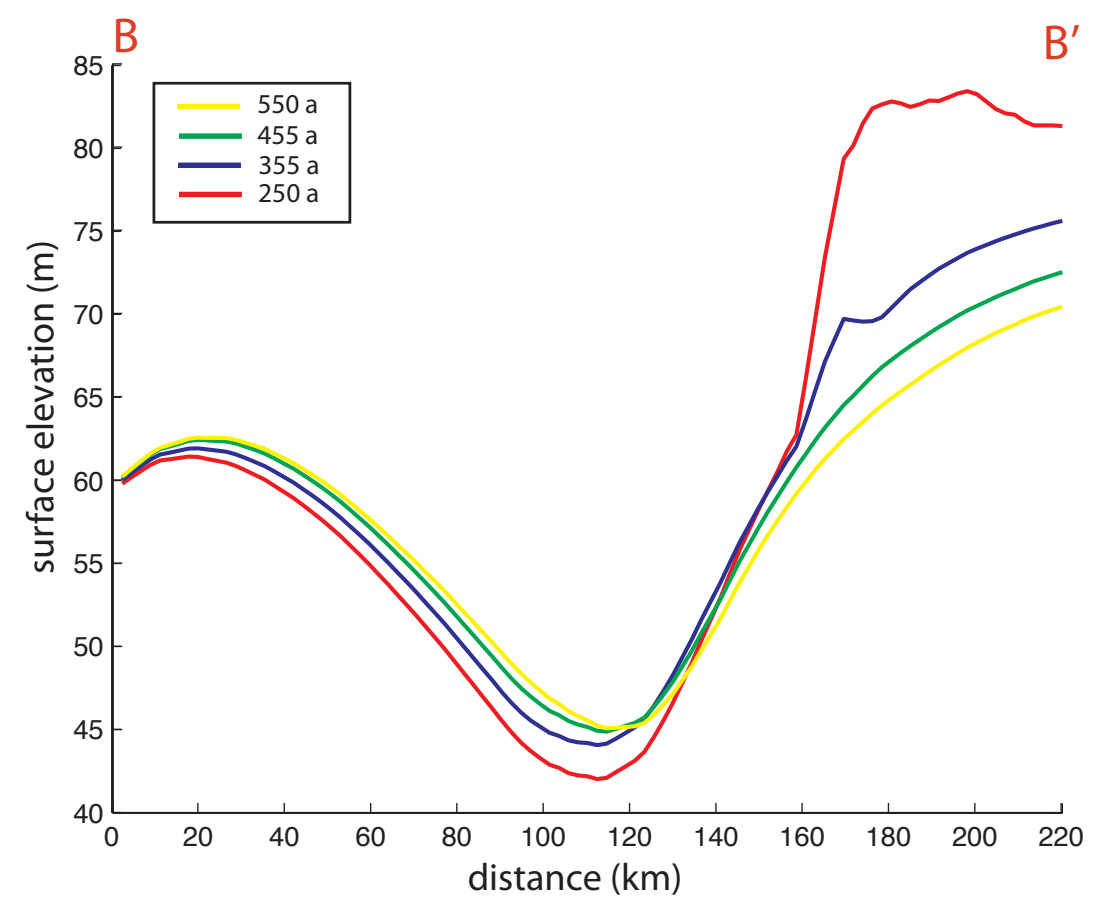

Figure 4.9. Across flow surface elevation profile. Red: surface elevation at 250 a; Blue: 355 a; Green 455 a; Yellow: 555 a. 


\subsubsection{CIR Stagnation}

In this experiment, grounded ice at the site of the present-day CIR is forced to stagnate at 100 a. Evidence from streaklines in the RIS suggest that CIR became stuck $\sim 1000$ years ago. Before CIR stagnates, the area upstream of the ice rise is dominated by transverse compression between the outlet flows from KIS and WIS (Fig. 4.10). When CIR stagnates and becomes an obstacle to flow, longitudinal strain rates increase due to compression and ice thickens (Fig. 4.11).

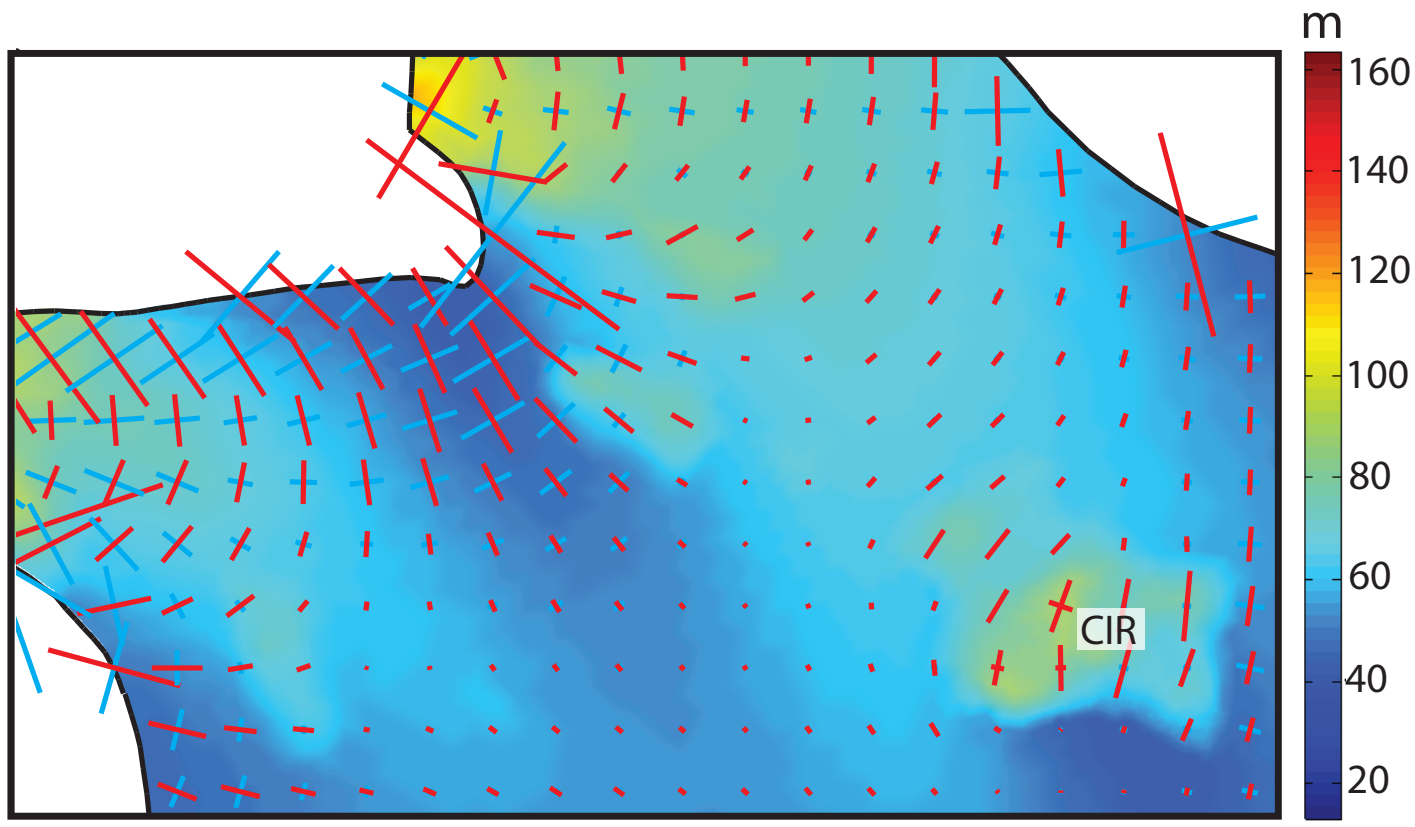

Figure 4.10. Principal strain rate components (blue is compression and red is extension) and ice surface elevation (m); 90 a into experiment 2: before CIR stagnation. 


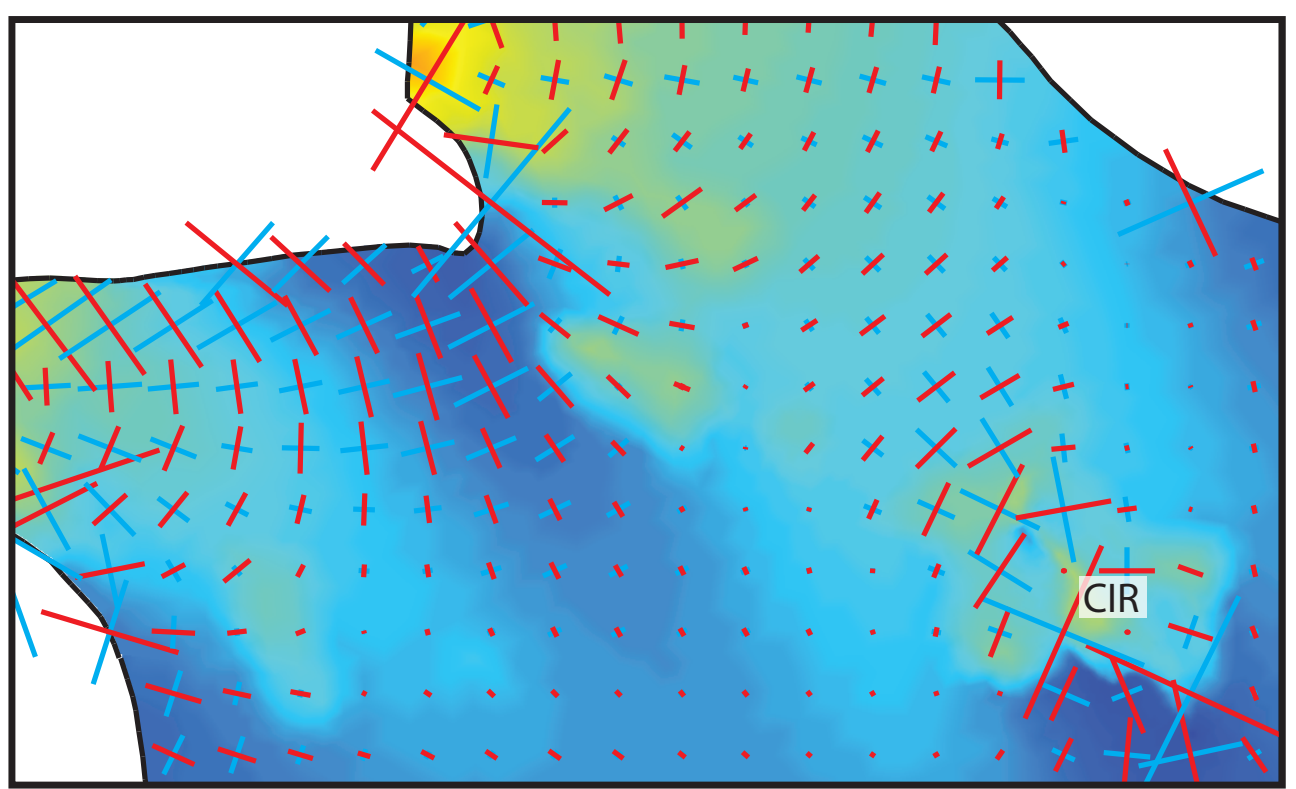

Figure 4.11. Principal strain rate components (blue is compression and red is extension) and ice surface elevation (m); 150 a into experiment 2: after CIR stagnation.

When CIR gets stuck, ice around it thickens and steepens, which generates the faster flow required to keep moving ice through the region despite the obstacle. The decreased rate of downstream stretching results - and thicker ice - results in newly grounded ice upstream of CIR, following the general outline of the bathymetry toward ER. Thickening directly upstream of CIR also generates a flatter across flow surface profile for the KIS outlet that diminishes, relatively, the rate of lateral spreading. Minor thickening and grounding occurs at the bathymetric highs along the left lateral margin and the DF (Fig. 4.13). 


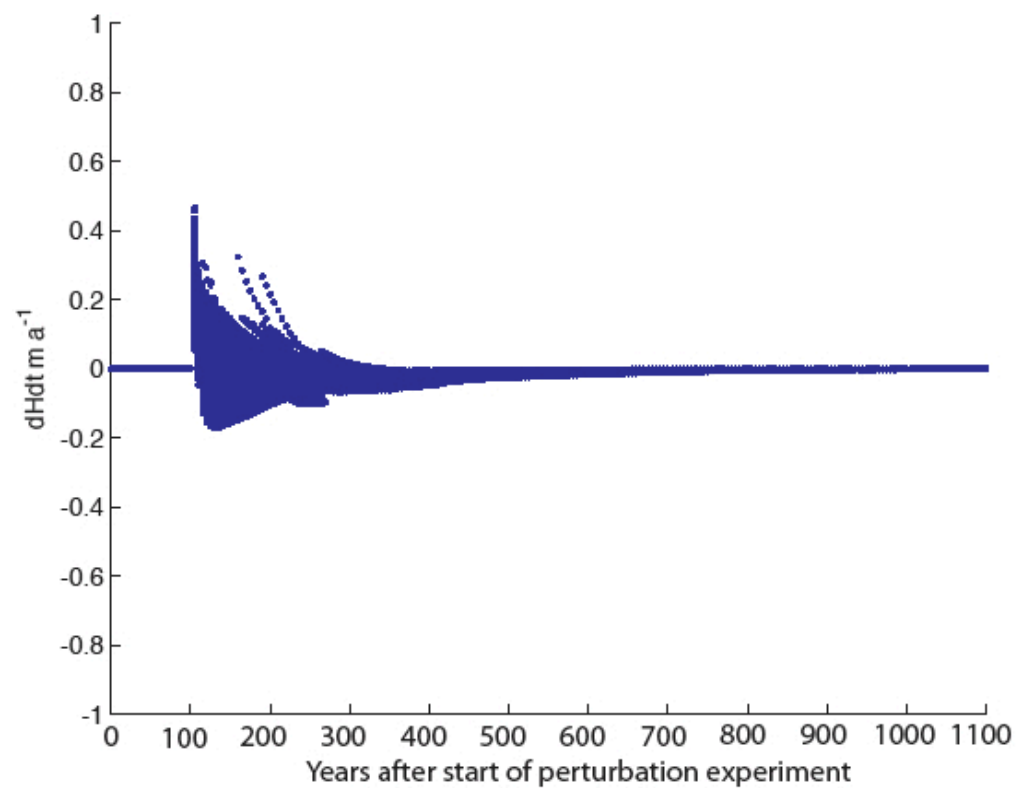

Figure 4.12. $\mathrm{dH} / \mathrm{dt}$ across the KIS ice plain for experiment 2 (table 4.1).

100 a CIR stagnates
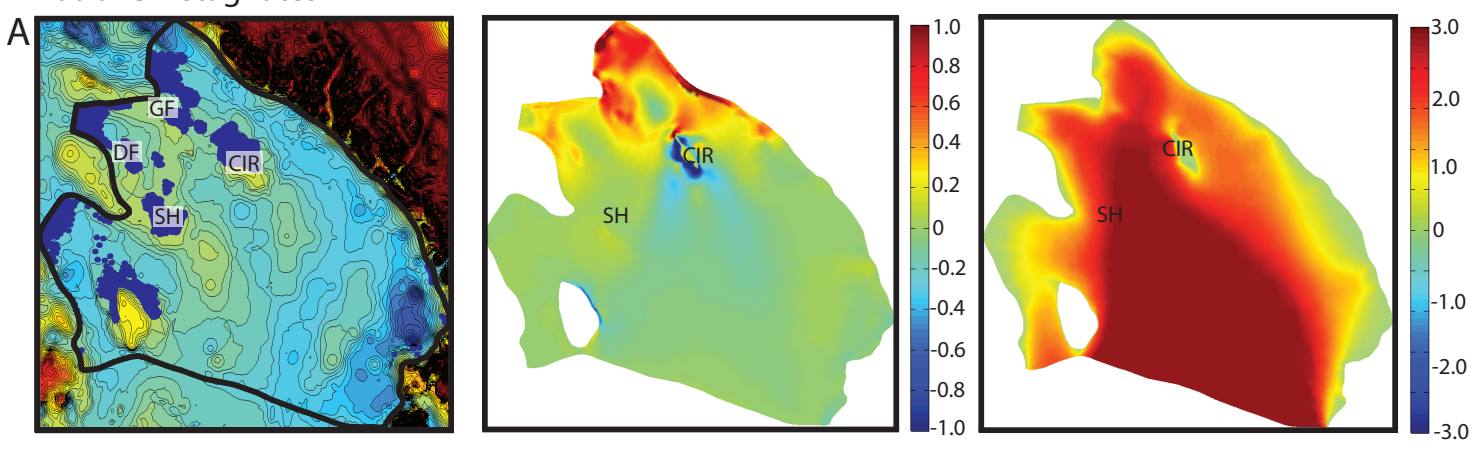

125 a CIR stagnated
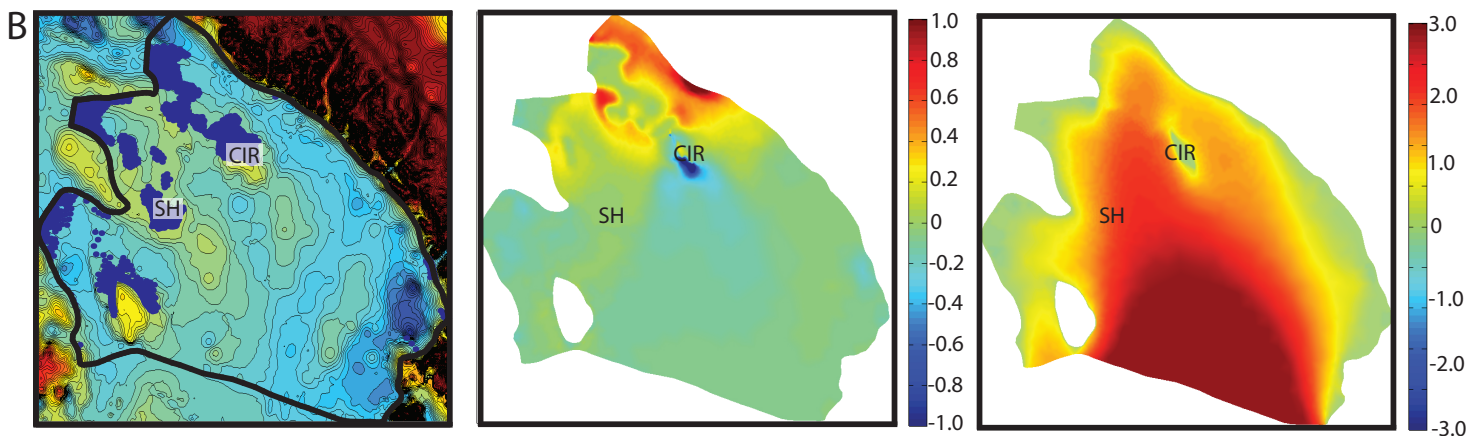

Figure 4.13. Experiment 2: CIR stagnates (table 4.1). Rows of panels represent model output from individual time steps. First column panels show shaded regions representing grounded nodes in the FEM domain. Contours are elevation with an interval of $25 \mathrm{~m}$. Second column panels are rate of thickness change, $\mathrm{dH} / \mathrm{dt}\left(\mathrm{m} \mathrm{a}^{-1}\right)$. Third column panels are rate of ice speed change, $\mathrm{dU} / \mathrm{dt}\left(\mathrm{m} \mathrm{a}^{-1}\right)$. Panels showing rates of change share the same scale to the far right. 


\subsubsection{Increased Basal Traction}

In this experiment, basal traction is increased from $0.01 \times 10^{9} \mathrm{~Pa} \mathrm{~s} \mathrm{~m}^{-1}$ to $0.1 \times 10^{9} \mathrm{~Pa}$ $\mathrm{s} \mathrm{m}^{-1}$ over a period of 100 years. The change is applied uniformly to the $\beta$ field but has an affect only where ice in the model domain is grounded. Ice at grounded nodes slows and also thickens. Locally, surface slopes dip outward towards floating ice so that the greatest rates of thickening are in areas of floating ice adjacent to grounded zones. One-hundred and fifty years after the basal traction increase is completed in the experiment, the greatest thickening occurs in the trough along the Trans Antarctic Mountains to the south of Mercer Ice Stream.

Changing basal traction creates transients that in some locations change sign as time progresses. An increase in basal traction initially leads to an increase in ice thickness due to a decrease in ice velocity over nodes in the model domain with grounded ice. However, in turn, thicker ice causes an increase in ice velocity and over time a new steady state is found. New grounding associated with increased basal traction on already grounded ice occurs over century time scales, and follows the bathymetry. At the KIS outlet, ice grounds around the topographic overdeepening and, in turn, the overdeepening thickens but remains afloat. The result is a grounding line advance around what becomes, in effect, a subglacial lake.

One hundred years after the beginning of the perturbation, ice downstream of WIS (in the ice shelf) speeds up while ice in the KIS outlet slows. This signature can be thought of as an ice mass "redistribution" where ice across the developed WIS ice plain has sufficiently thickened so that ice also speeds up across the outlet and into the ice shelf (Fig. 4.15). Surface slopes are highest across the WIS ice plain and dip outward toward the ice shelf that, at this time, includes the KIS outlet. In contrast, the KIS ice plain is slowly 
developing — or grounding — as the initial effects of increased basal traction are still being felt: ice velocity is decreasing and, thus, thickening.

On longer time scales (100s of years), ice mass is stored across the expanded WIS ice plain and not distributed off the plain as fast, either downstream or across in the KIS outlet. By 400 a into the perturbation experiment, the change in volume flux across the grounding zone is negative (Fig. 4.16).

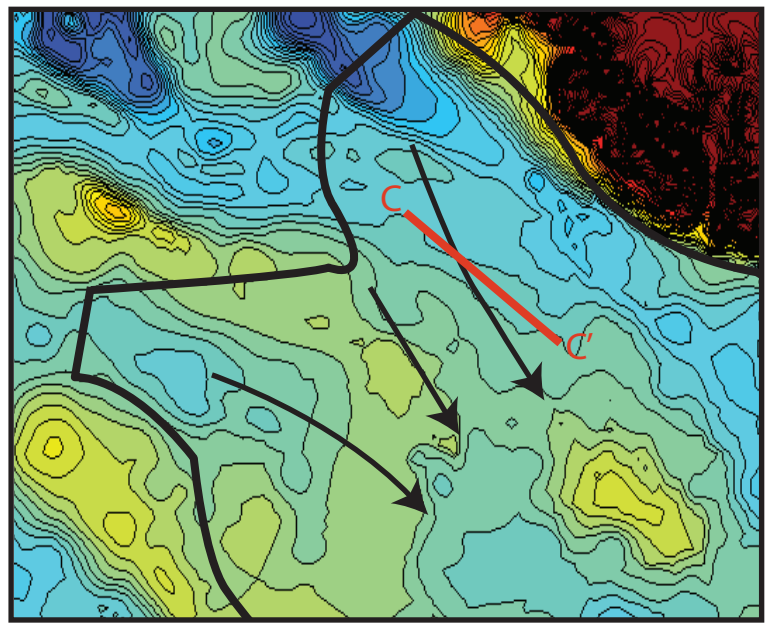

Figure 4.14. Transect location along flow for WIS ice plain (A-A') and bed topography for experiment 3 (table 4.1). Black arrows approximate ice flow azimuth when WIS is off and do not represent magnitude. 


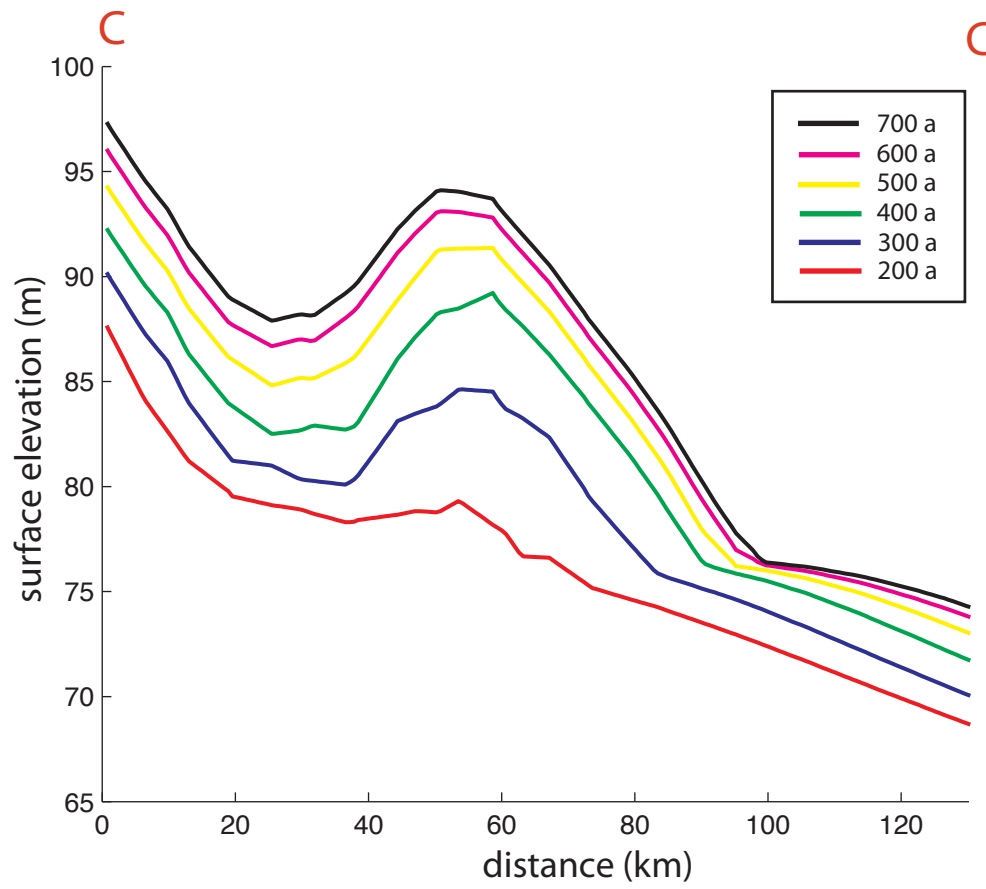

Figure 4.15. Along flow surface elevation profile. Red: surface elevation 200 a; Blue: 300 a; Green: 400 a; Yellow: 500 a; Magenta: 600 a; and Black: 700 a.

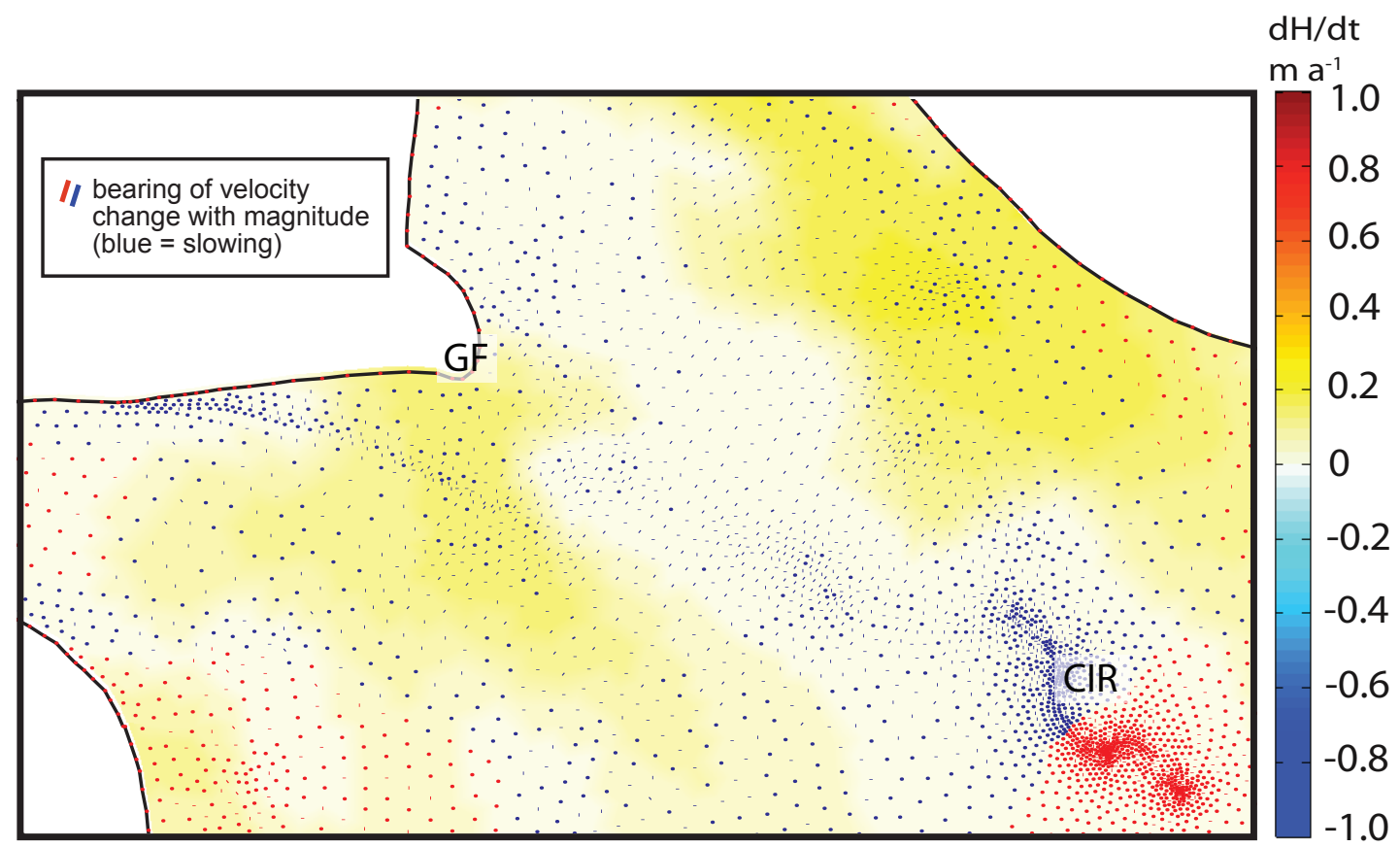

Figure 4.16. Change in volume flux map. Lines are bearing of velocity change and magnitude (blue is slowing ice) and rate of ice thickness change $\left(\mathrm{m} \mathrm{a}^{-1}\right)(400 \mathrm{a}$ into experiment 3 : increased basal traction). 
350 a beta up

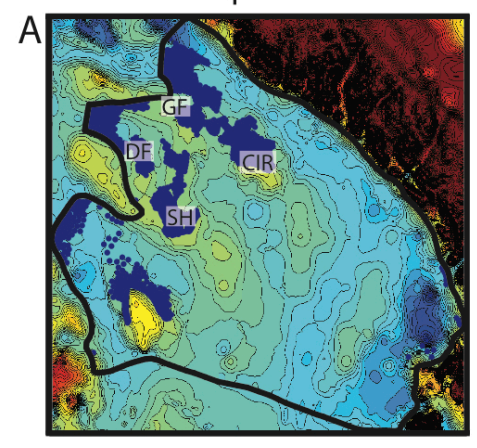

550 a beta up

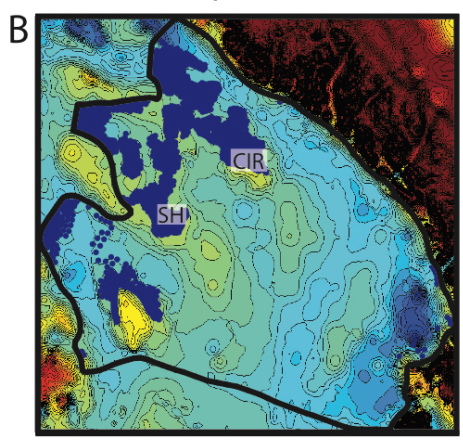

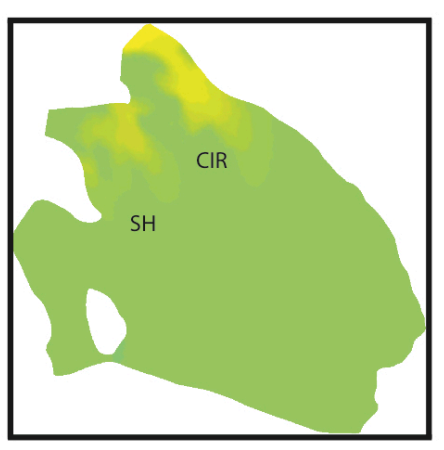
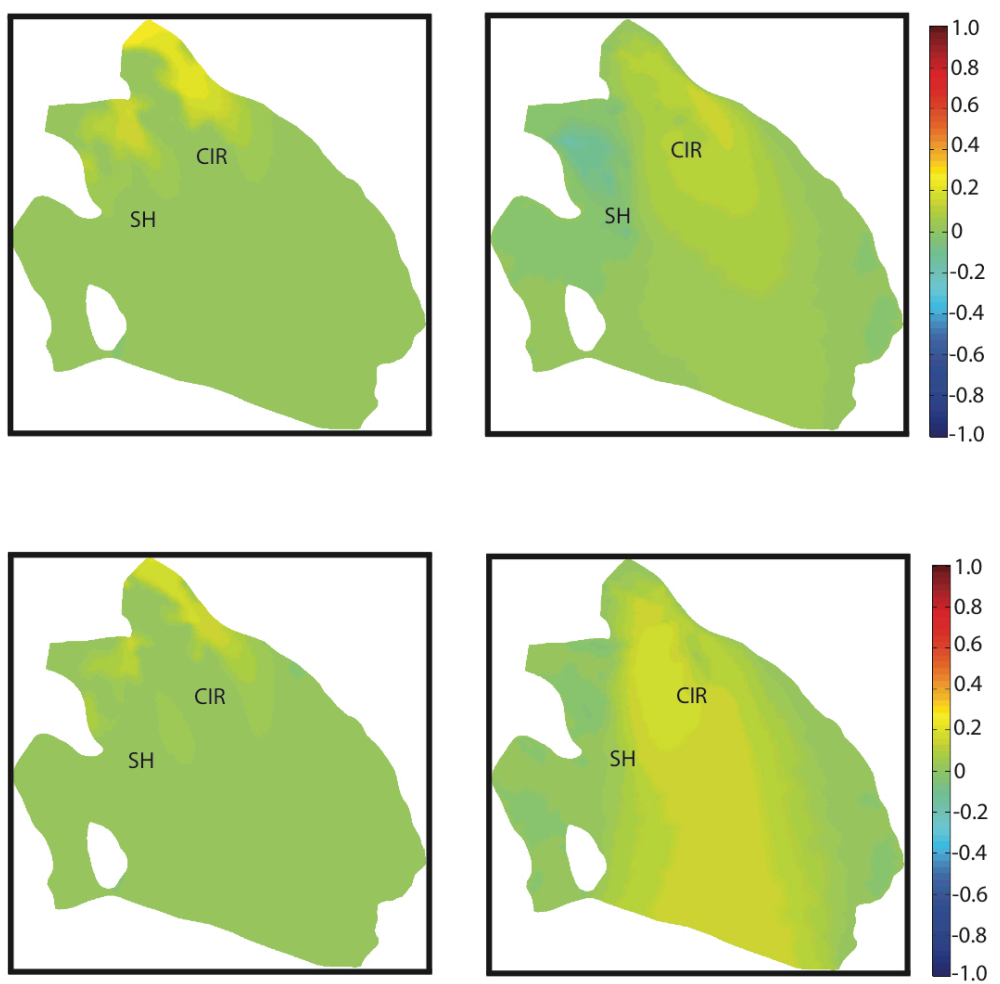

Figure 4.17. Experiment 3: Increased basal traction (table 4.1). Rows of panels represent model output from individual time steps. First column panels show shaded regions representing grounded nodes in the FEM domain. Contours are elevation with an interval of $25 \mathrm{~m}$. Second column panels are rate of thickness change, $\mathrm{dH} / \mathrm{dt}\left(\mathrm{m} \mathrm{a}^{-1}\right)$. Third column panels are rate of ice speed change, $\mathrm{dU} / \mathrm{dt}$ $\left(\mathrm{m} \mathrm{a}^{-1}\right)$. Panels showing rates of change share the same scale to the far right.

\subsubsection{CIR and SH Stagnation with Beta Increase}

In this experiment, ice is forced to stagnate at CIR and SH 100 and 200 years into the perturbation experiments, respectively. In addition, basal traction is increased from $0.01 \times 10^{9} \mathrm{~Pa} \mathrm{~s} \mathrm{~m}^{-1}$ to $0.1 \times 10^{9} \mathrm{~Pa} \mathrm{~s} \mathrm{~m}^{-1}$ over the intervening 100 years. In this simple way we represent one possible till response to a changed boundary condition (for example, due to freezing of basal water).

Locally high bed topography beneath CIR and SH has an important effect on grounding line location because it is relatively easy for ice to run aground at these locations and when it does, regional ice flow must adjust to the new obstacle to downstream transport. 
Stagnation of ice over CIR and SH (100 and 200 years into the model, respectively) force local thickening and steepening. Longitudinal compression increases upstream of CIR and further upstream longitudinal extension is reduced (Fig. 4.18). This mechanical context results in a negative change in volume flux between CIR and ER (Fig. 4.19). Local thickening, in turn, propagates upstream and causes floating ice to run aground. Rates of thickening are highest $\left(\sim 0.8 \mathrm{~m} \mathrm{a}^{-1}\right)$ across the southern portion of the KIS outlet, adjacent to the GF and newly grounded ice upstream of CIR (Fig. 4.24). This zone of thickening is at the confluence of KIS and WIS and thus can be seen as "communicating" flow change information between the two outlets (Fig. 4.19).

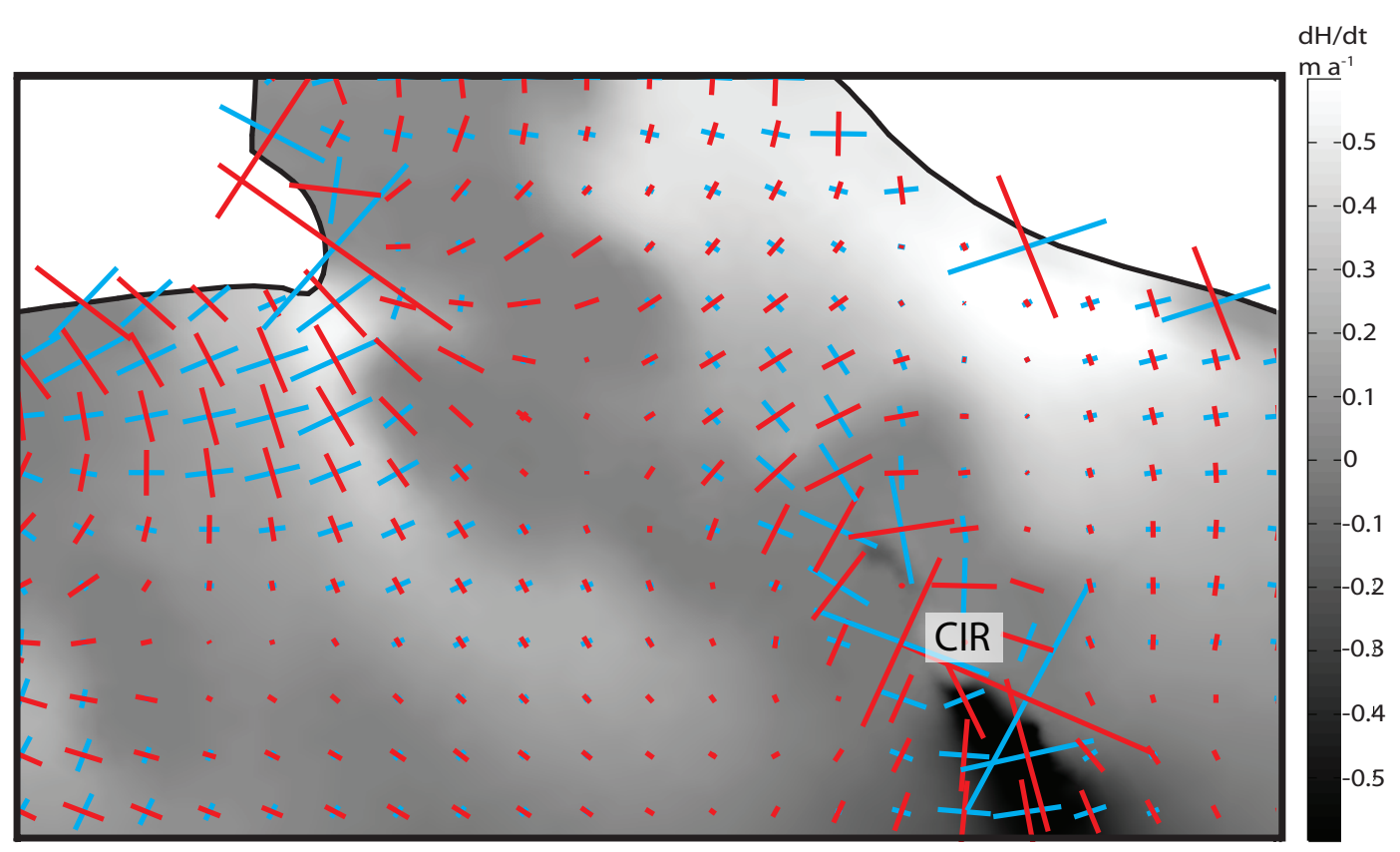

Figure 4.18. Principal strain rate components (blue is compressive and red is extensive) and rate of ice thickness change $\left(\mathrm{m} \mathrm{a}^{-1}\right) ; 195$ a into experiment 3: CIR and SH stagnation and increased basal traction. 


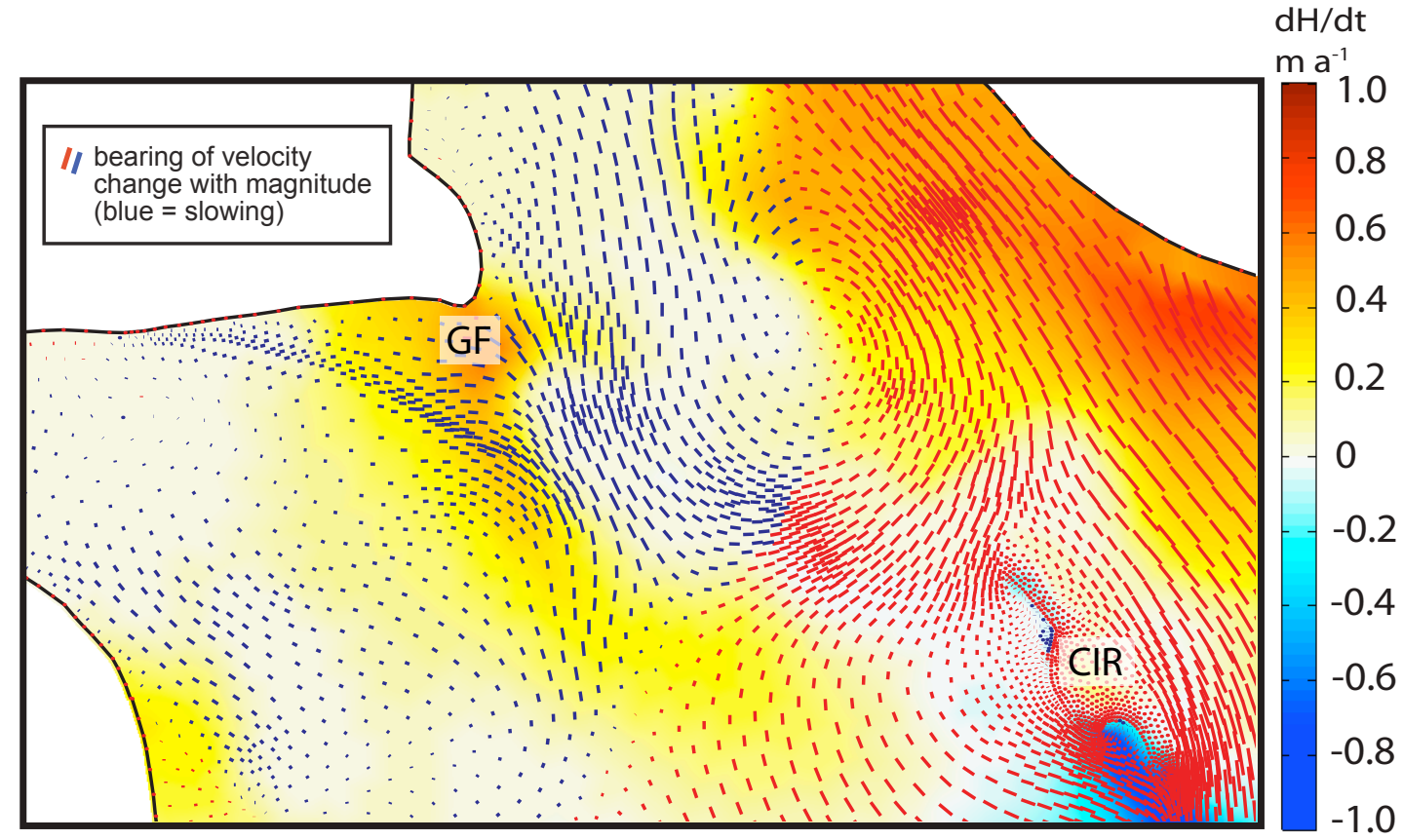

Figure 4.19. Change in volume flux map. Lines are bearing of velocity change and magnitude (blue is slowing ice) and rate of ice thickness change $\left(\mathrm{m} \mathrm{a}^{-1}\right)$ (195 a into experiment 4: CIR and SH stagnation and increased basal traction).

The KIS grounding line advances in a complicated pattern around the topographic overdeeping at the ice stream outlet. Grounded ice advances laterally where the bed topography is highest (along the margins of the ice stream outlet), particularly along the southern boundary (adjacent to ER) where the GF becomes completely grounded and connects with the former upstream KIS grounding line. After 290 a, the GF is completely grounded (Fig. 4.20) and longitudinal compression dominates upstream of the terrain (Fig. 4.21). When the GF runs aground, volume flux changes propagate upstream from the GF on short timescales ( $\sim 10$ years) into the main trunk of KIS, including the topographic overdeepening (Fig. 4.22). Surface gradients steepen from the marginally grounded ice terrains towards the overdeepening where thickening rates are the greatest (Fig. 4.22). 


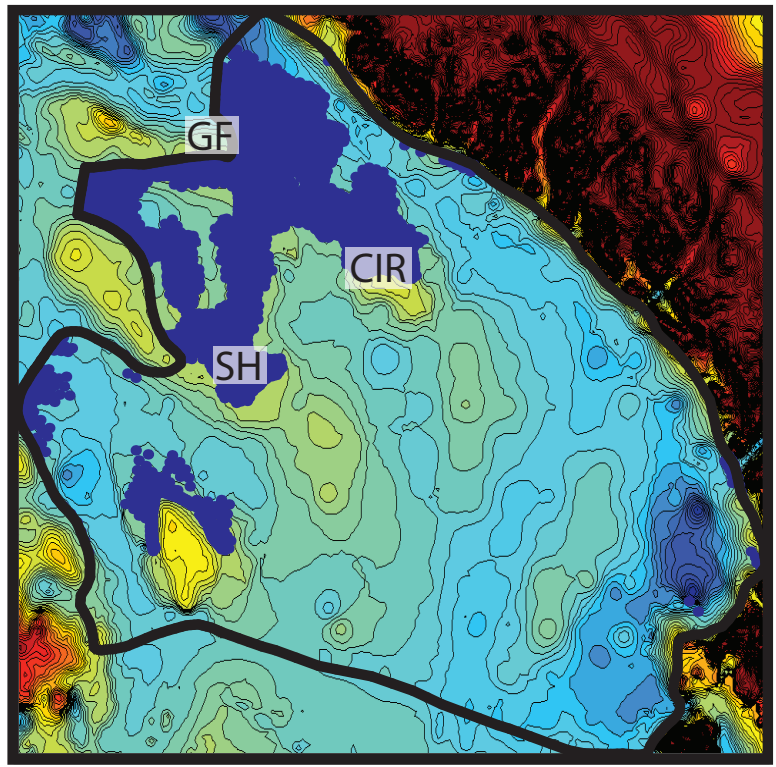

Figure 4.20. Shaded regions represent grounded nodes in the FEM domain (290 a into experiment 4: CIR and SH stagnation and increased basal traction).

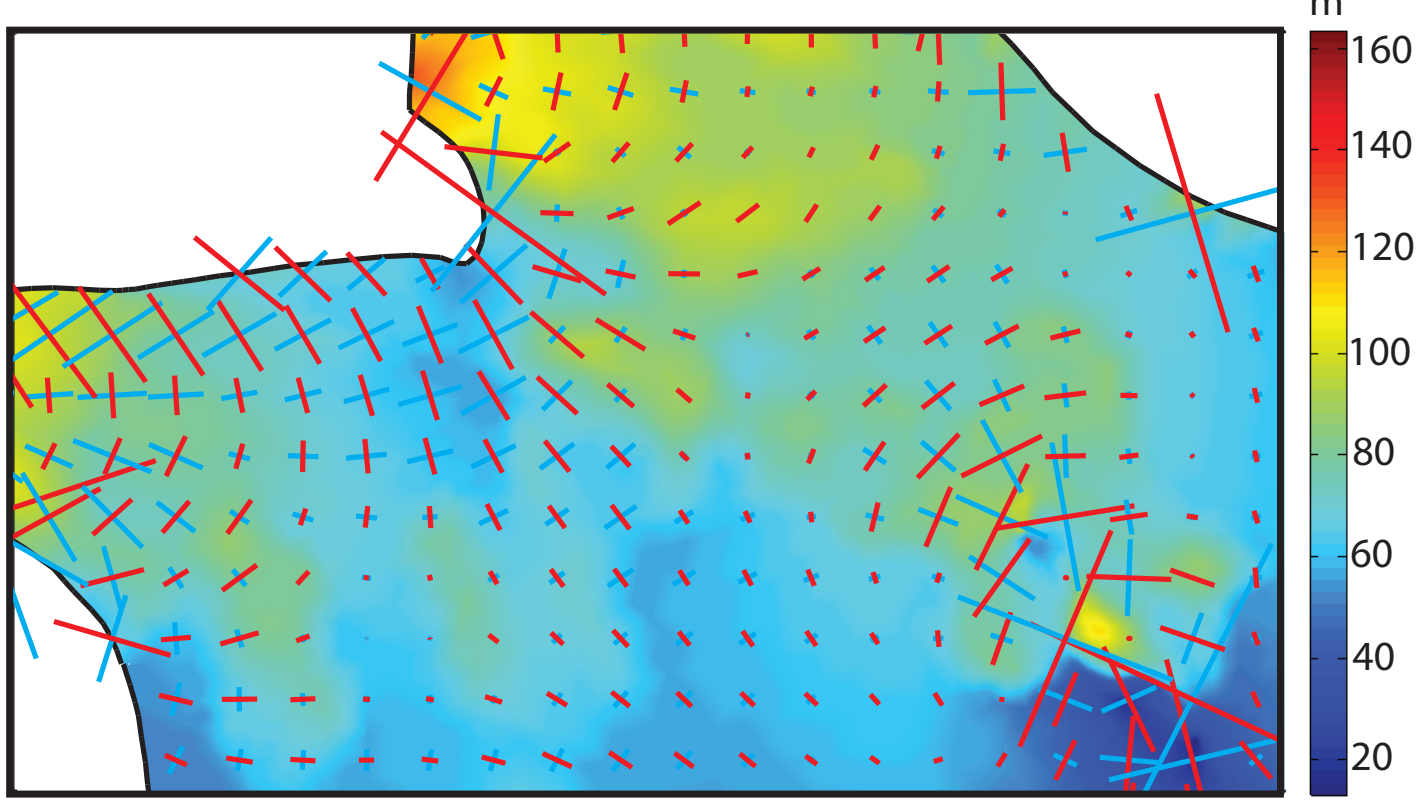

Figure 4.21. Principal strain rate components (blue is compressive and red is extensive) and ice surface elevation (m); 290 a into experiment 4 (table 4.1). 


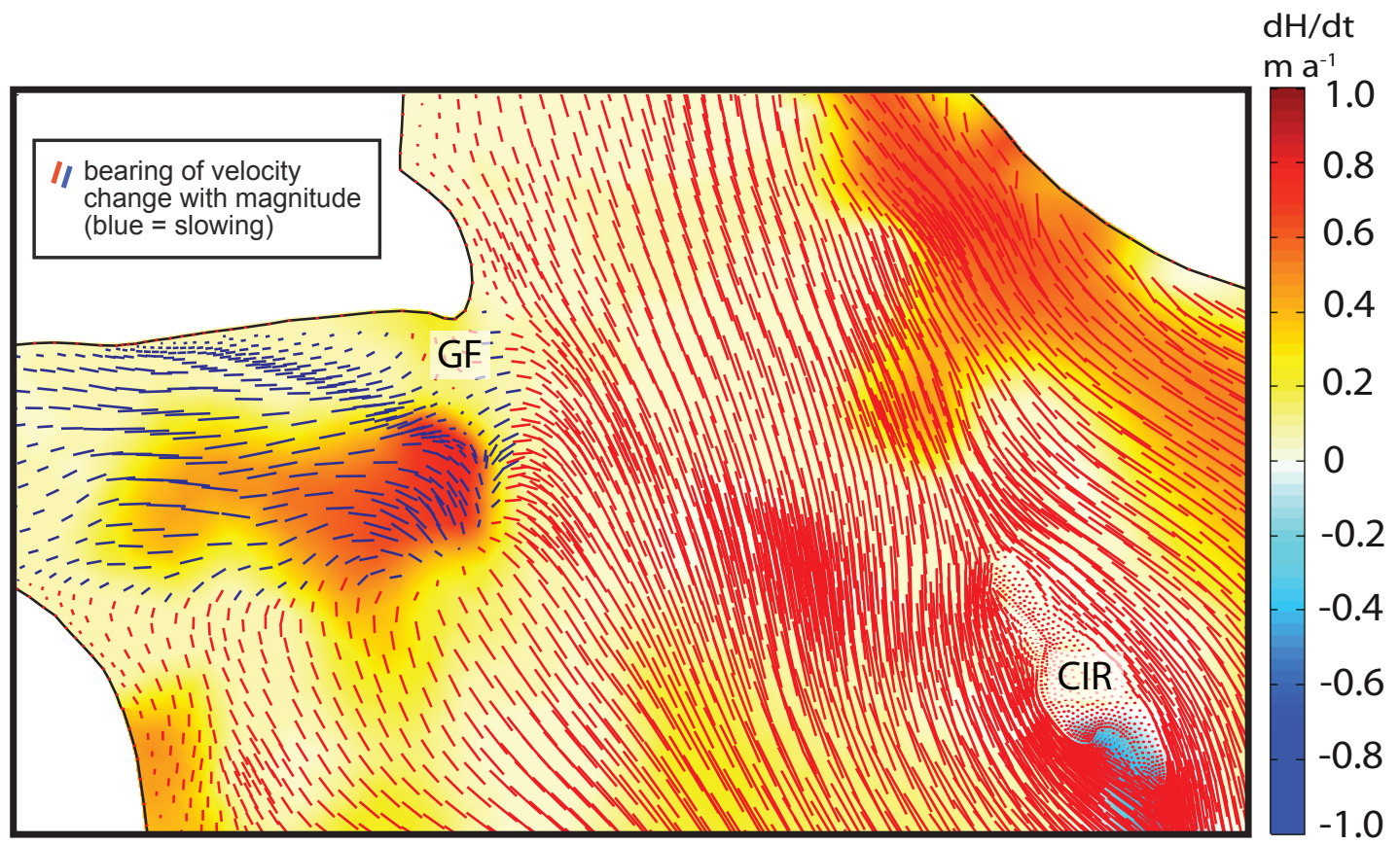

Figure 4.22. Change in volume flux map. Lines are bearing of velocity change and magnitude (blue is slowing ice) and rate of ice thickness change ( $\left.\mathrm{m} \mathrm{a}^{-1}\right) ; 290$ a into experiment 4 (table 4.1).

Grounding line advance is not geometrically simple and is guided by bathymetry, with local highs grounding first and leading in turn to the grounding of adjacent locations. The area of grounded ice grows as the coupled grounding and thickening feedback progresses (Fig. 4.24) but the result is not a uniform "advance" of the grounding line from one area toward another. Instead, a patchwork of grounded and floating areas develops as ice across the entire region thickens. Eventually, ice across much of the seafloor high at the downstream end of the overdeepening between ER and SD becomes grounded. By 350 a, most of the ice in the overdeepening region is grounded, though only lightly. The thickness in excess of buoyancy is $<10 \mathrm{~m}$ at 350 a. Notably, ice along the northern portion of the DF (where the bed is the deepest) remains afloat and is surrounded by grounded ice (Fig. 4.25). Here, the ice thickness is 50 to 60 meters in excess of the floatation thickness (Fig. 4.26). 


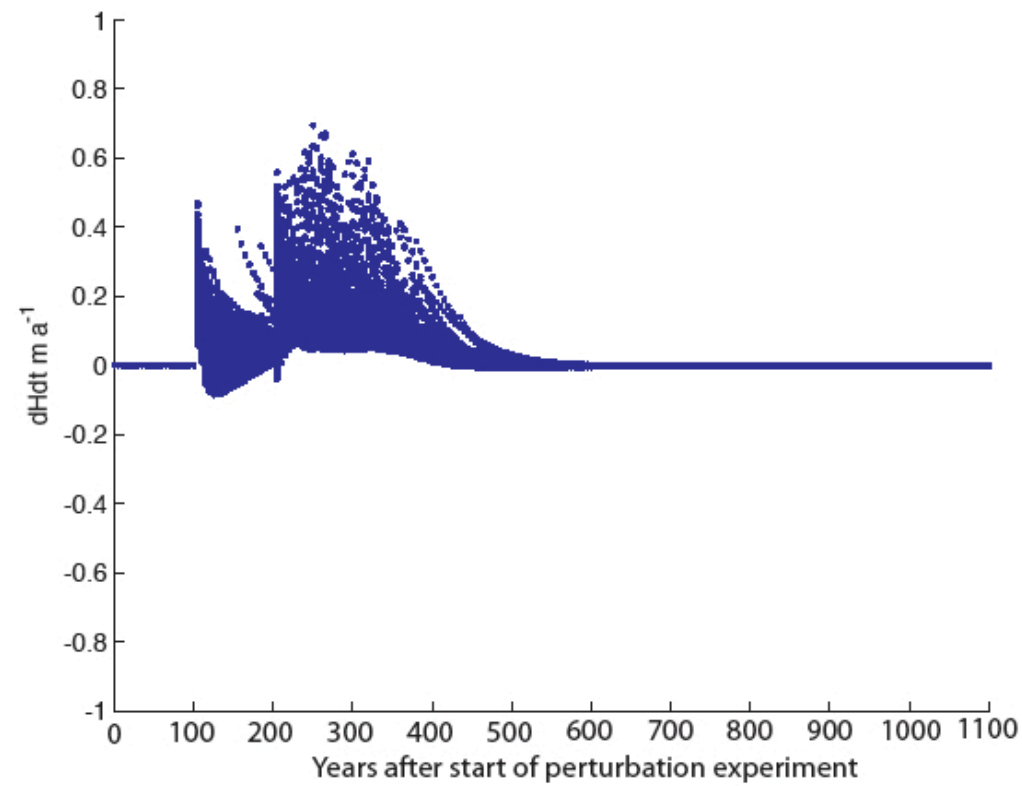

Figure 4.23. $\mathrm{dH} / \mathrm{dt}$ across the KIS ice plain for experiment 4 (table 4.1).

150 a CIR stuck + beta up
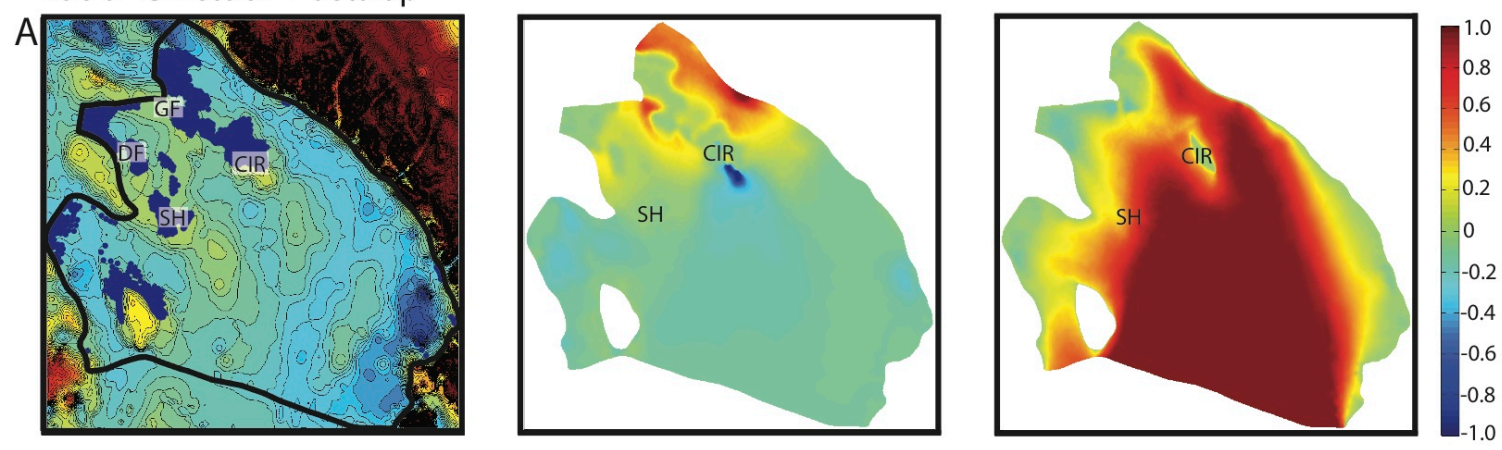

250 a CIR and SH stuck + beta up
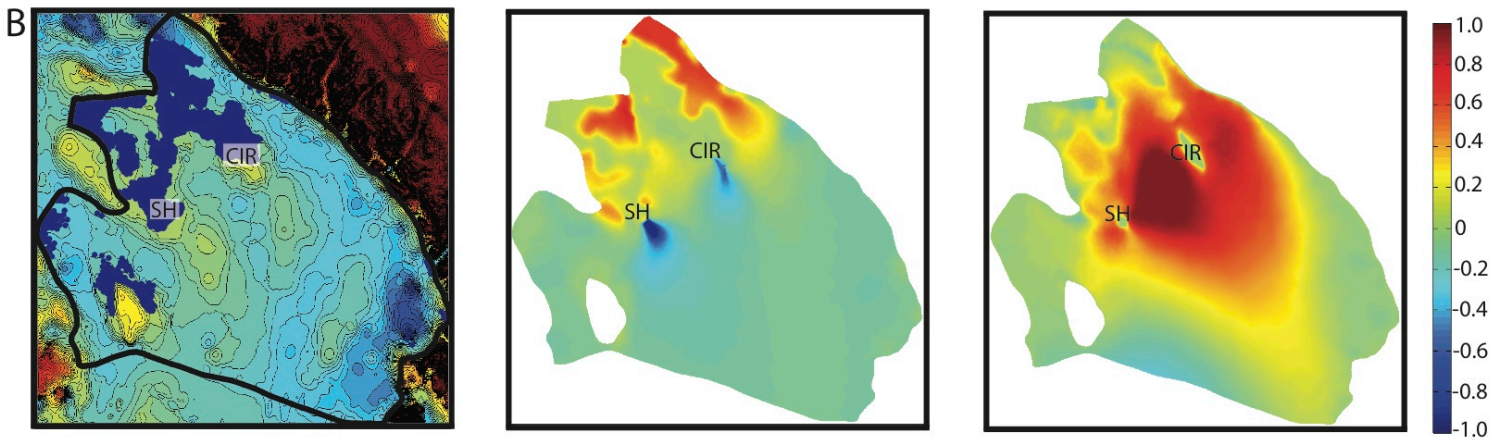

Figure 4.24. Experiment 4: CIR and SH stagnation and increased basal traction (table 4.1). Rows of panels represent model output from individual time steps. First column panels show shaded regions representing grounded nodes in the FEM domain. Contours are elevation with an interval of $25 \mathrm{~m}$. Second column panels are rate of thickness change, $\mathrm{dH} / \mathrm{dt}\left(\mathrm{m} \mathrm{a}^{-1}\right)$. Third column panels are rate of ice speed change, $\mathrm{dU} / \mathrm{dt}\left(\mathrm{m} \mathrm{a}^{-1}\right)$. Panels showing rates of change share the same scale to the far right. 
350 a CIR and SH stuck + beta up
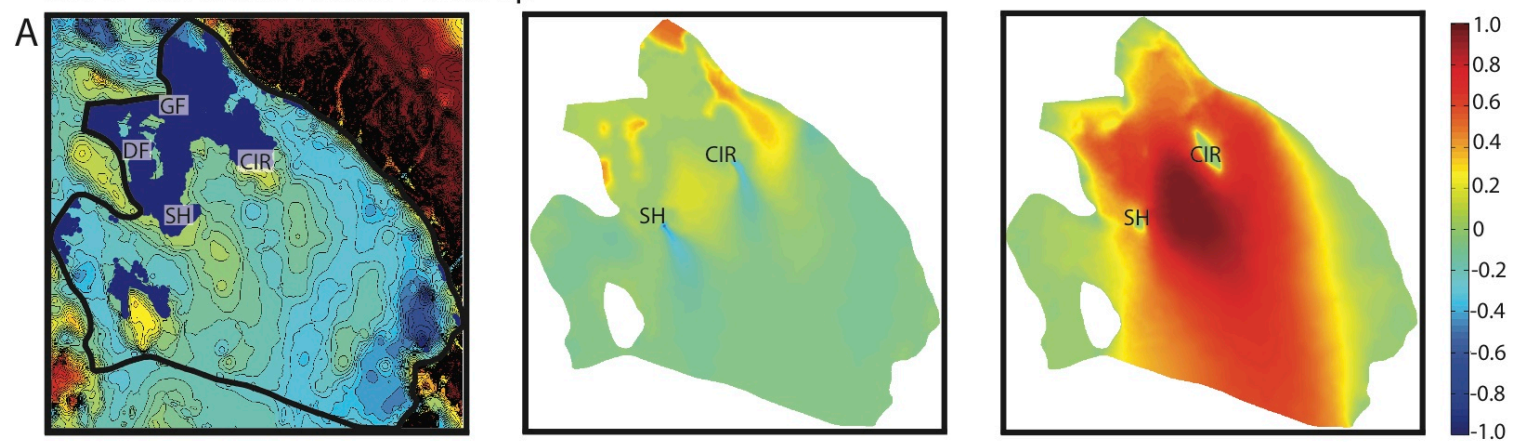

600 a CIR and SH stuck + beta up
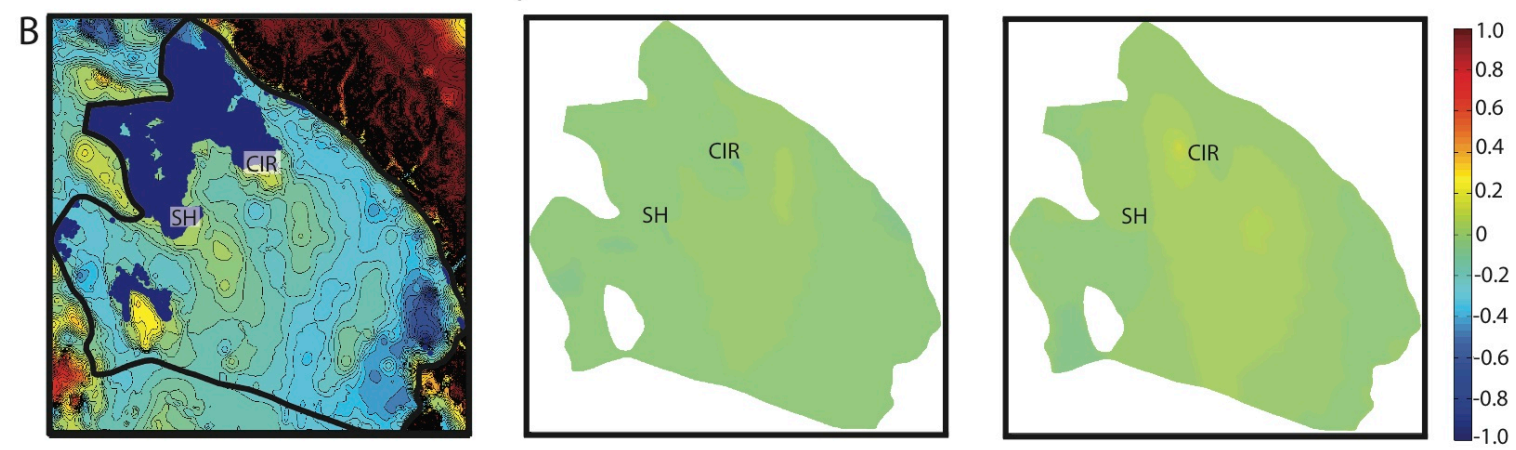

Figure 4.25. Experiment 4: CIR and SH stagnation and increased basal traction (table 4.1). Rows of panels represent model output from individual time steps. First column panels show shaded regions representing grounded nodes in the FEM domain. Contours are elevation with an interval of $25 \mathrm{~m}$. Second column panels are rate of thickness change, $\mathrm{dH} / \mathrm{dt}\left(\mathrm{m} \mathrm{a}^{-1}\right)$. Third column panels are rate of ice speed change, $\mathrm{dU} / \mathrm{dt}\left(\mathrm{m} \mathrm{a}^{-1}\right)$. Panels showing rates of change share the same scale to the far right.

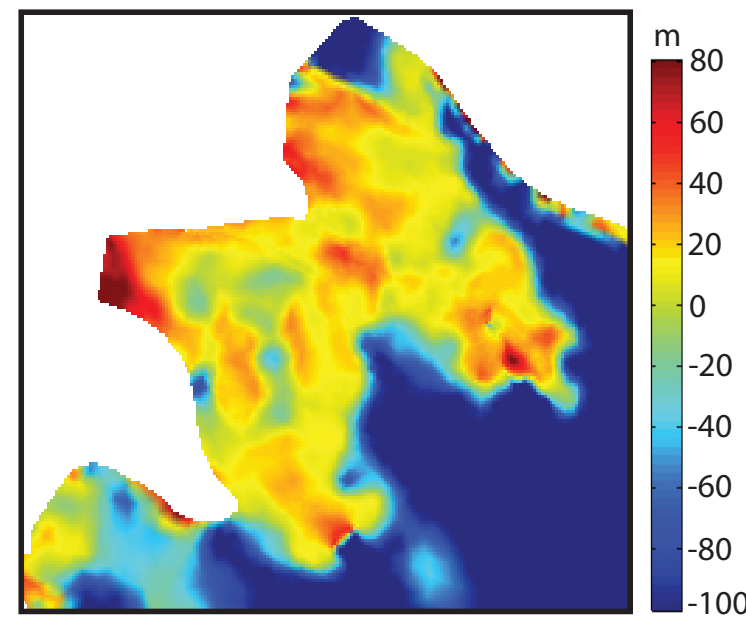

Figure 4.26. Height above buoyancy (m) for experiment 4 at 350 a. 


\subsubsection{Interesting Things}

The main outflow from KIS passes it by and ER diverts WIS flow away from here, this region is sensitive to different types perturbations. Indeed, it experiences some of the greatest thickening rates, (0.6-0.8 $\mathrm{m} \mathrm{a}-1) \sim 50$ years after CIR gets stuck and the basal traction

parameter increase is initiated. The contrasts among responses to different forcings will help determine what events took place in the past.

\subsection{The Role of the GF in Grounding Zone Dynamics}

In the experiments described above, thickness transients propagating upstream from the stagnated CIR and laterally from the WIS ice plain cause the GF and the surrounding area to frequently ground and remain grounded (Fig. 4.11b). Grounding of the GF leads to further transient effects across the KIS ice plain. Grounded and stagnant ice at the GF both narrows the ice stream outlet and flattens the transverse surface elevation profile and, in turn, thickens the main trunk of KIS and promoting further grounding. Having produced grounding in the GF region via stagnation of CIR and SH, we next examine the effect of stagnating the grounded GF ice. Again, the rationale is that basal freezing associated with grounding of previously floating ice, may act against fast sliding (Bindschadler et al., 1990).

\subsubsection{CIR, SH and GF Stagnation and Beta Increase}

Only in extreme cases do our perturbations to ice rises and basal traction generate a KIS grounding line seaward of the overdeepening between ER and SD. This contrast to the 
present day situation (and to the suggestion that the grounding line was located upstream of the overdeepening within the last several hundred years as suggested by Catania et al., 2006) motivates additional experiments. It is also worth noting that when we do produce grounding line advance, the sense of motion is transverse, from south toward the north, not along the axis of the ice stream. We are thus interested in perturbations that might yield thickening in the trunk of KIS sufficient to cause the grounding line to advance downstream across the overdeepening. In this experiment, CIR is forced to stagnate at $100 \mathrm{a}, \mathrm{SH}$ at $200 \mathrm{a}$ and the GF at $300 \mathrm{a}$. Additionally, basal traction increases from $0.01 \times 10^{9} \mathrm{~Pa} \mathrm{~s} \mathrm{~m}^{-1}$ to $0.1 \times$ $10^{9} \mathrm{~Pa} \mathrm{~s} \mathrm{~m}^{-1}$ over a period of 100 years (from 100 a to $200 \mathrm{a}$ ).

Due to thickness transients propagating upstream from stagnant CIR and SH and increased basal traction across the ice plain, by 250 a into the model experiment ice thickens sufficiently for ice to run aground across bathymetric highs at the downstream end of KIS. The greatest rates of thickening (0.6-0.8 $\left.\mathrm{m} \mathrm{a}^{-1}\right)$ at the KIS ice plain occur around the GF and similar rates are found in the adjacent floating ice region above the topographic overdeepening. The GF stagnates at $300 \mathrm{a}$ in order to investigate its effect on grounding in the KIS outlet. This scenario is most likely predicated on basal freezing related to the temperature gradient in the formerly floating ice and would depend in part on whether the subglacial water was fresh or salty. Smaller thickening rates $\left(0.3-0.4 \mathrm{~m} \mathrm{a}^{-1}\right)$ occur along the outboard edge of the DF at the northern KIS margin. Finally, grounded ice connects the downstream bathymetric high between the DF and GF (Fig. 4.28).

After the GF becomes stuck, grounded ice, following the general contours of the bed topography, spreads laterally across the KIS outlet toward the northern or right-lateral KIS margin. Ice grounds rapidly after GF stagnation $\left(\sim 0.4 \% \mathrm{a}^{-1}\right.$ by area). Ice directly 
downstream from the GF thins $\left(-0.2 \mathrm{~m} \mathrm{a}^{-1}\right)$ (Fig. 4.29), but remains grounded. By $400 \mathrm{a}$ much of the mouth of KIS features grounded ice. Small pockets of floating ice remain across the topographic overdeepening and the northern margin of the DF remains afloat (Fig. 4.30).

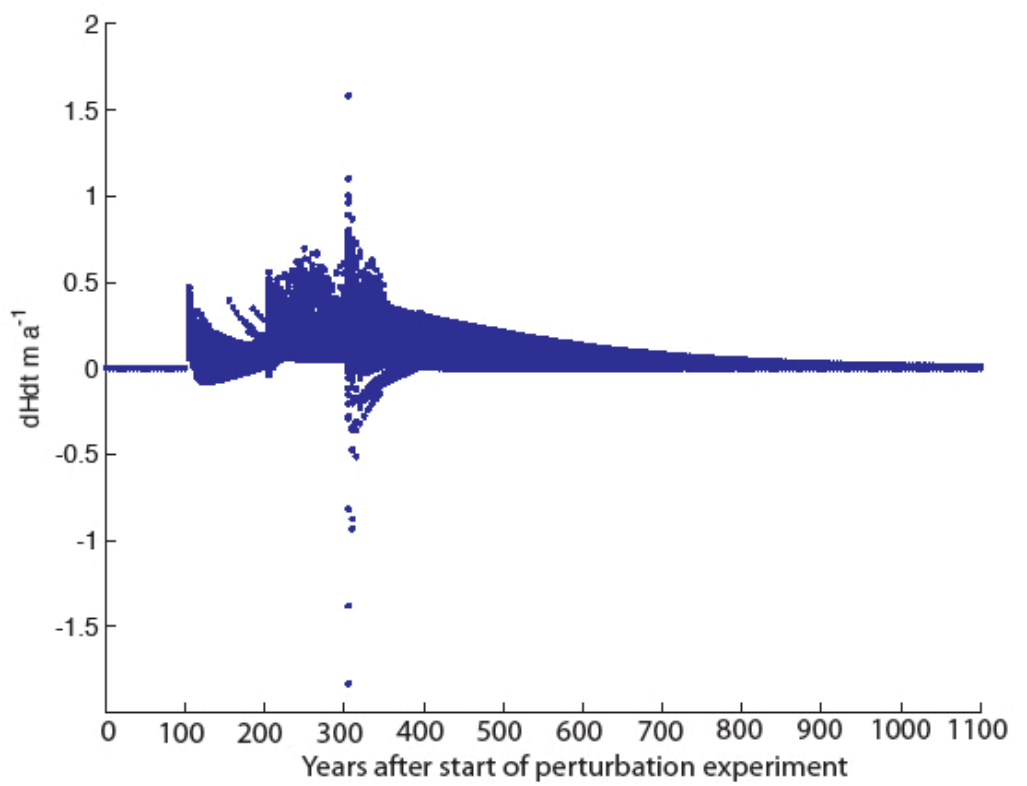

Figure 4.27. $\mathrm{dH} / \mathrm{dt}$ across the KIS ice plain for experiment 5 (table 4.1). 
250 a CIR and SH stuck + beta up
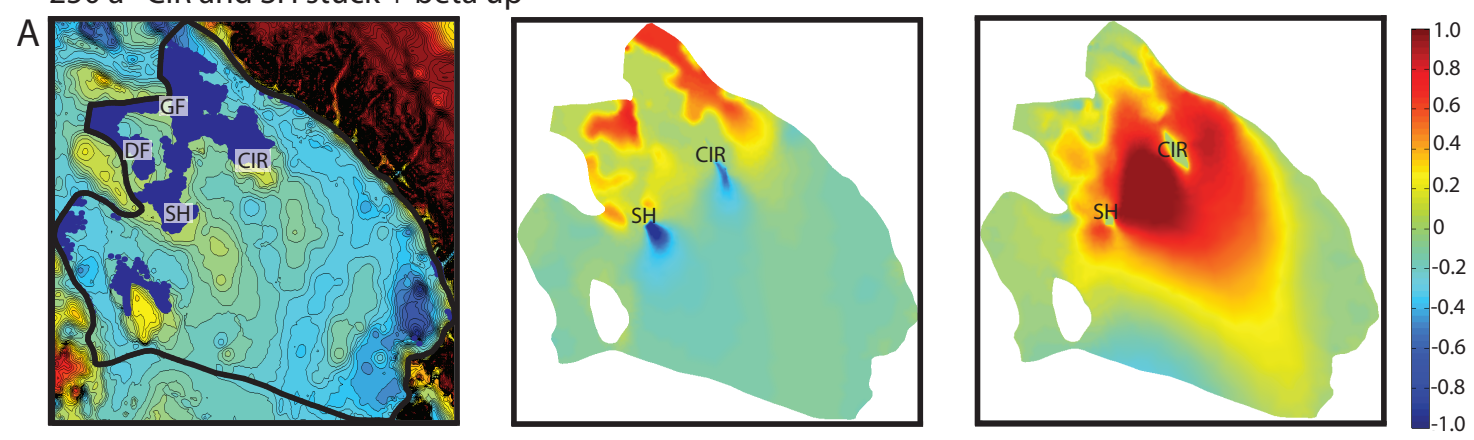

300 a CIR and SH stuck + GF grounds + beta up
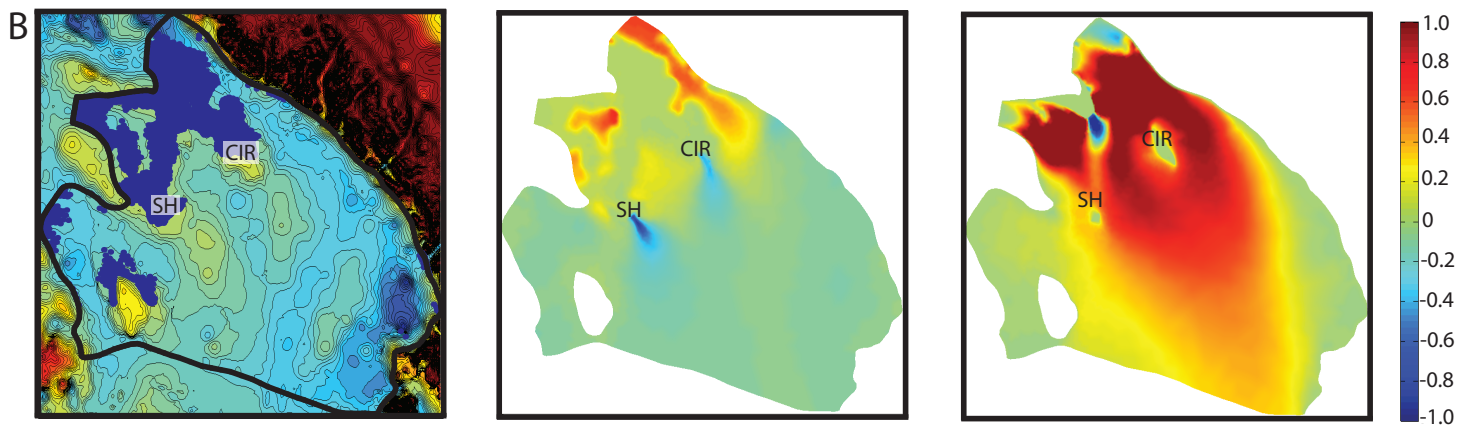

Figure 4.28. Experiment 5: CIR + SH and GF stagnation and increased basal traction (table 4.1). Rows of panels represent model output from individual time steps. First column panels show shaded regions representing grounded nodes in the FEM domain. Contours are elevation with an interval of $25 \mathrm{~m}$. Second column panels are rate of thickness change, $\mathrm{dH} / \mathrm{dt}\left(\mathrm{m} \mathrm{a}^{-1}\right)$. Third column panels are rate of ice speed change, $\mathrm{dU} / \mathrm{dt}\left(\mathrm{m} \mathrm{a}^{-1}\right)$. Panels showing rates of change share the same scale to the far right. 
350 a CIR, SH and GF stuck + beta
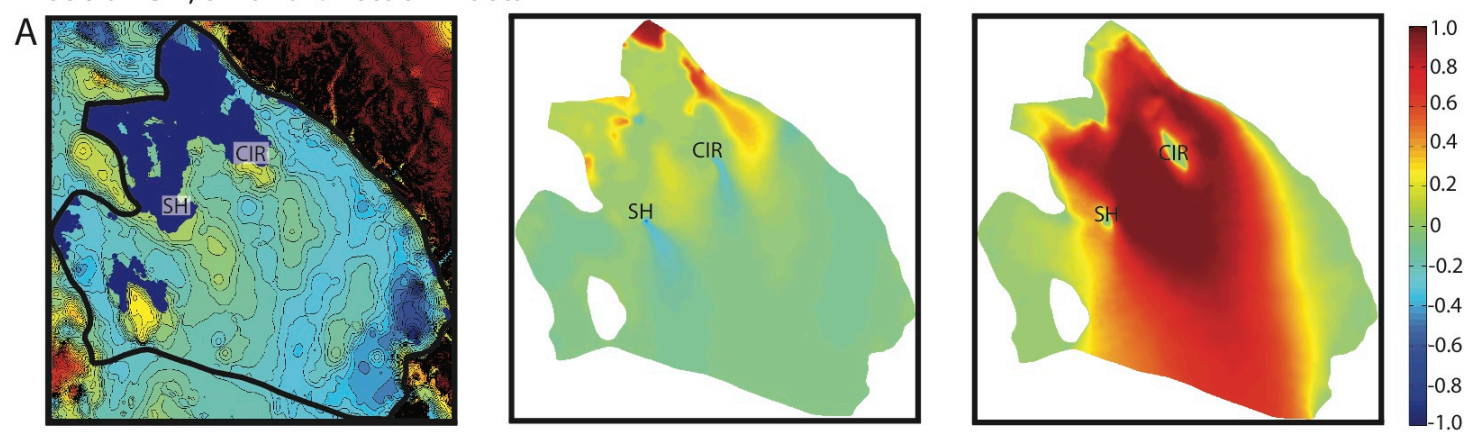

400 a CIR, SH and GF stuck + beta up
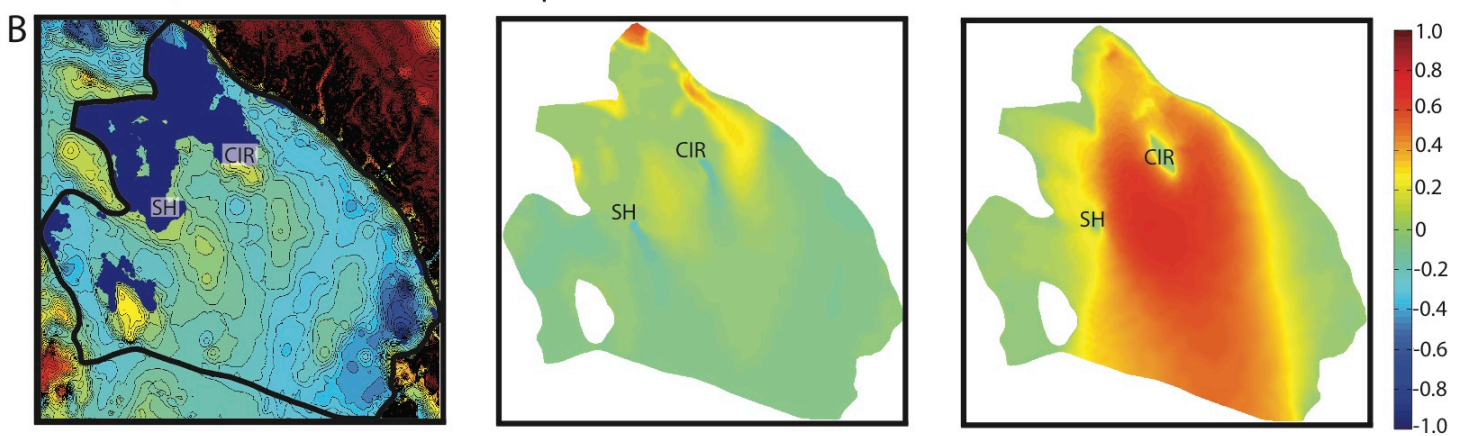

Figure 4.29. Experiment 5: CIR + SH and GF stagnation and increased basal traction (table 4.1). Rows of panels represent model output from individual time steps. First column panels show shaded regions representing grounded nodes in the FEM domain. Contours are elevation with an interval of $25 \mathrm{~m}$. Second column panels are rate of thickness change, $\mathrm{dH} / \mathrm{dt}\left(\mathrm{m} \mathrm{a}^{-1}\right)$. Third column panels are rate of ice speed change, $\mathrm{dU} / \mathrm{dt}\left(\mathrm{m} \mathrm{a}^{-1}\right)$. Panels showing rates of change share the same scale to the far right.

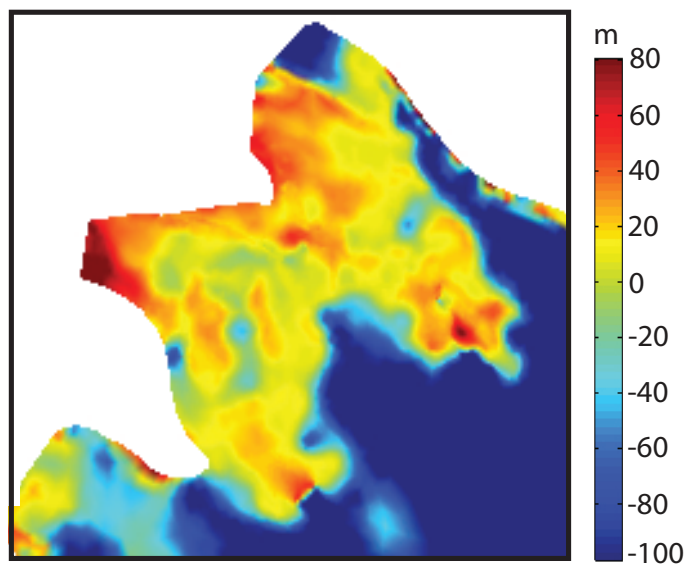

Figure 4.30. Height above buoyancy for experiment 5 at 350 a. 


\subsubsection{CIR and GF Stagnation and Beta Increase}

The relative importance of SH to KIS grounding line position is examined by reducing its effect in a model in which CIR and GF stagnate. SH is not forced to ground while CIR stagnates $100 \mathrm{a}$ and GF stagnates $200 \mathrm{a}$ into the perturbation experiment. Basal traction increases from $0.01 \times 10^{9} \mathrm{~Pa} \mathrm{~s} \mathrm{~m}^{-1}$ to $0.1 \times 10^{9} \mathrm{~Pa} \mathrm{~s} \mathrm{~m}^{-1}$ over a period of 100 years (from 100 a to 200 a).

In effect, we ask if transients resulting from changes on WIS are sufficient to drive grounding in the KIS overdeepening or if transients associated with SH stagnation are also required. We note that according to the crevasse record (Fahnestock et al., 2000), SH stagnation is a relatively recent event, similar in age to the recent shear margin reorganization in the downstream reach of KIS. The GF is upstream of CIR on the right lateral side and the DF is upstream of SH on the left lateral side. Specifically, it is important to understand the degree to which ice grounding around $\mathrm{SH}$ is a cause or an effect of the perturbations in order to understand the mechanical evolution of the KIS outlet.

Compared to previous experiments that include SH stagnation, the pattern of grounded ice across the KIS outlet is fundamentally different when $\mathrm{SH}$ is not forced to stagnate. At 300 a, much of the southern KIS margin shows similar transients to previous experiments: large thickening rates and grounded ice dominates the area around the GF and the ice plain stretching towards CIR (Fig. 4.34). However, without contemporaneous SH stagnation, thickness transients are nearly zero between the DF and $\mathrm{SH}$ and across the northern KIS margin. Additionally, less ice grounds across the bathymetric high situated at the downstream end of KIS compared to previous experiments. 
When SH does not stagnate, the left lateral side of the KIS outlet does not experience a thickness transient. At 300 a when the GF stagnates, the KIS outlet narrows and because of the new geometry, ice thickens in the main trunk. However, without a stuck SH (and the accompanying thickness transient and grounded ice expanding upstream) there is proportionally less longitudinal compression and the KIS trunk increases speed towards the ice front (Fig. 4.35). After GF stagnation (300 a), as ice speeds increase, longitudinal extension increases across the KIS outlet and ice thins (Fig. 3.32). At the same time, ice immediately downstream of the stagnant GF thins as the amount of ice advecting downstream of the feature is reduced (Fig. 4.35). By $400 \mathrm{a}$, much of the ice that had previously been grounded in the main KIS trunk has gone afloat, including the area around SH and the bathymetric high spanning laterally across the KIS outlet (Fig. 4.35).

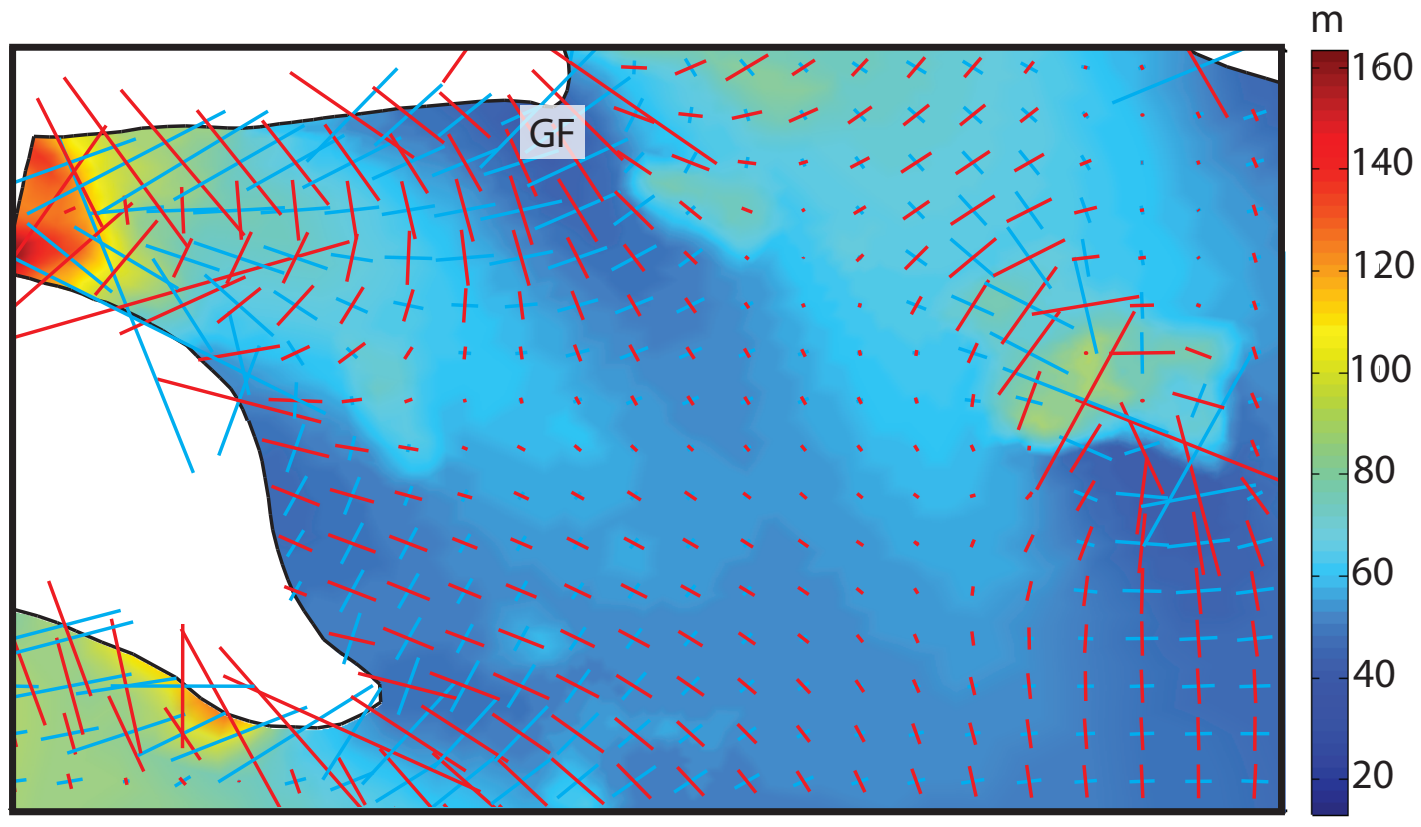

Figure 4.31: Principal strain rate components (blue is compressive and red is extensive) and ice surface elevation (m); 105 a into experiment 6 (table 4.1). 

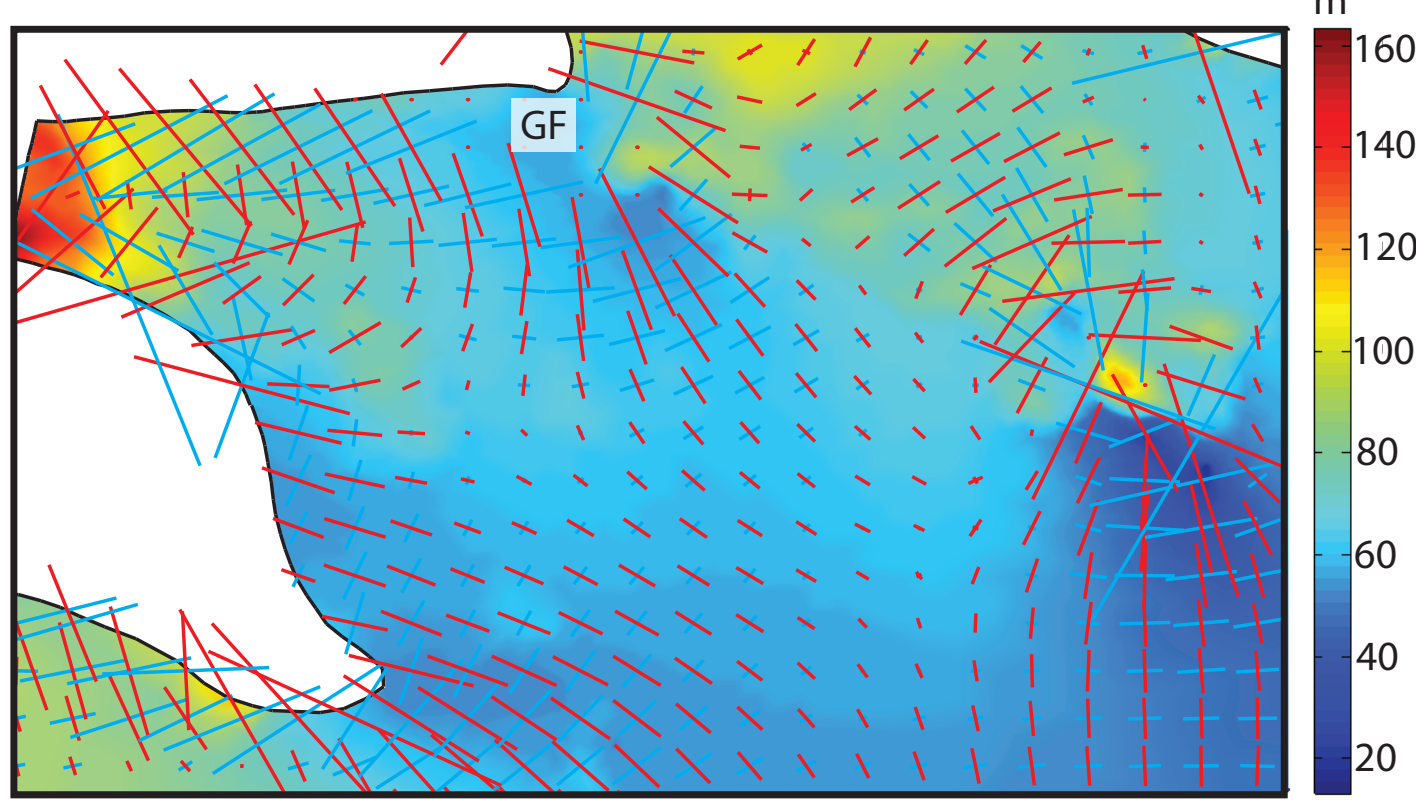

Figure 4.32: Principal strain rate components (blue is compressive and red is extensive) and ice surface elevation (m); 330 a into experiment 6 (table 4.1).

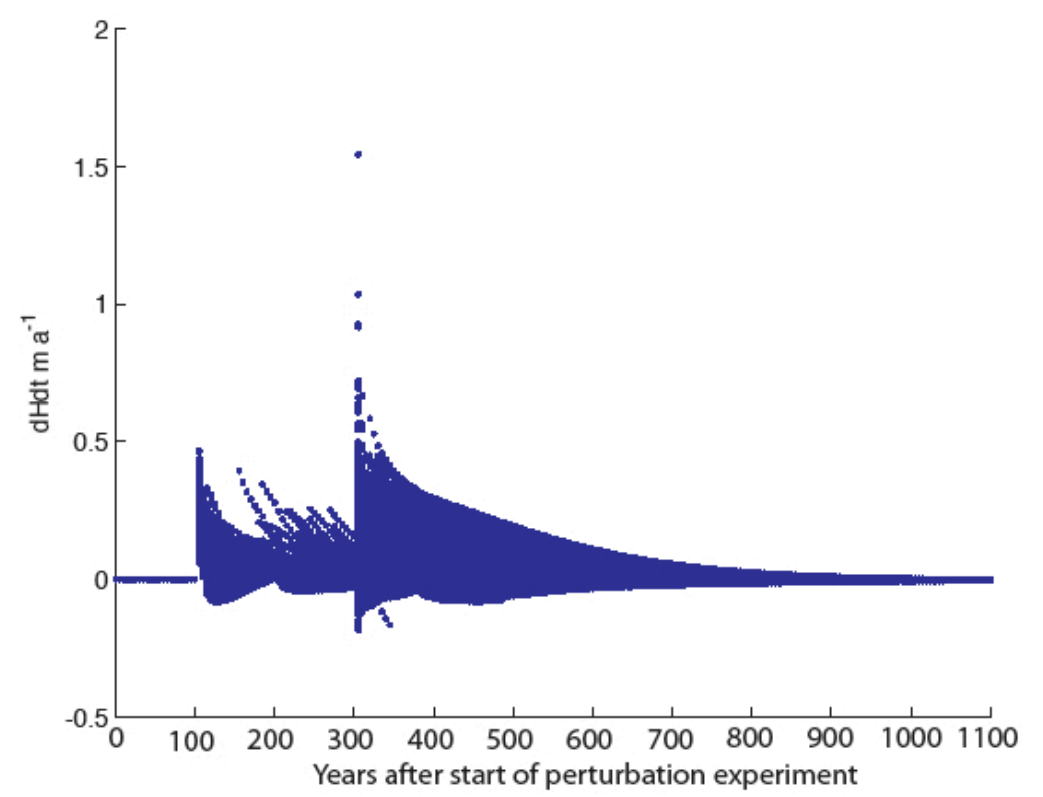

Figure 4.33. $\mathrm{dH} / \mathrm{dt}$ across the KIS ice plain for experiment 6 (table 4.1). 
150 a CIR stuck + beta up

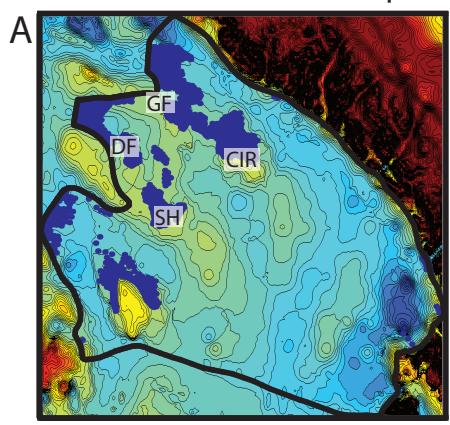

300 a CIR stuck + beta up

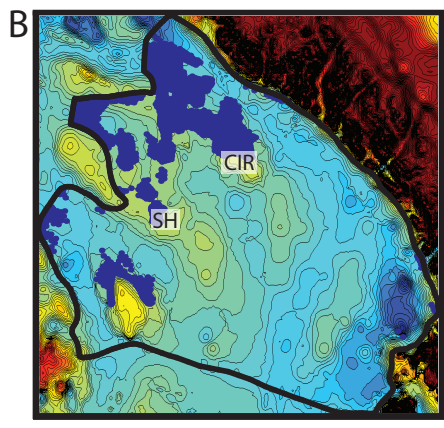

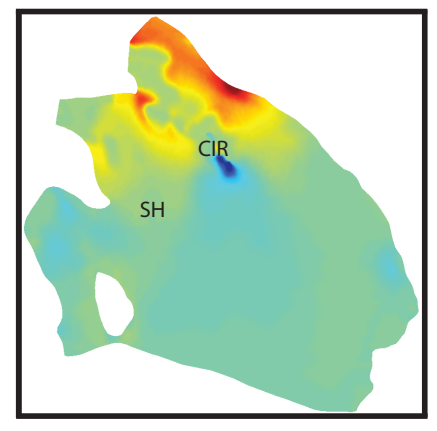
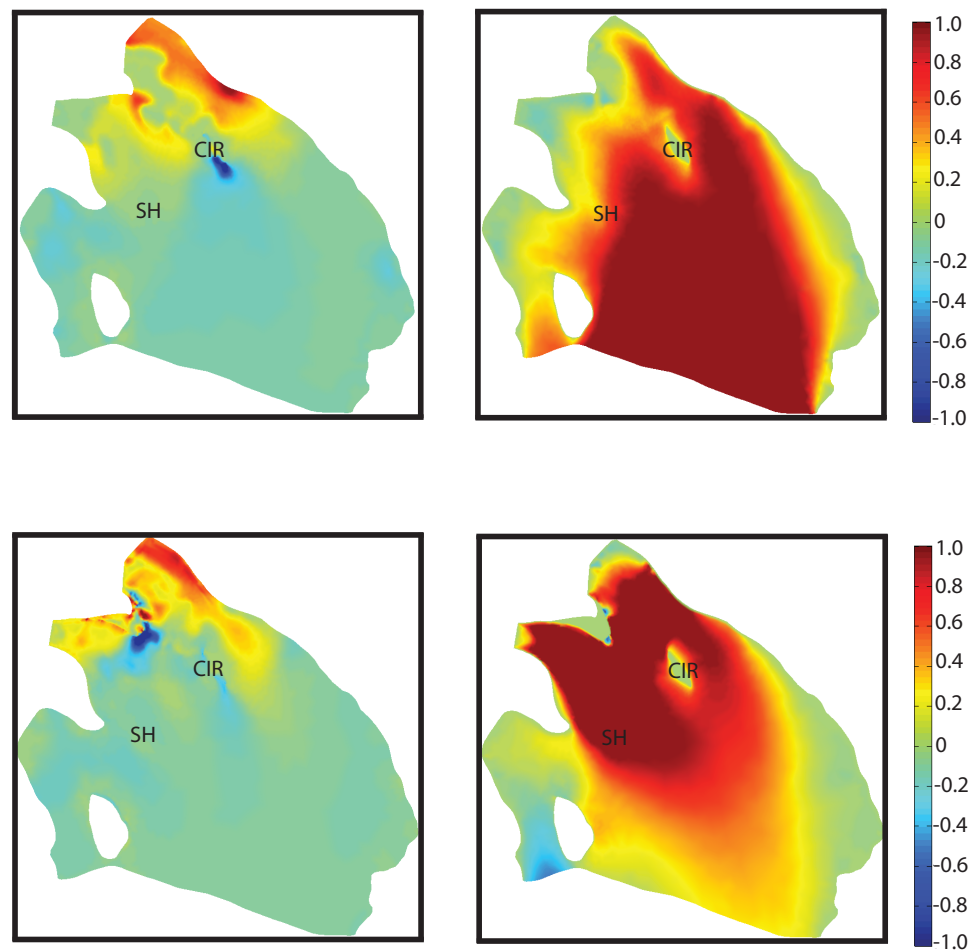

Figure 4.34. Experiment 6: CIR + GF stagnation and increased basal traction (table 4.1). Rows of panels represent model output from individual time steps. First column panels show shaded regions representing grounded nodes in the FEM domain. Contours are elevation with an interval of $25 \mathrm{~m}$. Second column panels are rate of thickness change, $\mathrm{dH} / \mathrm{dt}\left(\mathrm{m} \mathrm{a}^{-1}\right)$. Third column panels are rate of ice speed change, $\mathrm{dU} / \mathrm{dt}\left(\mathrm{m} \mathrm{a}^{-1}\right)$. Panels showing rates of change share the same scale to the far right. 
350 a CIR and GF stuck + beta
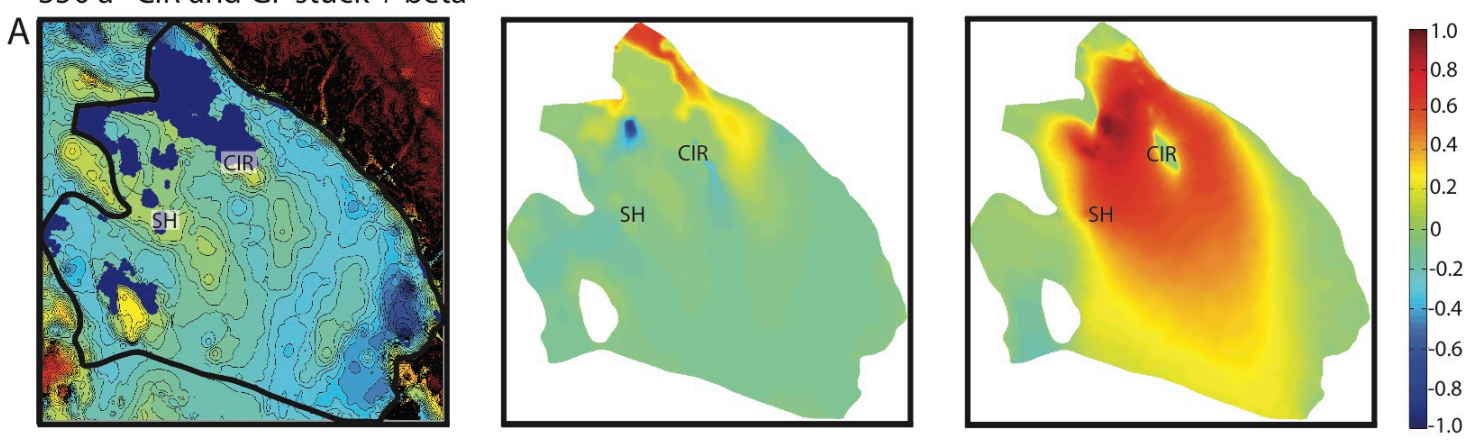

400 a $\mathrm{CIR}$ and GF stuck + beta
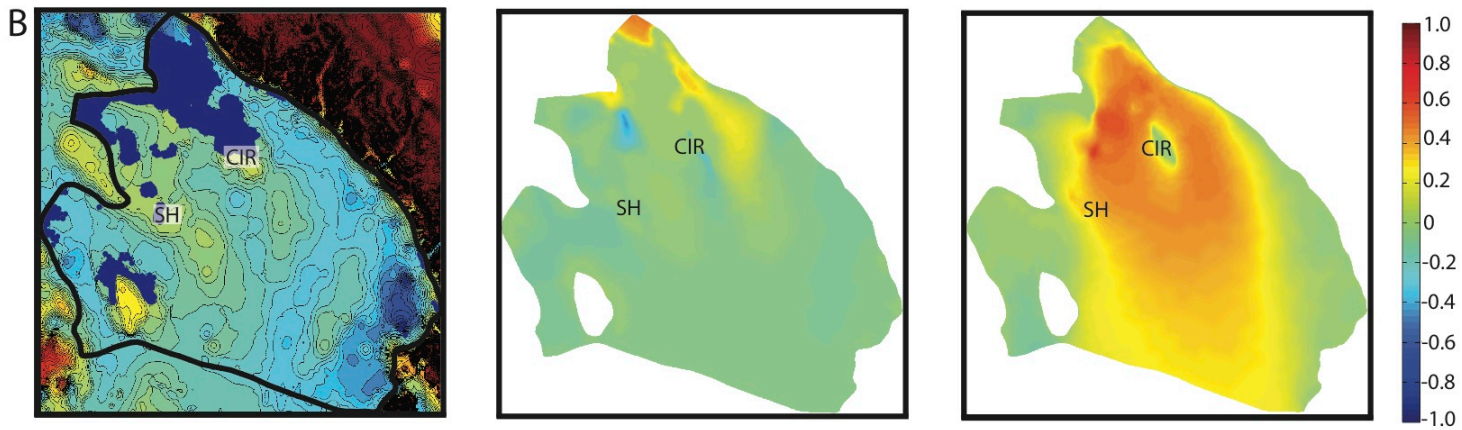

Figure 4.35. Experiment 6: CIR + GF stagnation and increased basal traction (table 4.1). Rows of panels represent model output from individual time steps. First column panels show shaded regions representing grounded nodes in the FEM domain. Contours are elevation with an interval of $25 \mathrm{~m}$. Second column panels are rate of thickness change, $\mathrm{dH} / \mathrm{dt}\left(\mathrm{m} \mathrm{a}^{-1}\right)$. Third column panels are rate of ice speed change, $\mathrm{dU} / \mathrm{dt}\left(\mathrm{m} \mathrm{a}^{-1}\right)$. Panels showing rates of change share the same scale to the far right.

\subsubsection{CIR, SH, GF and DF Stagnation and Beta Increase}

Here, all of the thickening mechanisms are employed during an individual model experiment. In this experiment, in addition to CIR, SH and GF stagnating, the DF stagnates at 500 a. At the time of DF stagnation much of the ice plain is lightly grounded (Fig. 4.38). Calculated height above buoyancy values are only $\sim 0-20 \mathrm{~m}$ for much of the ice plain (Fig. 4.36).

When the DF stagnates, the left lateral shear margin migrates inward and the ice stream outlet narrows. Due to this reorientation of the outlet geometry, the pattern of strain rates across the KIS outlet changes. As the outlet passes the SD and ER and widens, the 
overall transition from longitudinal compression to extension remains, however after DF stagnation the zone of extension is shifted inboard toward the center of KIS, paralleling margin migration. At $500 \mathrm{a}$, when the outlet narrows, ice across the outlet thickens and in turn, surface slopes steepen toward the grounding zone, and ice speed increases across the grounding zone and into the ice shelf (Fig. 4.38). Longitudinal extension increases, especially along the northern margin on the lee side of the DF.

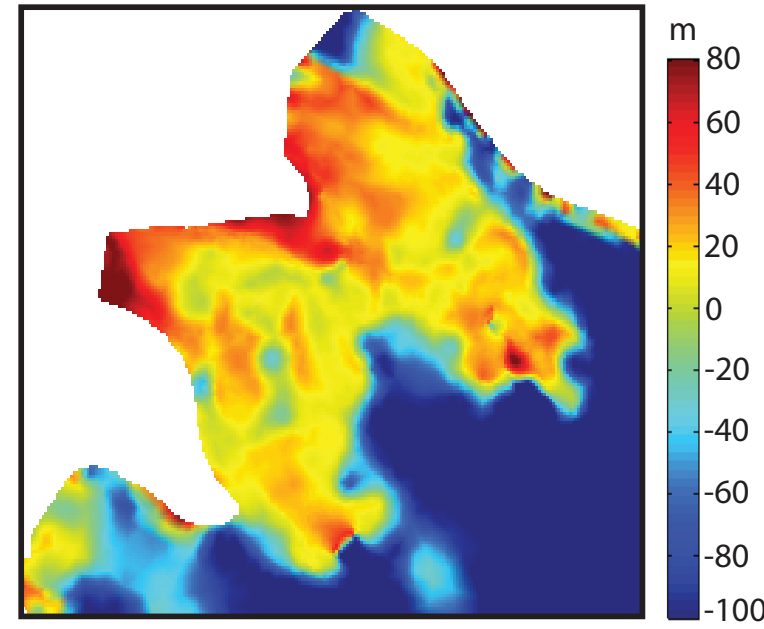

Figure 4.36. Height above buoyancy for experiment 7 at $380 \mathrm{a}$.

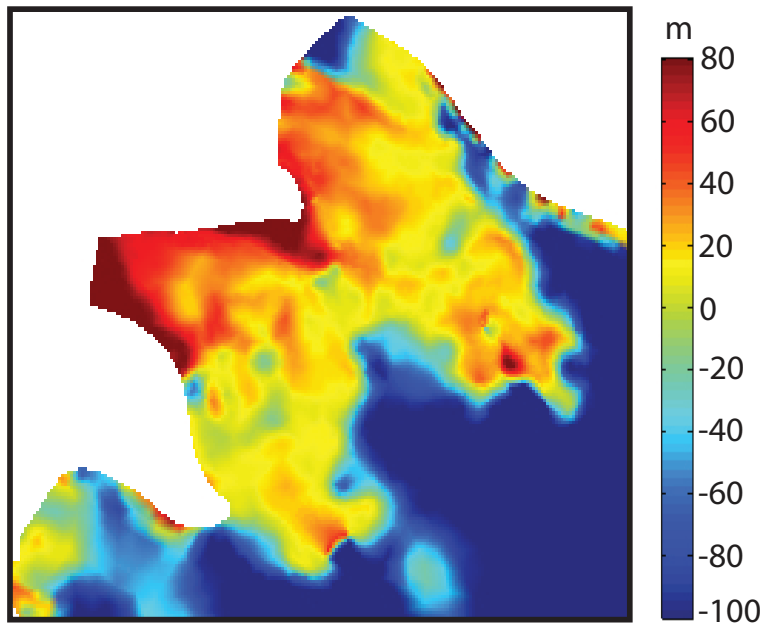

Figure 4.37. Height above buoyancy for experiment 7 at 420 a. 
300 a CIR and SH stuck + GF grounds + beta up
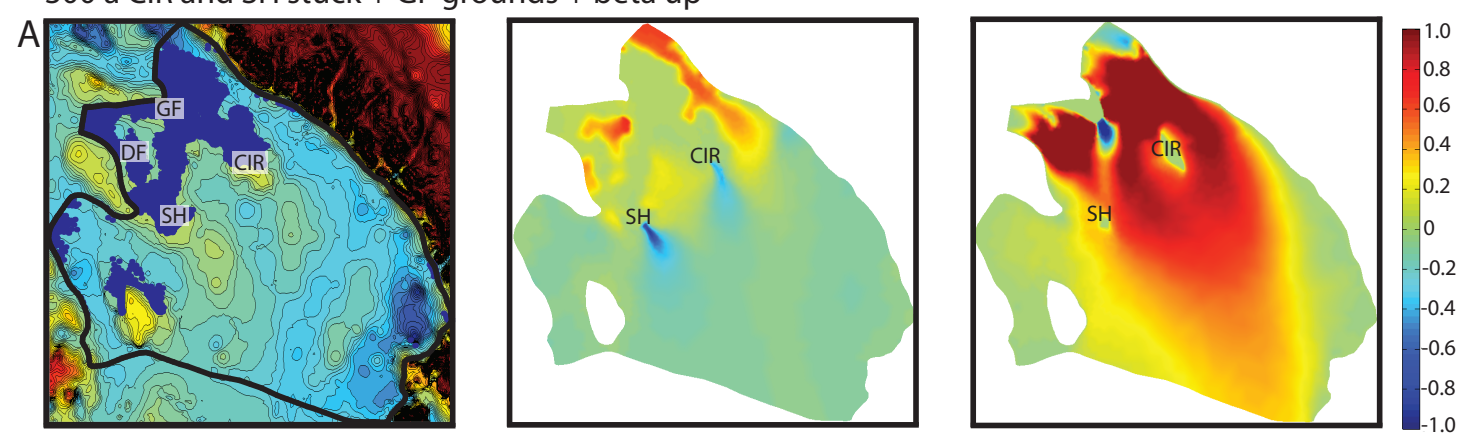

400 a WIS CIR and SH stuck + GF and DF grounds + beta up
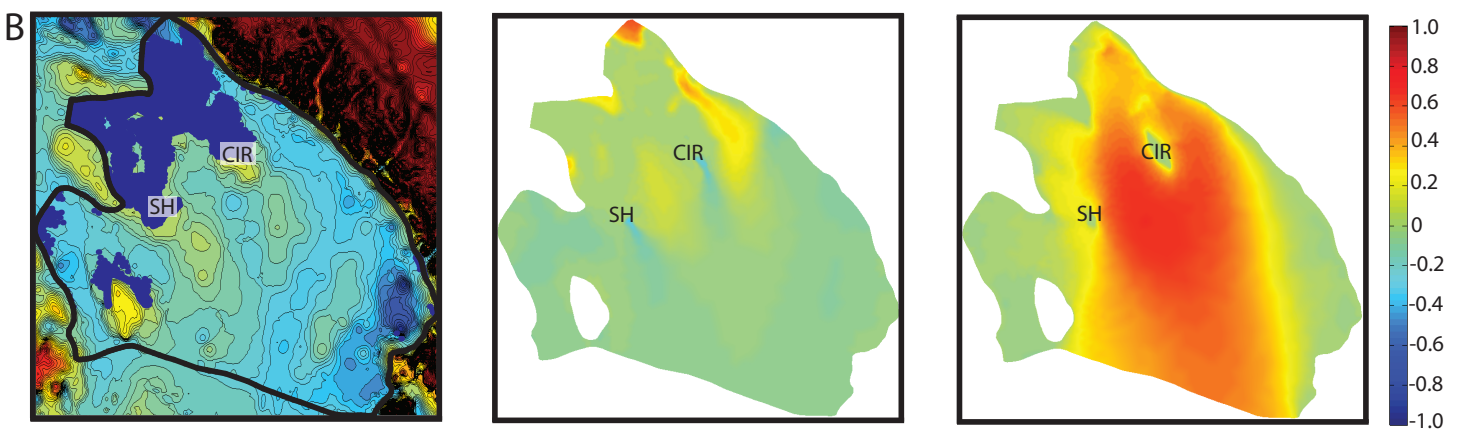

Figure 4.38. Experiment 7: CIR $+\mathrm{SH}+\mathrm{GF}+\mathrm{DF}$ stagnation and increased basal traction (table 4.1). Rows of panels represent model output from individual time steps. First column panels show shaded regions representing grounded nodes in the FEM domain. Contours are elevation with an interval of $25 \mathrm{~m}$. Second column panels are rate of thickness change, $\mathrm{dH} / \mathrm{dt}\left(\mathrm{m} \mathrm{a}^{-1}\right)$. Third column panels are rate of ice speed change, $\mathrm{dU} / \mathrm{dt}\left(\mathrm{m} \mathrm{a}^{-1}\right)$. Panels showing rates of change share the same scale to the far right. 
500 a CIR and SH stuck + GF and DF grounds + beta up
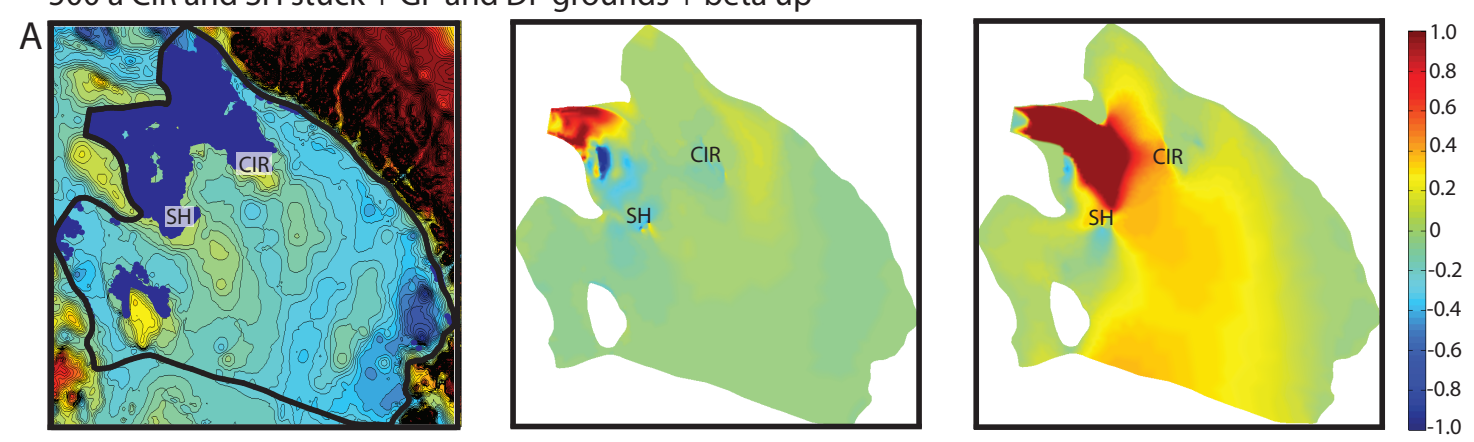

700 a CIR and SH stuck + GF and DF grounds + beta up
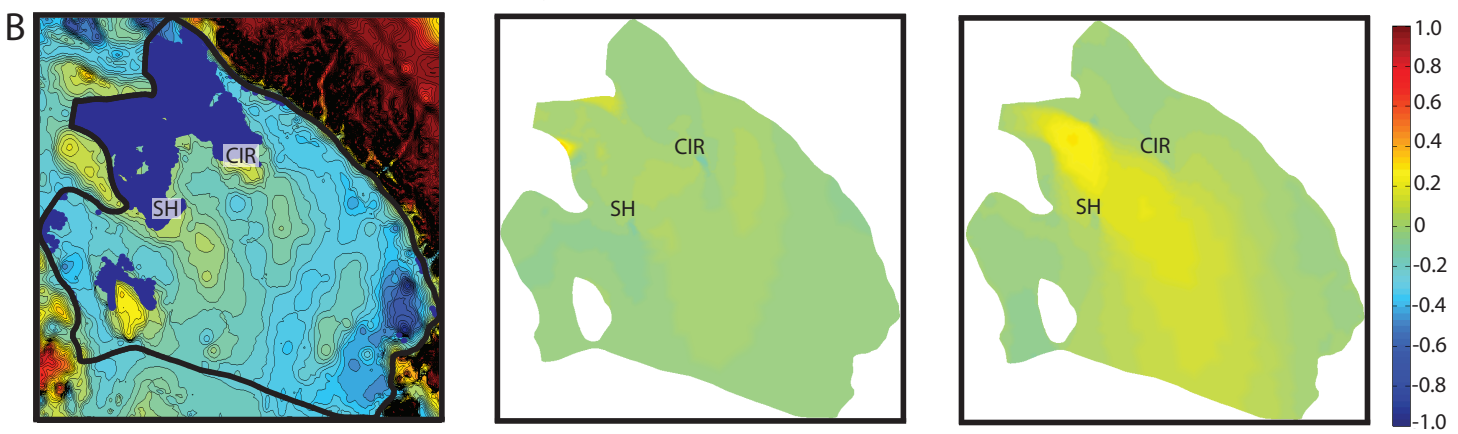

Figure 4.39. Experiment 7: $\mathrm{CIR}+\mathrm{SH}+\mathrm{GF}+\mathrm{DF}$ stagnation and increased basal traction (table 4.1). Rows of panels represent model output from individual time steps. First column panels show shaded regions representing grounded nodes in the FEM domain. Contours are elevation with an interval of $25 \mathrm{~m}$. Second column panels are rate of thickness change, $\mathrm{dH} / \mathrm{dt}\left(\mathrm{m} \mathrm{a}^{-1}\right)$. Third column panels are rate of ice speed change, $\mathrm{dU} / \mathrm{dt}\left(\mathrm{m} \mathrm{a}^{-1}\right)$. Panels showing rates of change share the same scale to the far right.

\subsubsection{CIR, GF and inner DF basal traction increase and Beta Increase}

This experiment directs out attention to the evolution of the left lateral margin of the KIS outlet. Of the perturbations discussed above, the stagnation of $\mathrm{SH}$ and DF occur along the left lateral KIS margin. Experiment 6 shows that ice goes afloat over multi-decadal time scales in the KIS outlet when both SH and DF are allowed to remain flowing. That result leads to the present experiment investigating the relative importance of the DF region in the grounding history of KIS. In this experiment basal traction increases from $0.1 \times 10^{8}$ to $1.0 \times$ $10^{8}$ only at inner DF nodes between 100 and 200 a. The bathymetry is $\sim 50 \mathrm{~m}$ higher at the 
inner DF than the portion of the DF closer towards SD. Where the bathymetry is highest, the inner DF is grounded during steady state.

By 250 a the WIS ice plain has expanded and adjacent ice is slowing and thickening. The thickening signal propagates at an advective time scale with ice flow across the grounding zone and into the ice shelf. As ice across the ice plain thickens, less ice mass advects across the grounding zone and the ice shelf thins (Fig. 4.40). When the GF stagnates, additional ice thins in the floating KIS outlet (Fig. 4.41). The development of a grounded WIS ice plain and GF stagnation limits the amount of ice flowing into the ice shelf and, in particular, towards the KIS outlet. Without SH stagnation, there is not enough ice grounded on the DF side of the outlet to induce slowing and thickening ice and, as a result, additional grounded ice. One conclusion that might be drawn from this result is that grounding line advance on KIS did not originate with a "margin jump" on the SD side of the outlet. This result is explored in greater depth in the next experiment. 
150 a CIR stuck + inner DF beta up + beta up
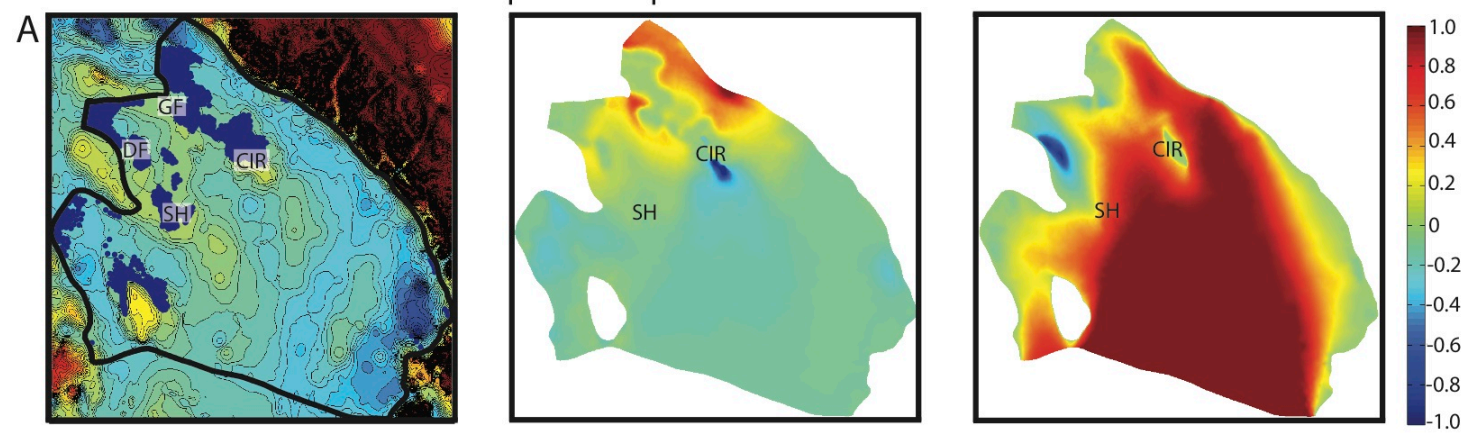

250 a CIR stuck + inner DF beta up + beta up
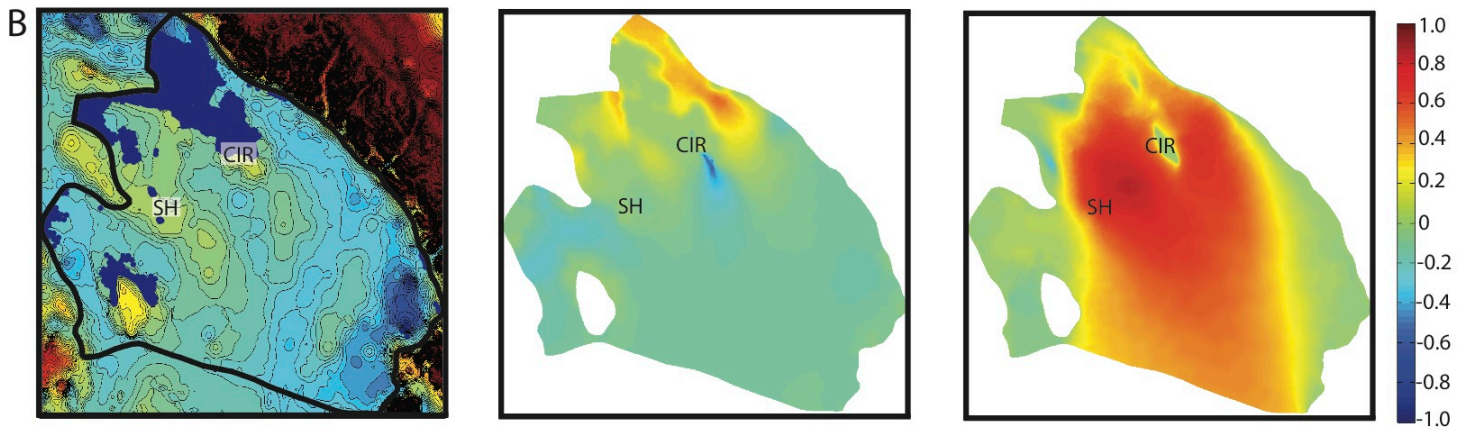

Figure 4.40. Experiment 8: CIR + SH + GF stagnation + DFin stuck and increased basal traction (table 4.1). Rows of panels represent model output from individual time steps. First column panels show shaded regions representing grounded nodes in the FEM domain. Contours are elevation with

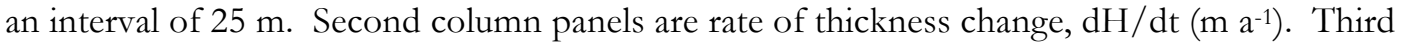
column panels are rate of ice speed change, $\mathrm{dU} / \mathrm{dt}\left(\mathrm{m} \mathrm{a}^{-1}\right)$. Panels showing rates of change share the same scale to the far right. 
350 a CIR and GF stuck + inner DF beta up + beta up
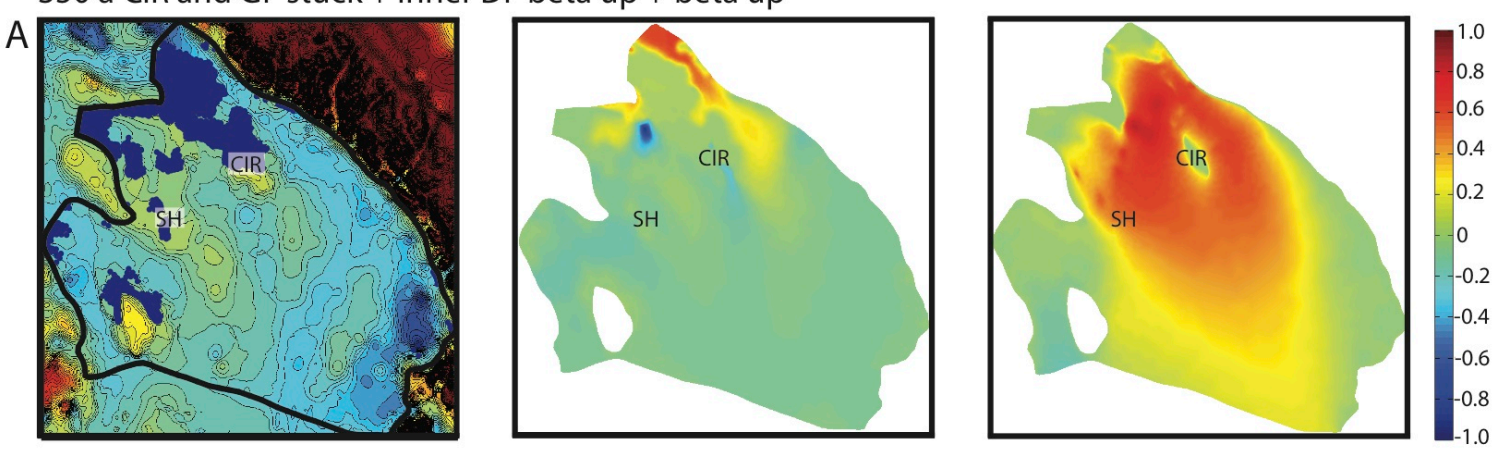

450 a CIR and GF stuck + inner DF beta up + beta up
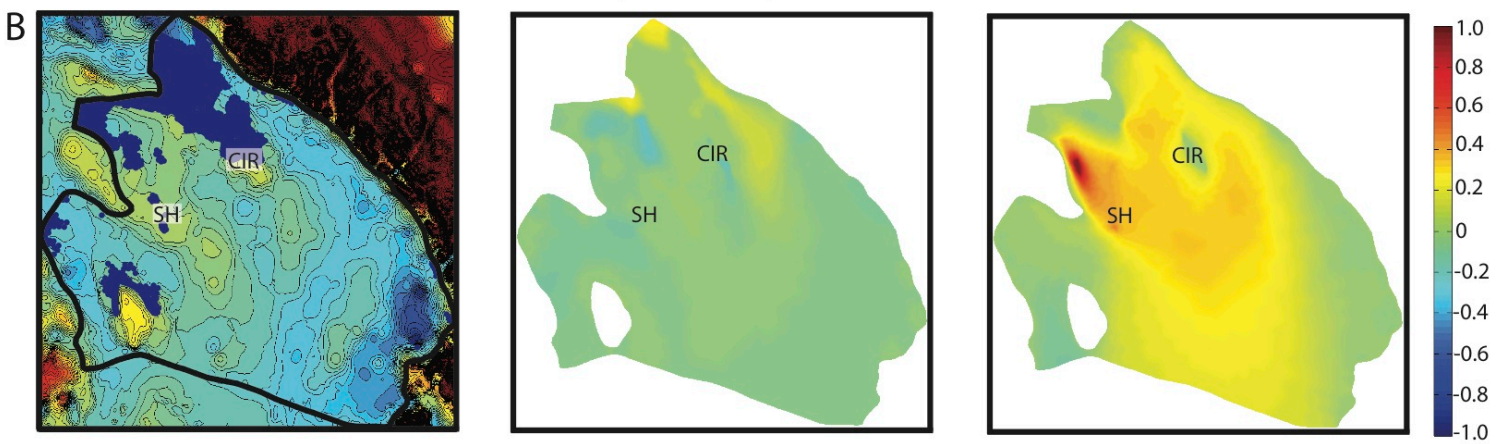

Figure 4.41. Experiment 8: CIR + SH + GF stagnation + DFin stuck and increased basal traction (table 4.1). Rows of panels represent model output from individual time steps. First column panels show shaded regions representing grounded nodes in the FEM domain. Contours are elevation with an interval of $25 \mathrm{~m}$. Second column panels are rate of thickness change, $\mathrm{dH} / \mathrm{dt}\left(\mathrm{m} \mathrm{a}^{-1}\right)$. Third column panels are rate of ice speed change, $\mathrm{dU} / \mathrm{dt}\left(\mathrm{m} \mathrm{a}^{-1}\right)$. Panels showing rates of change share the same scale to the far right.

\subsubsection{Investigating variations in basal traction at $\mathrm{SH}$}

This experiment investigates the role of $\mathrm{SH}$ in generating grounding across the KIS outlet. Like the DF, SH is a feature on the right lateral margin of the outlet but unlike the $\mathrm{DF}$, it rests atop a relative high on the sea floor. The crevasse record downstream of SH suggests that the ice rise stagnated relatively recently and around the time of margin reorganization near the DF, 150 years ago (Fahnestock, 2000). The previous experiment leads us to question the ability of an inward "margin jump" on the DF side of the ice stream outlet to generate grounding across the overdeepening. The $\mathrm{SH}$ is an interesting feature because it is situated adjacent and immediately downstream of the sill spanning the 
downstream reach of the KIS outlet. Previous experiments show that grounding across the KIS outlet is, at least partially, predicated on thickness transients originating at the ice rise and taking advantage of the elevated topography across the sill.

In this experiment basal traction increases at grounded nodes at $\mathrm{SH}$ from $0.1 \times 10^{8}$ to $1.0 \times 10^{8}$ between 100 and 200 a. By 250 a, the WIS ice plain is fully developed due to thickness transients arising from a combination of increasing basal traction and CIR stagnation. At the same time, ice that had grounded upstream of SH due to thickness transients originating at the ice rise quickly goes afloat. As in the previous experiment, ice across the KIS outlet remains afloat as the WIS ice plain develops.

Without a greater contribution of ice from the WIS ice plain advecting south of CIR after that area thickens, the ice shelf thins across the KIS outlet. Additionally, without full stagnation of SH, thickening along the right-lateral margin of the downstream end of KIS is not large enough to take advantage of the sill oriented across flow. Less grounding here limits longitudinal compression upstream and, in turn, allows ice to remain afloat. Further work might involve adjusting basal traction values to allow more ice to flow into the KIS outlet from the WIS ice plain during these experiments. It may be that basal traction across the WIS ice plain was small enough in the past to promote increased flow around the GF around the time of SH stagnation. 
225 a CIR and GF stuck + SH beta and background beta up
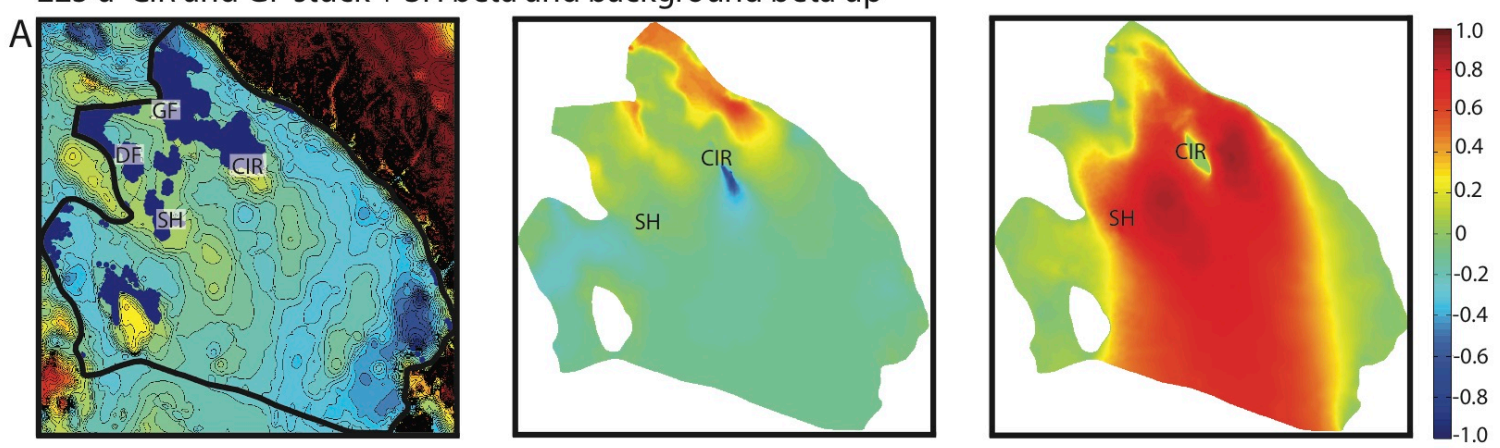

375 a CIR and GF stuck + SH beta and background beta up
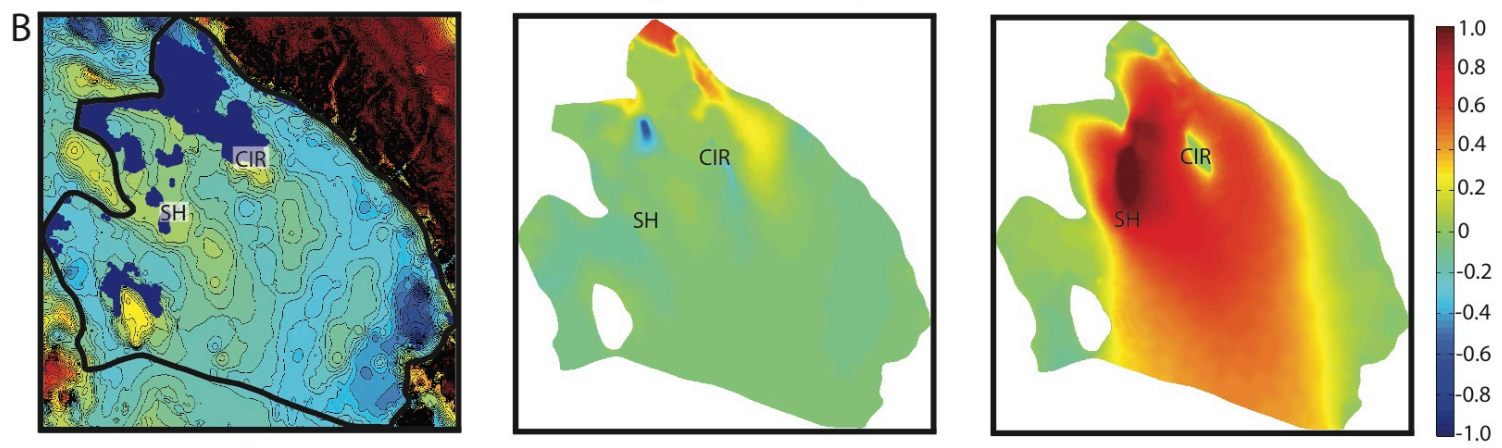

Figure 4.42. Experiment 9: CIR + GF stagnation + SH $\beta$ increase at stuck nodes and increased basal traction (table 4.1). Rows of panels represent model output from individual time steps. First column panels show shaded regions representing grounded nodes in the FEM domain. Contours are elevation with an interval of $25 \mathrm{~m}$. Second column panels are rate of thickness change, $\mathrm{dH} / \mathrm{dt}(\mathrm{m} \mathrm{a}$ 1). Third column panels are rate of ice speed change, $\mathrm{dU} / \mathrm{dt}\left(\mathrm{m} \mathrm{a}^{-1}\right)$. Panels showing rates of change share the same scale to the far right.

\subsection{Discussion}

The numerical modeling experiments suggest that the effects of an internally-driven perturbation initiated at one location may be transmitted quickly across the low-slope ice plain and, in turn, affect the grounding zone of an adjacent ice stream. This has implications for grounding line position at the downstream end of KIS and WIS. Of particular interest is how certain perturbations, or combinations of perturbations, yield grounding line advance across the KIS outlet. 


\subsubsection{Thickness Transients}

Transients in the thickness field may be generated by variations in the mass flux from upstream, changes in surface or basal accumulation rates, basal melt rate, basal traction and changes in the geometry of the ice shelf. The internally-driven perturbations considered here are forced by increasing basal traction across the ice plain either as a fractional change on grounded ice, grounding of floating ice, or stagnation of grounded ice. The record of past ice flow inferred from streaklines in the RIS suggests that the ice rises became stuck within the last 1000 years, but before KIS stagnation 150 years ago (Fahnestock et al., 2000 and Bindschadler, 1993). Once initiated, thickness transients propagate away from the area where they are generated and the coupled thickening and grounding feedback leads to grounding line advance across affected parts of the ice plain.

Thickness transients, and in turn waves of grounding ice, advance rapidly across the ice plain. Ice grounds on decadal to century time scales, but generally ice goes afloat on shorter times scales than grounding events because when ice first grounds it is only just above the floatation threshold - "lightly grounded" - and thus vulnerable to switching if a process to drive thinning is applied. In the experiments outlined above, the height above buoyancy for newly ( $<50$ years) grounded nodes in the KIS ice plain is less than $\sim 10 \mathrm{~m}$. For example, when WIS shuts down, ice across the WIS ice plain quickly goes afloat within $\sim 50$ years after the perturbation, but large portions of the ice plain remain afloat $\sim 250$ years after WIS reactivates.

In the numerical modeling experiments, grounding line advance, while not uniform across ice stream outlet - especially in the case of KIS - proceeds rapidly $(\sim 50 \mathrm{~km}$ per century). Hulbe and Fahnestock (2007) note that while this is much faster than the one 
measured contemporary retreat rate of $30 \mathrm{~m} \mathrm{a}^{-1}$ (Thomas et al., 1988), the rate found in the numerical model simulations here is embraced by the suggestion in Thomas et al. that due to the low relief ice plain, the rate of retreat could be up to 20 times higher than the observed rate.

Thickness transients across the ice plain are thus clearly involved in the phasing of discharge cycles and also grounding line migration. For example, transients originating at CIR and SH, cause ice to ground across the KIS outlet. Furthermore, local changes to surface slopes accompanying thickness transients lead to a redistribution of potential gradients directing basal water flow and may, in turn, further modify basal traction.

\subsubsection{Thickness transients associated with changes in ice stream flux}

When ice flux through the outlet of one ice stream decreases, surface gradients change across the downstream ice plain where bed topography does not vary a great deal. When one ice stream stagnates, the longitudinal surface profile on an adjacent ice stream flattens due to increasing longitudinal extension at the downstream end. Surface slopes are directly related to mass flux conservation. If less ice is transport though the wide outlet region at the downstream end of WIS, smaller surface slopes are required than when you have more mass to transport. When longitudinal surface gradients lessen, transverse terms become more important.

In experiment 1, when WIS stagnates, ice in between the KIS and WIS outlets thickens. This area includes the modern day GF flat ice terrain. This is an "interflow" area on the lee side of ER, in the sense that faster flowing ice passes it by on the sides. When both KIS and WIS outlets are discharging fast, before the start of perturbations, surface 
elevation between the two outlet flow zones is $\sim 10-20 \mathrm{~m}$ less than within the outlet flows. When WIS shuts off, transverse surface gradients cause thickening in this particular interflow region, in part because bathymetry is relatively high here. It is likely that interflow regions, or those on the lee sides of inter stream ridges, are prone to having relatively thin ice thicknesses and the flat surface gradients and are thus sinks for basal water distribution.

\subsubsection{Thickness transients associated with increases in basal traction}

In the numerical modeling experiments the parameter controlling basal traction is increased over a time span of a hundred years either across the entire ice plain or, in addition, at local areas that have high topography, such as $\mathrm{SH}$, or terrains that have stagnated in the past before KIS shut down, such as the DF. Basal traction, or basal drag, is the resistive stress due to friction at the bed that, in addition to friction at the ice stream margins and tension or compression up-and-down flow equal the driving stress.

When basal traction is increased, grounded locations become "obstacles" of some magnitude, with varying spatial extent. On short time scales (years), ice thickens at these locations where the sliding speed is lowered. Initially, ice at the location of the changed basal traction thickens, which in turn leads to upstream thickening as ice is inhibited along its downstream path and downstream thinning as less ice moves across the site of the obstruction and to those downstream locations. This rearrangement is temporary, however, because the changing thickness is accompanied by changes to surface slope and velocity.

The coupled thickness and velocity adjustment to a change in basal traction plays out on a century time scale. When ice in one region slows, the resulting decrease in local stretching causes ice thickness to increase, and in turn local surface slopes increase. Thicker 
and steeper ice flows relatively faster, leading to increased stretching and thinning. Through these coupled changes, the ice thickness and velocity come to some new steady state configuration in accord with the changed basal traction. Where relatively thicker ice results, its advection toward the grounding line may yield grounding line advance.

Both regional geometry and the pattern of ice flow mediate the effect that changes in one location may have in others. Across-flow transmission of a perturbation is most likely along contours of equal bed elevation but often where a transverse signal is present, alongflow effects are larger. For example, changing basal traction on the WIS ice plain modifies thickness and grounding on the GF but grounding (and stagnation) in the GF region has a limited effect on ice in the main trunk of the adjacent ice stream. By the time the WIS ice plain reaches its approximate modern extent by 300 a into the perturbation experiments, lateral distribution of ice from the WIS ice plain into the KIS outlet is limited. When SH does not stagnate, in experiments 5, 8 and 9, ice across the KIS outlet remains afloat. In each of these experiments, without along-flow compression from stagnant and grounded ice around SH, when the GF stagnates and the KIS outlet narrows, ice speeds up and by increased longitudinal extension, thins and goes afloat. It may be that the topography at the downstream end of the outlet - particularly the topographic high spanning its width enhances longitudinal extension near the grounding line.

\subsubsection{Thickness transients associated with ice rises and obstructions to flow}

The formation of an ice rise in the floating ice shelf creates an obstruction to ice flow. Upstream of the ice rise longitudinal compression acts as a resistance to flow, whereas extension occurs exists downstream of the obstruction. MacAyeal et al. (1987) estimated 
that the resistance generated by CIR accounts for about half the "back-pressure" force on WIS and Mercer Ice Stream. In order to transmit the same ice mass downstream as before the formation of the ice rise, ice around the obstruction thickens and the downstream surface gradient increases.

The longitudinal compression created by the ice rise has further mechanical effects upstream. Ice thickens immediately upstream of the ice rise and this causes further reduction in longitudinal extension upstream. In experiment 2, when CIR stagnates, ice grounds upstream of the ice rise and connects with grounded ice in the WIS ice plain and the GF. This is the same as the modern configuration of the WIS grounding line.

\subsubsection{Bed Topography and Grounding Zone Dynamics}

The grounding line advances across the KIS outlet in a complicated manner. The distribution of thickness transients propagating upstream or across the ice plain is modified and, to a great extent, controlled by the location of high points in the bed (Fig. 4.44). In experiments that yield grounding line advance, after ice grounds marginally across high points in the bed, the pattern of grounding zone advance across the overdeepening is transverse across the KIS outlet and not along the ice stream flowline. In this respect, the effect of bed topography leads to some unexpected results from the numerical modeling experiments.

Thickness transients propagating upstream from, for example, CIR and $\mathrm{SH}$ are associated with a change in volume flux in the direction of the thickness transient (Fig. 4.43). Because the bed modifies where thickness transients occur, it is also responsible for modifying volume flux changes. 
Certain areas at the KIS outlet are predisposed to ground based on their bed topography. The lateral margins, and in particular, the inner DF and the GF, where the bed topography is high, often act as "corridors" where thickness transients can be transmitted across the ice plain. A sill, or a bathymetric high, connecting the two ice stream corners near the DF on the right-lateral side and the GF on the other, marks the downstream edge of the overdeepening. Ice grounds across the length of the sill only when SH grounds - although it also grounds on a longer time scale (at $\sim 550$ a) during experiment 3 when basal traction is increased without any additional perturbations. SH represents the main mechanism to decrease downstream stretching across the right lateral side of the KIS outlet. When SH does not ground, ice in the outlet speeds up and thins, particularly over the sill, before going afloat.

The overdeepening eventually fills in to become lightly grounded ice across a newly formed KIS ice plain. Small areas of floating ice remain over topographic depressions. That is, residual lakes are formed. If lakes formed in this way under the GF, DF, or elsewhere, the water within them may be brackish. In general, ice remains afloat longer along the northern edge of KIS. This is due, in part, to the topographic depression on the inboard side of the DF and, additionally, early in the perturbation experiments (within the first hundred years) rates of positive thickness change are larger along the southern margin of KIS (near the GF) in comparison to rates across the northern half of the ice stream. This is due to large thickness gradients propagating to the GF from CIR and the WIS ice plain, as well as the layout of the bed topography. 


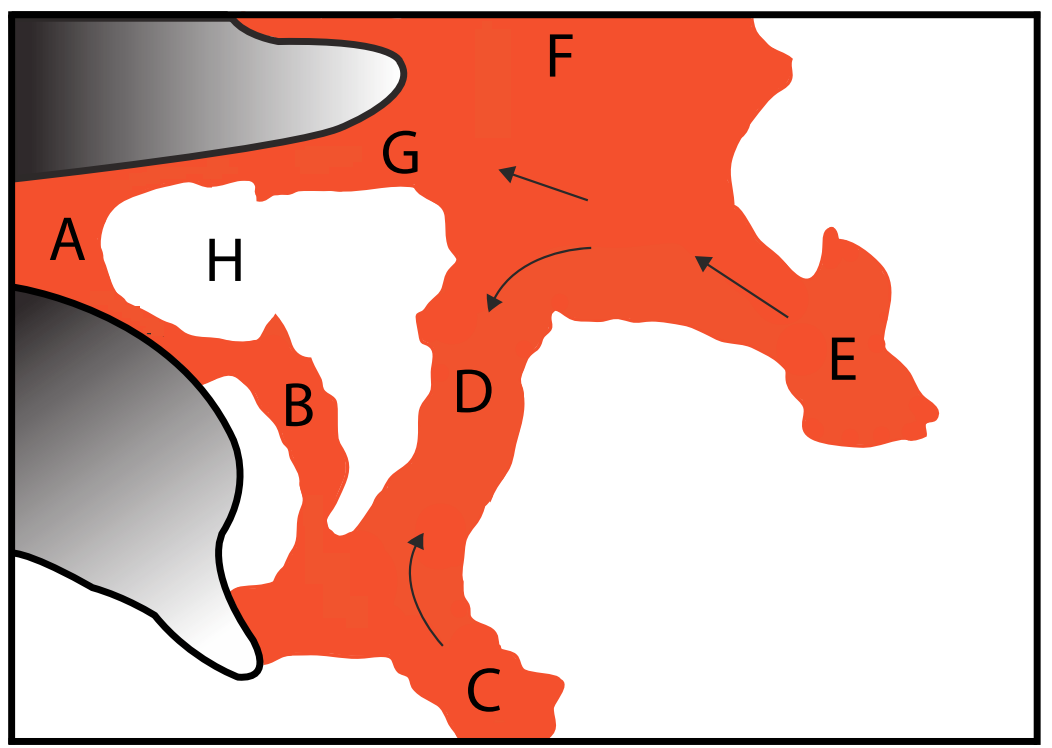

Figure 4.43. Schematic showing the evolution of grounded ice (red) across the KIS ice plain and northern WIS ice plain when CIR and SH shut down and background values for basal traction $(\beta)$ increase (from $0.01 \times 10^{9} \mathrm{~Pa} \mathrm{~s} \mathrm{~m}^{-1}$ to $0.1 \times 10^{9} \mathrm{~Pa} \mathrm{~s} \mathrm{~m}^{-1}$ ). Extent of grounded ice is taken to be $\sim 750$ years ago (after both CIR and SH became stuck). Letters label the upstream "steady-state" KIS grounding line position (A), the inner DF (B), SH (C), the bathymetric high across the KIS outlet (D), CIR (E), the northern WIS ice plain (F), the GF and surrounding terrain (G) and the overdeepening in the bed topography $(\mathrm{H})$. Arrows represent general trend of thickness transients and, in turn, grounded ice propagating across the KIS outlet.

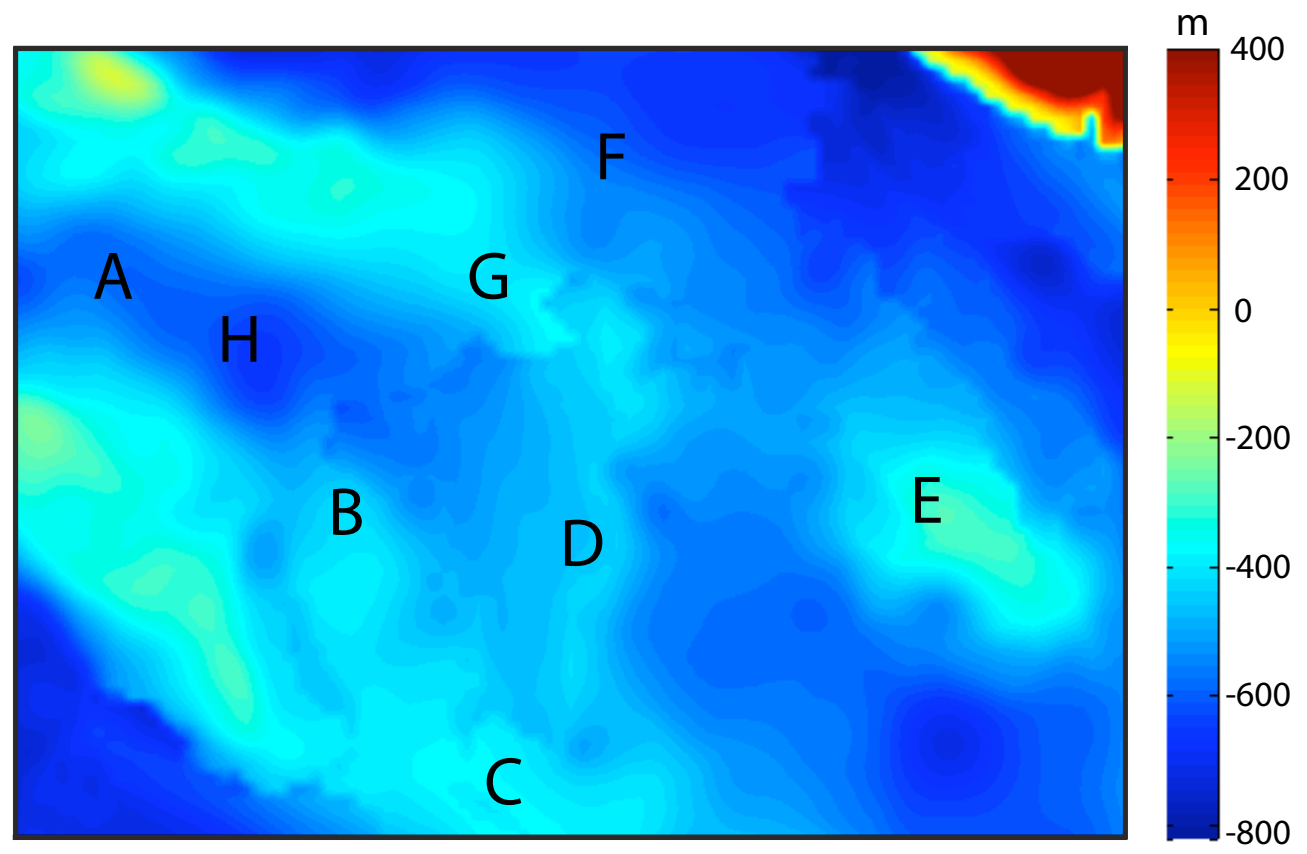

Figure 4.44. Bed topography (m) (BEDMAP1_plus, BAS) beneath the area annotated in the above figure. Geographic locations (A through $\mathrm{G}$ ) described above are also shown. 


\subsubsection{The Role of the GF in KIS Grounding Zone Dynamics}

The way in which grounding in the GF affects flow in the main trunk of the ice stream depends in part on events elsewhere in the region and these, in turn, depend on the geographic setting. The GF is situated along the left lateral downstream KIS margin, whereby stagnation of the flat-ice terrain results in a reorganization of the ice stream geometry. The spatial layout of the bed topography here, when combined with the small variations in ice thickness across the ice plain connecting the downstream portions of KIS and WIS, encourages a lateral connection between the two adjacent ice streams via thickness transients traveling, preferentially, along routes defined by the bed.

Grounded and stagnant ice at the GF narrows the KIS outlet, thickening the main trunk of the ice stream and, in turn, leading to further grounding. The magnitude of the effect depends on what is happening at the opposite margin of the ice stream. Thickness transients originating at $\mathrm{SH}$ ground ice along the northern margin and, in turn, allow for the effects of GF stagnation to be felt in the middle of the ice stream and across the overdeepening.

Surface morphology and ice stratigraphy across the GF confirms that the region grounded quickly within the last few hundred years. A prominent surface lineation separates the GF flat-ice terrain from ER. Catania (2004) asserted that this lineation was not likely a relict ice stream margin because it wraps around ER, and thus also away from the paleo ice flow direction and also because deep layers within the ice stratigraphy are intact, thus suggesting that strain rates were smaller than present-day values along lateral shear margins. Instead, she argues, that the lineation is a past grounding line (Catania, 2004). Downwarped internal layers over the narrow region below the lineation suggest that this was the site of 
localized basal melting caused by large tidal currents in areas with small water column thickness (along the grounding line in a sub-ice shelf cavity) (MacAyeal, 1985). Our analysis supports this view in that in the absence of stagnant ice on CIR, the mechanical setting of the area favors relatively thin ice and thus flotation. The pattern of grounding across the GF in the numerical modeling experiments investigated here suggests that the grounding line moved through the area before the GF stagnated. It is likely that the observed distribution of basal crevasses across the modern GF flat-ice terrain reflects this movement of the grounding line.

The embayment along the northern shore of the $\mathrm{SD}$ is a likely modern analogue for a floating GF at the time before KIS stagnation (Fig. 4.45). The embayment shares a mechanical setting with the GF in that both features reside on the leeside of an interstream ridge. The Siple Ice Stream (SIS) is situated immediately to the north of the SD and ice speeds in the ice stream are less than $50 \mathrm{~m} \mathrm{yr}^{-1}$. To the north and adjacent to SIS is Bindschadler Ice Stream (BIS) which shows greater surface texture variation and ice speeds up to $\sim 400 \mathrm{~m} \mathrm{yr}^{-1}$. The embayment is part of the RIS and its shoreline is defined by deep bathymetry below the ice shelf abutting the elevated topography of the SD.

Ice flowing through the SIS and adjacent BIS goes afloat in the RIS and creates a 5$10 \mathrm{~km}$ wide strip of heavily crevassed ice that separates the fast moving BIS ice from more slowly moving ice. Large effective strain rates define the shear zone, ranging from $0.2 \mathrm{a}^{-1}$ near the grounding line to $0.05 \mathrm{a}^{-1}$ farther from the coast.

Inboard of this shear zone is a second - and more faint - shear zone lightly defining the shoreline separating the SD from the RIS. Surface crevasses are observed along this floating boundary. Upstream, they are older fractures advecting into the shelf from the 
grounded left-lateral shear margin of BIS but as the ice approaches the shore of SD and the relatively large shear stresses there, a new episode of propagation yields a narrow band arcuate crevasses. The remainder of the shoreline shows a much fainter shearing imprint because ice in the inner embayment is slow moving and flowing from the nearly stagnant SIS. Thus, this portion of the shoreline shows greatly reduced surface crevassing, but it is likely that the region also exhibits buried crevasses due to local melting along the shoreline grounding zone.

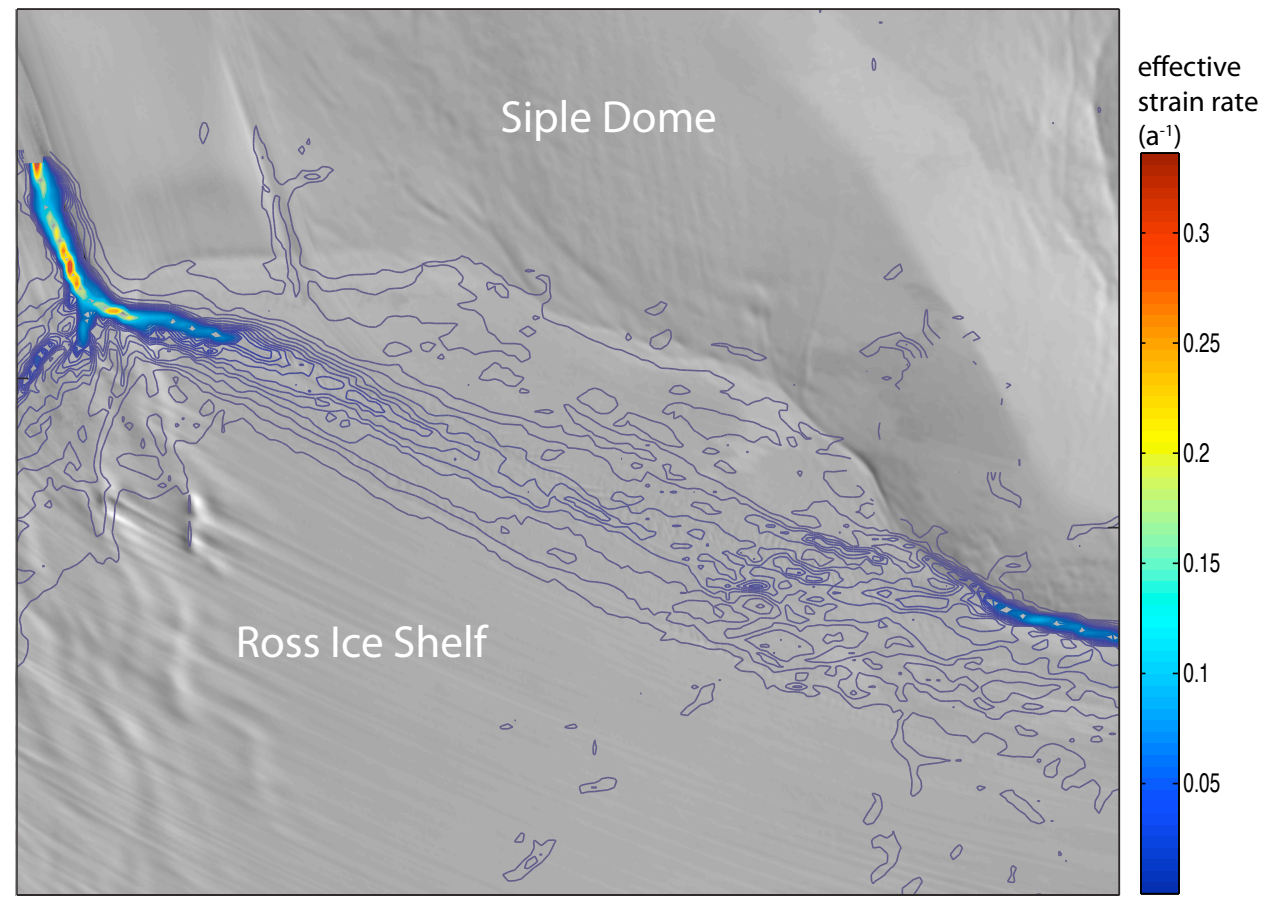

Figure 4.45. Calculated effective strain rates $\left(\mathrm{a}^{-1}\right)$ for the northern SD embayment overlaying MOA image.

\subsubsection{The Duckfoot as a remnant lake}

Grounding line migration from a previous location upstream at KIS to its presentday location requires advance across the overdeepening in the bed between ER and SD. The forward slope on the upstream side of the overdeepening is a theoretically expected location for a stable grounding line and indeed, it is easy to generate this configuration in models that 
represent the region with fast-flowing ice streams and non-stagnant CIR and SH. Forcing the grounding line to advance seaward from that location is more challenging. This is because the bed is very deep and the outlet is wide enough that there is little to slow the rate of downstream thinning once ice has gone afloat over the deep region.

When grounding line advance does occur, it is not in the direction of ice flow but transverse to flow. This outcome makes the case for thinking about grounding line "stability" as determined by more than the bed slope in the along-flow direction. For example, when grounding line advance does occur, it proceeds first marginally around the overdeepening and then laterally from south to north and not along the axis of the ice stream. In experiments in which the GF stagnates, ice spreads laterally across the KIS outlet relatively quickly—on the scale of tens of years. However, transverse advance across the outlet is only accommodated when accompanied by stagnation of the right-lateral (or northern) ice rise SH - situated, geographically, opposite of where transverse grounding line advance initiates at the left-lateral corner of KIS.
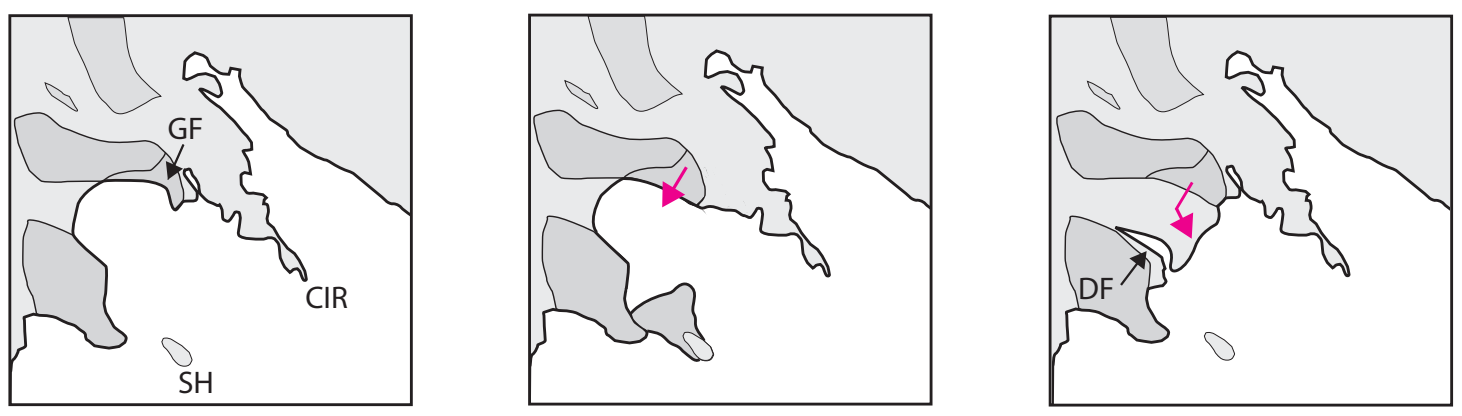

Figure 4.46. Schematic showing sequence leading to formation of a remnant lake around the Duckfoot during lateral grounding line advance.

The sequence of transverse grounding line advance across the overdeepening leads to a new interpretation of the relic inboard DF margin. Alley et al. (2006) outline a 
hypothesis where during a glacial advance across an outlet, the ice shelf grounds on a proglacial sill and, in turn, traps subglacial water below the remnant floating ice immediately upstream of the sill. In this scenario, subsequent ice shelf freeze-on to the sill and a new reversal of the ice-air surface slope over the sill leads to ice thickening upstream. The experiments discussed here confirm such a scenario. Rather than a shear margin created as the ice stream outlet narrowed, this boundary may instead have be a former grounding line location (Fig. 4.46). In the DF remnant lake scenario, a grounding line advancing from south to north across the ice stream until it encounters the relative low in the bed beneath the DF. The arrival of the grounding line creates a wedge-shaped lake with the old, outer margin and the new grounding line as its shores. As ice stream ice continues to flow downstream past the lake, a shear margin develops where the paleogrounding line is pinned along the relatively shallow inboard shore. In the numerical modeling experiments where grounding line advance proceeds seaward of the present-day grounding line location, a remnant lake is formed at the relative low in the bed at the outer DF, creating adjacent margins along the lake shores. The inboard margin uses the topographic high at the inner DF as an underpinning point. The bathymetry at the outer DF is $\sim 50 \mathrm{~m}$ lower than the relatively shallow inner DF.

In this scenario, the dating of relic margins bounding the DF represents the timing and evolution of the remnant lake. Before the formation of the lake, the outboard DF margin is the grounding line between the floating ice shelf and SD. Lateral shear along the outboard margin decreases after the formation of the new inboard margin. Shearing along that margin continues until ice stream stagnation. The inboard grounding line remains active until ice stream stagnation. 


\section{Chapter 5}

\section{SYNTHESIS}

The work presented in this paper focuses on processes near the downstream end of Kamb and Whillans Ice Streams that lead to changes in ice stream boundaries and ice stream flux. The downstream setting of these ice streams, encompassing the broad ice plain and grounding zone, is complicated. Bathymetry is important in determining ice stream flow in ways that may not be obvious. Our results suggest that a simple flowline view of grounding line migration is misleading and that transverse slopes are an important control on migration pattern. Additionally, bathymetric depressions support the formation of subglacial lakes that adjust basal water routing below an ice stream. The observations and numerical modeling experiments investigated in this paper create a clearer view of how grounding line and lateral margin position respond to these features and other internal perturbations. A new view of grounding zone behavior contributes to greater understanding West Antarctic Ice Sheet mass balance. In this section I present the main conclusions from the work outlined in previous chapters.

\subsection{Ice Mechanics}

The data presented in chapter 2 uses surface and bed topography and velocity datasets to perform a mechanical analysis of the downstream reaches of KIS and WIS. Ice speeds are highest in the main trunk of an active ice stream and ice speeds change quickly from fast moving to slow moving along the lateral margins. Lateral shear margins separate 
the ice stream from adjacent terrains. High effective strain rates along the shear margins lead to mechanical thinning of the ice over a narrow zone $(\sim 10-20 \mathrm{~km})$.

The majority of subglacial lakes at the downstream end of WIS are located along shear margins. One such lake, Subglacial Lake Englehardt (SLE), is part of a flat-ice terrain along the left lateral margin of WIS. The local hydraulic potential gradient is oriented towards the flat ice terrain and away from the main trunk of WIS. The hydraulic potential gradient also changes from high to low along the shear margin between upstream and downstream locations. This suggests that subglacial meltwater production that originates at upstream locations and is, in turn, diverted towards the shear margin, moves downstream along the shear margin and collects in large lows in the hydraulic potential gradient, such as SLE.

\subsection{Characterization of Flat-Ice Terrains and Subglacial Lakes at the Outlets of Kamb Ice Stream and Whillans Ice Stream}

The mechanical setting of SLE and the surrounding flat-ice terrain are revealed by analysis using a high-resolution DEM and ice surface images from the Polar Geospatial Data Center. The flat ice profile across the terrain is evidence that the lake area is in hydrostatic equilibrium. The highest effective strain rates $\left(0.01-0.04 \mathrm{a}^{-1}\right)$ across the flat-ice terrain are concentrated along the outboard shear margin, defining the northern most WIS boundary. This zone features en echelon arcuate crevasses and delineates the outboard shoreline of SLE. The analysis in chapter 3 presents evidence for a separate set of en echelon arcuate crevasses along the inboard shoreline of SLE. This area represents a second zone of shearing where basal traction increases outside of the subglacial lake terrain. 
Based on their shared mechanical and geomorphological settings, SLE is a possible modern analogue for the stagnant Duckfoot (DF) flat-ice terrain. Both right lateral downstream terrains have inboard and outboard zones of shear (the DF features relict buried near surface crevasses) bounding a low relief flat-ice topography. It follows that the DF is a likely location for a subglacial lake in the time before KIS stagnation. The work in chapters 2 and 3 explores the hypothesis that the formation of a subglacial lake along a shear margin sets the stage for a margin jump by creating a band of elevated shear stress along the inboard shore.

If the DF was the site of a shear-margin type subglacial lake prior to KIS shut down, its function may have been similar to the function of the contemporary SLE. Today, SLE collects and episodically discharges subglacial meltwater water. If the faintness of surface crevasses over the inboard lakeshore are accepted as evidence of a relatively recent origin for the lake, then it is not unreasonable to suggest a relationship between the development of that lake and other ongoing changes across the WIS ice plain region. Such relationships may also have existed for a DF margin lake.

\subsection{Grounding Zone Dynamics}

Weertman (1974) hypothesized that grounding line retreat would continue unstably in the presence of an inward sloping bed topography. Subsequent work (Schoof, 2007 and Nowicki and Wingham, 2008) has clarified but supported that general conclusion. The work outlined here adds complexity to this theory and leads to several interesting conclusions regarding grounding line migration at ice stream outlets. In the model experiments discussed in chapter 4, when grounding line advance does occur across the KIS outlet, it is mediated 
by the overdeepening in the bed and proceeds not in the direction of ice flow but transverse to flow.

The perturbations result in a variety of short-term (century or less) fluctuations in ice stream speed, flow-direction, ice thickness and, in turn, grounding line position. Cross communication between ice streams, in this case between KIS and WIS, is facilitated by thickness transients that lead to negative changes in volume flux upstream of where the perturbations originated. When SH does not stagnate, longitudinal compression along the right-lateral side of the KIS is absent, yielding little grounding line advance. Bathymetry modifies the simple mechanical processes resulting from the set of perturbations so that as ice thickens and runs aground, it does so preferentially at high points in the bed topography.

In the numerical model experiments that yield grounding line advance, grounding spreads laterally from south to north across the KIS outlet and the outer DF remains floating as a remnant subglacial lake. This suggests a second framework in which to view this flat ice terrain, one in which the margin lake is not a product of ice mechanics (as was suggested in section 5.2) but is instead a product of a geometrically complicated grounding line advance. What remains the same is the effect of the new shoreline on ice mechanics and an arrangement — post grounding and lake formation — that facilitates a jump from an older, outer shear margin to a younger, inner margin. The unmistakable result in our models, that the grounding line advances not down the trunk of the ice stream but from the south, favors this interpretation.

In our pursuit of a role for the DF in KIS grounding line advance from a supposed past upstream location, we have instead come to make the following assertions. Subglacial Lake Engelhardt is a young (decades to centuries) feature and may be facilitating a margin 
jump on WIS as that ice stream's ice plain adjusts to changing subglacial traction. We suggest (without evidence) that as an exit path for subglacial water, SLE may play a part in the basal traction variation. The DF is evidence of grounding line advance from the south, across the mouth of KIS. That advance, in turn, was predicated on the stagnation of CIR, which promoted grounding in the GF region, and stagnation of SH. In all, the full three dimensional context is essential for correct representation of grounding line migration. 


\section{References Cited}

Alley, R.B., Dupont, T.K., Parizek, B.R., Anandakrishnan, S., Lawson, D.E., Larson, G.J., and Evenson, E.B., 2006, Outburst flooding and the initiation of ice stream surges in response to climatic cooling: A hypothesis: Geomorphology, v. 75, p. 76-89.

Alley, R. B., Anandakrishnan, S., Bentley, C.R., and Lord, N., 1994, A water-piracy hypothesis for the stagnation of Ice Stream C, Antarctica: Annals of Glaciology, v. 20, p. 187-194.

Alley, R. B., and Whillans, I.M., 1991, Changes in the West Antarctic ice sheet: Science, v. 254, p. 959-963.

Alley, R. B. and Bentley, C.R., 1988, Ice-core analysis on the Siple Coast of West Antarctica: Annals of Glaciology, v. 11, p. 1-7.

Anandakrishnan, S., Alley, R., Jacobel, R., and Conway, H., 2001, The flow regime of Ice Stream $\mathrm{C}$ and hypotheses concerning its recent stagnation. In R. B. Alley and R. A. Bindschadler, eds, The West Antarctic Ice Sheet: Behavior and Environment, v 77 of Antarctic Research Series: American Geophysical Union, p. 283-294.

Anandakrishnan, S. and Alley, R. B., 1997, Stagnation of Ice Stream C, West Antarctica by water piracy: Geophysical Research Letters, v. 24, n. 3, p. 265-268.

Anderson, J., Shipp, S., Lowe, A., Wellner, J., and Mosola, A., 2002, The Antarctic ice sheet during the Last Glacial Maximum and its subsequent retreat history: A review: Quaternary Science Review, v. 21, p. 49-70.

Bell, R., Ferraccioli, F., Creyts, T., Braaten, D., Corr, H., Das, I., Damaske, D., Frearson, N., Jordan, T., Rose, K., Studinger, M., 2011, Widespread persistent thickening of the East Antarctic Ice Sheet by freezing from the base: Science, v. 331, n. 6024, p. 15921595.

Behrendt, J.C., 1999, Crustal and lithospheric structure of the West Antarctic Rift System from geophysical investigations - a review: Global and Planetary Change, v. 23, p. $25-44$.

Bindschadler, R., Vornberger, P., and Gray, L., 2005, Changes in the Ice Plain of Whillans Ice Stream, West Antarctica: Journal of Glaciology, v. 51, n. 175, p. 620-636.

Bindschadler, R.A., King, M.A., Alley, R.B., Anandakrishnan, S., and Padman, L., 2003, Tidally controlled stick slip discharge of a West Antarctic ice stream: Science, v. 301, n. 5636, p. 1087-1089.

Bindschadler, R., 1998, Future of the West Antarctic Ice Sheet: Science, v. 282, p. 428-429. 
Bindschadler, R., Roberts, E., and Iken, A., 1990, Age of Crary Ice Rise, Antarctica, determined from temperature-depth profiles: Annals of Glaciology, v. 14, p. 13-16.

Bindschadler, R.E, 1993, Siple Coast Project research of Crary Ice Rise and the mouths of Ice Streams B and C, West Antarctica: review and new perspectives: Journal of Glaciology, v. 39, n. 133, p. 538-552.

Bougamont, M., Tulaczyk, S. and Joughin, I., 2003, Response of subglacial sediments to basal freeze-on 2. application in numerical modelling of the recent stoppage of Ice Stream C, West Antarctica: Journal of Geophysical Research, v. 108(B4). Art. No. 2233.

Carter, S.P., and Fricker, H.A., 2012, The supply of subglacial meltwater to the grounding line of the Siple Coast, West Antarctica: Annals of Glaciology, v. 53, p. 267-280.

Carter, S. P., Fricker, H.A, Blankenship, D.D., Johnson, J.V., Lipscomb, W.H., Price, S.F., and Young, D.A., 2011, Modeling 5 years of subglacial lake activity in the MacAyeal Ice Stream (Antarctica) catchment through assimilation of ICESat laser altimetry: Journal of Glaciology, v. 57, p. 1098-1112.

Catania, G. A., Hulbe, C., Conway, H., Scambos, T.A., and Raymond, C.F., 2012, Variability in the mass flux of the Ross ice streams, West Antarctica, over the last millennium: Journal of Glaciology, v. 58, n 210, p. 741-752, doi: 10.3189/2012JoG11J219.

Catania, G. A., Scambos, T.A., Conway, H., and Raymond, C.F., 2006., Sequential stagnation of Kamb Ice Stream, West Antarctica: Geophysical Research Letters, v. 33(L1), Art. No. 4502, doi: 10.1029/2006GL026430.

Catania, G., Conway, H., Raymond, C., and Scambos, T., 2005, Surface morphology and internal layer stratigraphy in the downstream end of Kamb Ice Stream, West Antarctica: Journal of Glaciology.

Catania, G.A., 2004, The dynamic history of Kamb Ice Stream, West Antarctica: Controls on streaming behavior and ice stream shutdown: Ph.D. thesis, University of Washington.

Cazenave, A. and Llovel, W., 2010, Contemporary sea level rise: The Annual Review of Marine Science, v. 2:145 73, doi: 10.1146/annurev-marine-120308-081105.

Christoffersen, P., Tulaczyk, S., 2003, Response of subglacial sediments to basal freeze on 1. Theory and comparison to observations from beneath the West Antarctic Ice Sheet: Journal of Geophysical Research, v. 108.

Conway, H., Hall, B., Denton, G., Gades, A., and Waddington, E, 1999, Past and future grounding-line retreat of the West Antarctic ice sheet: Science, v. 286, p. 280-283. 
Cuffey, K. M., and Paterson, W. S. B., The Physics of Glaciers. 4th ed. Burlington, MA: Butterworth-Heinemann/Elsevier, 2011. Print.

Echelmeyer, K. and Harrison, W. D., 1999, Ongoing margin migration of Ice Stream B, Antarctica: Journal of Glaciology, v. 45, n. 150, p. 361-369.

Echelmeyer, K. A., Harrison, W. D., Larsen, C., and Mitchell J. E., 1994, The role of the margins in the dynamics of an active ice stream: Journal of Glaciology, v. 40, n. 136, p. $527-538$.

Engelhardt, H. and Kamb, B., 1997, Basal hydraulic system of a West Antarctic ice stream: constraints from borehole observations: Journal of Glaciology, v. 43, n. 144, p. 207231.

Fahnestock, M., Scambos, T., Bindschadler, B., and Kvaran, G., 2000, A milennium of variable ice flow recorded by the Ross Ice Shelf, Antarctica: Journal of Glaciology, v. 46, n. 155, p. 652- 664 .

Fricker, H. A., Scambos, T., Carter, S., Davis, C., Haran, T, and Joughin, I., 2010, Synthesizing multiple remote-sensing techniques for subglacial hydrologic mapping: application to a lake system beneath MacAyeal Ice Stream, West Antarctica: Journal of Glaciology, v. 56, n. 196, p. 187-199.

Fricker, H. A., Scambos, T., 2009, Connected subglacial lake activity on lower Mercer and Whillans Ice Stream, West Antarctica, 2003-2008: Journal of Glaciology, v. 55, n. 190, p. 303-315.

Gudmundsson, G. H. and Raymond, M., 2008, On the limit to resolution and information on basal properties obtainable from surface data on ice streams: Cryosphere, v. 2, p. 167-178, doi:10.5194/tc-2-167-2008.

Harrison, W., Echelmeyer, K., and Larsen, C., 1998, Measurement of termperature in a margin of Ice Stream B, Antarctica: implications for margin migration and lateral drag: Journal of Glaciology, v. 44, n. 148, p. 615-624.

Hulbe, C. and Fahnestock, M., 2007, Century-scale discharge stagnation and reactivation of the Ross ice streams, West Antarctica: Journal of Geophysical Research, v. 112(F3), F03S27, doi: 10.1029/ 2006JF000603.

Hulbe, C. L. and Fahnestock, M.A., 2004, West Antarctic ice-stream discharge variability: mechanism, controls and pattern of grounding-line retreat: Journal of Glaciology, v. 50, n. 171, p. 471-484, doi: 10.3189/172756504781829738. 
Hulbe, C. L., and MacAyeal, D.R., 1999, A numerical model of coupled inland ice sheet, ice stream, and ice shelf flow and its application to the West Antarctic Ice Sheet: Journal of Geophysical Research, v. 104(B11), 25349-25366.

Jacobel, R., Scambos, T., Nereson, N., and Raymond, C., 2000, Changes in the margin of Ice Stream C, Antarctica: Journal of Glaciology, v. 46, n. 152, p. 102-110.

Jacobson, H. P., and Raymond, C.F., 1998, Thermal effects on the location of ice stream margins: Journal of Geophysical Research, v. 103(12), p. 111-122.

Joughin, I., R. A. Bindschadler, M. A. King, D. Voigt, R. B. Alley, S. Anandakrishnan, H. Horgan, L. Peters, P. Winberry, S.B. Das and G. Catania. 2005. Continued deceleration of Whillans Ice Stream, West Antarctica: Geophysical Research Letters, v. 32, L22501, doi:10.1029/2005GL024319.

Joughin, I., Tulaczyk, S., Bindschadler, R., and Price, S.F., 2002, Changes in West Antarctic ice stream velocities: observations and analysis: Journal of Geophysical Research, v. 107(B11), doi: 10.1029/2001JB001029.

Kamb, B., 2001, Basal Zone of the West Antartic Ice Streams and its role in lubrication of their rapid motion The West Antarctic Ice Sheet Behavior and Environment: American Geophysical Union, p. 157-199.

Le Brocq, A. M., Payne, A. J., Vieli, A., 2010, An improved Antarctic dataset for high resolution numerical ice sheet models (ALBMAP v1): Earth System Science Data, v. 2, p. 247-260, doi: 10.5194/essd-2-247-2010.

MacAyeal, D. R., Bindschadler, R.A., and Scambos, T.A., 1995, Basal friction of ice stream E, West Antarctica: Journal of Glaciology, v. 41, n. 138), p. 247-262.

MacAyeal, D. R., 1992, Irregular oscillations of the West Antarctic Ice Sheet: Nature, v. 359, p. 29-32.

MacAyeal, D. R., 1989, Ice-shelf response to ice-stream discharge fluctuations: Iii. The effects of ice-stream imbalance on the Ross Ice Shelf, Antarctica: Journal of Glaciology, v. 35, n. 119, p. 38-42.

MacAyeal, D., and Thomas, R., 1986, The effects of basal melting on the present flow of the Ross Ice Shelf, Antarctica: Journal of Glaciology, v. 32, n. 110, p. $72-86$.

MacAyeal, D. R., 1985, Tidal rectification below the Ross Ice Shelf. In S. Jacobs, ed, Oceanology of the Antarctic Continental Shelf, volume 43 of Antarctic Research Series. American Geophysical Union, p. 109-132. 
MacAyeal, D. R., 1984, Thermohaline circulation below the Ross Ice Shelf: A consequence of tidally induced vertical mixing and basal melting: Journal of Geophysical Research, v. 89(C1), p. 597-606.

Merry, C. J. and Whillans, I.M., 1993, Ice-flow features on Ice Stream B, Antarctica, revealed by SPOT HRV imagery: Journal of Glaciology, v. 39, n. 133, p. 515-552.

Motyka R.J., Hunter L., Echelmeyer K.A., and Connor C., 2003, Submarine melting at the terminus of a temperate tidewater glacier, LeConte Glacier, Alaska, U.S.A. Ann. Glaciology, v. 36, p. 57-65, doi: 10.3189/172756403781816374.

Nowicki, S. M. J. and Wingham, D. J., 2008, Conditions for a steady ice sheet-ice-shelf junction: Earth and Planetary Science Letters, v. 265, p. 245-255.

Parizek, B. R., Alley, R.B., and Hulbe, C.L., 2003, Subglacial thermal balance permits ongoing grounding-line retreat along the Siple Coast of West Antarctica: Annals of Glaciology, v. 36, p. 251-256.

Raymond, C. F., 1996, Shear margins in glaciers and ice sheets: Journal of Glaciology, v. 42, n. 140 , p. $90-102$.

Raymond, C. F., Echelmeyer, K.A, Whillans, I.M., and Doake, C.S.M., 2001, Ice stream shear margins. In R. B. Alley and R. A. Bindschadler, eds, The West Antarctic Ice Sheet: Behavior and Environment, volume 77 of Antarctic Research Series. American Geophysical Union, p. 137-155.

Retzlaff, R., and Bentley, C.R., 1993, Timing of stagnation of ice stream C, West Antarctica from short pulse-radar studies of buried surface crevasses: Journal of Glaciology v. 39, p. 553-561.

Rignot, E., Mouginot, J., and Scheuchl, B., 2011, MEaSUREs InS AR-Based Antarctica Ice Velocity Map. Boulder, Colorado USA: NASA EOSDIS Distributed Active Archive Center at NSIDC.

Scambos, T.A., Haran, T.M., Fahnestock, M.A, Painter, T.H., and Bohlander, J., 2007, MODIS-based Mosaic of Antarctica (MOA) data sets: continent-wide surface morphology and snow grain size: Remote Sensing Environment, v. 111(2-3), p. 242257.

Schoof, C., 2012, Thermally driven migration of ice-stream shear margins: Journal of Fluid Mechanics, v. 712, p. 552-578, doi:10.1017/jfm.2012.438.

Schoof, C. 2007. Ice sheet grounding line dynamics: Steady states, stability and hysteresis. Journal of Geophysical Research Earth Surface, 112, F03S28 (doi:10.1029/2006JF000664). 
Sergienko, O.V. and Hulbe, C.L., 2011, 'Sticky spots' and subglacial lakes under ice streams of the Siple Coast, Antarctica: Annals of Glaciology, v. 52, n.58, p. 18-22.

Sergienko, O.V., MacAyeal, D.R., and Bindschadler, R.A., 2007, Causes of sudden, shortterm changes in ice-stream surface elevation: Geophysical Research Letters, v. 34, doi: 10.1029/2007GL031775.

Shabtaie, S., and Bentley, C.R., 1987, West Antarctica ice streams draining into the Ross Ice Shelf: configuration and mass balance: Journal of Geophysical Research, v. 92(B2), p. 1311-1336.

Shabtaie, S., Whillans, and I.M., Bentley, C.R., 1987, The morphology of ice streams A, B, and C, West Antarctica, and their environs: Journal of Geophysical Research, v. 92(B9), p. 8856-8883.

Shabtaie, S. and Bentley, C.R., 1988, Ice-thickness map of the West Antarctic ice streams by radar sounding: Annals of Glaciology, v. 11, p. 126-136.

Shipp, S., Anderson, J., and Domack, E., 1999, Late Pleistocene-Holocene retreat of the West Antarctic Ice-Sheet system in the Ross Sea: Part 1 - Geophysical results. Geological Society of America Bulletin, v. 111, n.10, p. 1486-1516, doi: 10.1130/0016-7606(1999)<1486:LPHROT>2.3.CO;2.

Smith, B.E., Fricker, H.A., 2009, An inventory of active subglacial lakes in Antarctica detected by ICESat (2003-2008): Journal of Glaciology, v. 55, p. 573-595.

Studinger, M., Bell, R.E., Blankenship, D.D., Finn, C.A., Arko, R.A. and Morse, D.L., 2001, Subglacial sediments: a regional geological template for ice flow in West Antarctica. Geophysical Research Letters, v. 28(18), p. 3493-3496.

Thorsteinsson, T., Waddington, E. and Fletcher, R., 2003, Spatial and temporal scales of anisotropic effects in ice-sheet flow: Annals of Glaciology, v. 37, p. 41-48.

Tulaczyk, S., Kamb, B., and Engelhardt, H., 2000a, Basal mechanics of Ice Stream B, West Antarctica. I. Till mechanics: Journal of Geophysical Research, v. 105(B1), p. 463481.

Tulaczyk, S., Kamb, B., and Engelhardt, H., 2000b, Basal mechanics of Ice Stream B, West Antarctica. II. Undrained-plastic-bed model. Journal of Geophysical Research, v. 105(B1), p. 483-494.

Vaughan, D. G., Bamber, J.L, Giovinetto, M.B., Russell, J., and Cooper, A. P. R., 1999, Reassessment of net surface mass balance in Antarctica: Journal of Climatology, v. 12, n. 4, p. 933-946. 
Vogel, S. W., Tulaczyk, S., Kamb, B., Engelhardt, H., Carsey, F., Behar, A.E., Lane, A.L., and Joughin, I., 2005, Subglacial conditions during and after stoppage of an Antarctic ice stream: Is reactivation imminent?: Geophyical. Research Letters, v. 32, L14502, doi:10.1029/2005GL022563.

Weertman, J., 1974, Stability of the junction of an ice sheet and ice shelf: Journal of Glaciology, v. 13, n. 67, p. 3-11.

Weertman, J., 1964b, The theory of glacier sliding: Journal of Glaciology, v. 5, n. 39, p. 287 303.

Whillans, I., van der Veen, C.J., 1997, The role of lateral drag in the dynamics of Ice Stream B, Antarctica: Journal of Glaciology, v. 43, n. 144, p. 231-237.

Whillans, I., Jackson M., and Tseng Y.-H., 1993, Velocity pattern in a transect across Ice Stream B, Antarctica: Journal of Glaciology, v. 39, n. 133, p. 562-572.

Whillans, I. M. and van der Veen, C.J., 1993, Patterns of basal drag on Ice Streams B and C, Antarctica: Journal of Glaciology, v. 39, n. 133, p. 437-446.

Wright, A. P., Siegert, J.M., Le Brocq, A.M., and Gore, D.B., 2008, High sensitivity of subglacial hydrological pathways in Antarctica to small ice-sheet changes: Geophysical Research Letters, v. 35, L17504, doi: 10.1029/2008GL034937. 